\title{
The Parsi Dilemma: \\ A New Zealand Perspective
}

\author{
By \\ David John Weaver
}

\begin{abstract}
A thesis
submitted to Victoria University of Wellington in fulfilment of the requirements for the degree of Master of Arts in Asian Studies
\end{abstract}

Victoria University of Wellington

2012 


\section{Contents}

$\begin{array}{lll}\text { Abstract } & \text { ii }\end{array}$

Preface $\quad$ iii

Glossary $\quad$ vi

Abbreviations $\quad$ vii

Part 1 Orientation

Chapter 1 Introduction 1

2 A Brief History of the Parsi Community in India 16

3 The Parsi Community in New Zealand and Diaspora comparisons $\quad 30$

Part 2 Parsi Identity

Chapter 4 Individualism and the Parsi Community $\quad 40$

5 The Impact of Religion on the Parsi Identity 49

6 Social and Economic Factors and the Parsi Community 59

Part 3 Individuality and the Future for Parsis in New Zealand and World-wide; A New Zealand Perspective

$\begin{array}{ll}\text { Chapter } 7 \text { Individualism } & 73\end{array}$

Chapter 8 Possible Future Directions 96

Part 4 Conclusions

$\begin{array}{ll}\text { Chapter } 9 \text { Overview } & 105\end{array}$

10 Conclusions 109

$\begin{array}{lr}\text { Appendix A Interview Questions } & 115\end{array}$

$\begin{array}{ll}\text { Bibliography } & 117\end{array}$ 


\begin{abstract}
The Parsis of India are a very small but important ethnic group, traditionally living in Gujarat but in modern times mainly located in Bombay, where, under the British Raj, they established themselves as leading merchants, politicians and professional people with an influence far exceeding their numerical strength. Since Indian Independence in 1947, that influence has declined as has the total size of the Parsi community in India. Many members of the community have dispersed overseas and during the last twenty years, New Zealand has emerged as a growing destination of choice.

Many reasons have been put forward both by academia and by members of the Parsi community itself for the steeply declining numbers ranging from religious and ethnic exclusivity to loss of fecundity and consequential fall in the birth-rate to below the sustainability level. In my initial research for this thesis, I became aware that one reason for the decline, which did not feature in academic discourses but which seemed to be important, was the significance of Parsi culture, in particular the traditional emphasis on individual achievement, at the expense of communal cohesion.

In seeking to corroborate my hypothesis, along with whether or not the current drive to migrate from India to countries such as New Zealand is having a positive or negative influence on the long-term chances for Parsi survival, I have carried out in-depth interviews with a cross-section of Parsis now resident in New Zealand. The outcomes of these interviews, together with a careful study of Parsi history and an analysis of their very distinctive culture, form the basis for my study. These outcomes and analyses have created an overall picture, which has confirmed my belief that the most important contributing factor to demographic decline amongst the Indian Parsi community has been their traditional drive towards individual material success. They have also shown that individual choice has been the principle post-Independence migratory driving force. There are more negative than positive elements associated with this migratory drive with the future of both Parsi identity and Zoroastrianism under serious threat through increasing dispersal and religious, ethnic and cultural dilution. This deteriorating situation is further exacerbated by internal strife fuelled by passionate ethno-religious debate over the best way forward.
\end{abstract}




\section{Preface}

The writing of my thesis can best be described as a journey of discovery. As I have progressed, I have become increasingly enthralled by the history of the Parsis and how this has impacted on their present situation, in India and in the wider diaspora, including the comparatively recent establishment of a small but growing Parsi community in New Zealand. I have investigated and discussed the importance of the Parsi propensity to act as individuals rather than as a single communal entity and the likely future for this tiny but important group of people, both here in New Zealand and globally. Along the way, I have learnt to admire their fortitude, their graciousness, their dedication to their religious beliefs and their undoubted ability to achieve success in whatever field of endeavour they select. They are potentially a very real asset to New Zealand society and their example is one which we could all benefit from if a way could be found to raise awareness of their unique culture amongst a wider audience.

I feel that, in deference to all those members of the Parsi community in New Zealand that I have interviewed, it would be appropriate for me to borrow a courtesy from Indonesia. When I lived there in the 1950s, it was always customary to open a speech by apologising to the audience in advance for any mistakes contained in the main body of the speech. I would like to do the same thing to all my Parsi friends: I have endeavoured to represent everyone's views in a completely unbiased fashion, but the fact remains that I am a Juddin, a non-Parsi, looking in on Parsi culture from the outside. As such, although I have done my very best to present the facts accurately and sympathetically, there are bound to be some gaps in my knowledge and understanding. I would like to apologise in advance for any lapses or errors of omission.

Some of my Parsi interviewees would have preferred me to use the word Zarathushtee rather than Zoroastrian, because they say the word Zoroastrian is a Greek corruption. Whilst acknowledging that this might well be so, I have stuck with the word Zoroastrian except when quoting, because it is the expression most commonly used and therefore best understood by academics.

Parsis have a somewhat relaxed approach to the English spelling of Parsi words which can give rise to misunderstandings. For example, some of my interviewees use the 
spelling Parsee rather than Parsi and both these alternative forms of spelling also appear in different academic works. In similar fashion names such as Jeejeebhoy can be spelled in several different ways, for instance Jijibhoy, as used by John Hinnells, or Jejeebhoy as used by Jesse Palsetia. ${ }^{1}$ Again, except when quoting, I have used the most common spelling rather than follow any particular style.

In similar vein is the age-old problem of what to do when an important city changes its name during a period of history under review, in this instance Bombay becoming Mumbai in 1995. This problem is compounded by most but not all Parsis still referring to Mumbai as Bombay. I have used the word Bombay when referring to the time prior to the change and, except when quoting, have used Mumbai thereafter.

As I have explained in my thesis, the Parsi community can be broadly divided into two main groups: conservatives and liberals. Alternative words for the former include orthodox or traditional, although many conservatives dislike being labelled orthodox as being too closely associated with fundamentalism, which they vehemently reject. Alternative descriptive words for liberals include moderates and reformists.

I would like to acknowledge with grateful thanks all those at Victoria University who have made the writing of this thesis not just possible but enjoyable. In particular I would like to thank Dr Rick Weiss, Senior Lecturer in Religious Studies, my first supervisor, who agreed to take me on as one of his postgraduate students and has consistently encouraged and helped me. Likewise I would like to thank Professor Sekhar Bandyopadhyay, Professor of History, my second supervisor, who has reviewed my work from time to time and unfailingly helped to unblock any log jams along the road. I must also acknowledge with thanks the important part played by Dr Bernadette Vine, from the School of Linguistics and Applied Language Studies, who arranged for the many hours of verbal recordings of my interviews to be transcribed in such an excellent and professional manner that my task of collating information became a simple one. Without all the expert assistance that I received from members of the Victoria University library

\footnotetext{
${ }^{1}$ John R. Hinnells, The Zoroastrian Diaspora: Religion and Migration (Oxford: Oxford University Press, 2005, 1.); Jesse S.Palsetia, The Parsis of India: Preservation of Identity in Bombay City (New Delhi: Manohar, 2008), 44.
} 
staff, particularly from Tony Quinn, I would not have been able access all the books necessary for my research.

Adrian Simcock, a retired member of the New Zealand Foreign Service and a past New Zealand High Commissioner in India, who shares my deep interest in the Indian subcontinent, kindly agreed to take on the task of being my proofreader, a role which he has fulfilled with distinction. Thank you.

Finally and most importantly I want to acknowledge and thank all the members of the New Zealand Parsi community, both in Wellington and Auckland, who not only gave me so generously of their time and hospitality, but also made me feel so very welcome in their homes. Without their input, my thesis would not have been possible. They made my task a pleasure to undertake because of their readiness to answer all my questions in such an open fashion. My interviews were always enjoyable and not infrequently accompanied by gales of laughter. My responses together with my subsequent views concerning my general hypotheses would not have been achieved without the amazingly frank answers which I received to my interview questions. The lack of any hint of defensiveness on the part of each and every one of those interviewed is a testimony to their self-confidence as Parsis now living in New Zealand and the pride that they have in their unique heritage. In particular, I would like to thank Mr Tehmus Mistry for introducing me to other members of the Parsi community in Auckland and for giving me an insight into its history and current circumstances. 


\section{Glossary $^{2}$}

Agiary: Fire temple.

Ahura Mazda: 'Wise Lord', 'Lord Wisdom', term used for God.

Anjuman: Association.

Atash: Sacred fire.

Atash Bahram: Highest ranking fire temple.

Avesta: The Zoroastrian holy book.

Baag: Housing colony or compound

Dastur: High priest.

Dokhma: Tower of Silence.

Farohar: The winged symbol of Ahura Mazda or of the Fravashi.

Fravashi: The Guardian Angel; also the heavenly 'soul' which all people are thought to have.

Jashan: Traditional Zoroastrian religious ceremony of blessing or honouring.

Juddin: A non-Zoroastrian.

Kusti: Sacred lambskin cord worn round the waist after initiation.

Mazdayasni: 'Worshippers of Mazda', A common term within the Parsi community for Zoroastrians.

Mobed: Priest.

Navjote: Initiation ceremony.

Nirang: Consecrated bull's urine used in certain religious and ceremonial rites.

Panchayat: Traditional name for a governing body; the best known and most important one is the Bombay Parsi Panchayat.

Shetia: Merchant-prince or man of influence and standing in Bombay society

Sudra: Sacred white cotton undershirt worn after initiation.

Vendidad: Text in the Avesta detailing purity laws.

Zarathushtee/Zarathushti/Zarathoshti: Sometimes preferred alternatives to the Greek word Zoroastrian.

Zarathushtra: Iranian alternative for the Greek term for the Prophet Zoroaster.

\footnotetext{
${ }^{2}$ Hinnells, 825-827; Palsetia, 338-340.
} 


\section{Abbreviations}

AZA Australian Zoroastrian Association

BPP Bombay Parsi Panchayat

FEZANA Federation of Zoroastrian Associations in North America

TMZA Traditional Masdayasni Zoroastrian Anjuman

TMZANZ Traditional Mazdayasni Zarathushtee Anjuman of New Zealand

WZO World Zoroastrian Organisation

ZANZ Zarathushti Association of New Zealand

ZCT Zoroastrian Community Trust of New Zealand

${ }^{3}$ Hinnells, xv-xvii. 


\section{$\underline{\text { Part } 1 \text { Orientation }}$}

\section{Chapter 1 Introduction}

\section{General Outline}

Academic studies, both recent and not so recent, have described and commented on various aspects of Parsi life in India, but none have specifically tried to answer the question as to why their brilliance, influence and success as individuals has not translated into a cohesive and expanding community. Of particular interest are the causes, to be examined in detail later in my thesis, of the steep decline in total numbers of Parsis living in India since Indian independence and of the increasing numbers of Parsis migrating to an ever-widening circle of countries during the same period. One of these destinations has been New Zealand, where the number of Parsis now resident has risen from a mere handful in the 1990s to a current estimate of approximately 1200. My thesis will seek to research and explain these quite dramatic demographic trends amongst what is a minute, but culturally and qualitatively highly interesting, important, and now globally based, community. Parsis are a fascinating ethnic group, well deserving of wider appreciation both globally and by New Zealand academia.

John Hinnells, the leading modern exponent on Parsi dispersal from India, states that in the early twenty-first century there were approximately 860 Zoroastrians living in New Zealand. ${ }^{1}$ Hinnells uses the word 'Zoroastrian' to include and as an alternative to the word 'Parsi' stating in his book The Zoroastrian Diaspora: Religion and Migration, that many younger members of the international community [of Parsis] wish to be known simply as Zoroastrians. ${ }^{2}$ I, on the other hand, make a clear distinction between 'Parsis' as being the descendants of Zoroastrians who have traditionally lived in India as a

\footnotetext{
${ }^{1}$ John R. Hinnells, "Parsis in India and the Diaspora in the Twentieth Century and beyond," John R. Hinnells and Alan Williams eds., Parsis in India and the Diaspora (London and New York: Routledge, 2007), 271.

${ }^{2}$ Hinnells, 4.
} 
community, and 'Zoroastrians,' who were born and lived, or whose recent ancestors were born and lived, in Iran; both are followers of the Zoroastrian religion.

Utilising interviews with the sizable Parsi community in New Zealand as my primary source material in order to obtain a New Zealand perspective, I intend to explore and seek to explain why the Parsi community in India, which has played such an important leadership role in many facets of Indian life since the early nineteenth century, has not grown and prospered, but rather declined so steeply in numbers since India's independence in 1947. In addition, I will consider the relationship between population decline in India and the increasing global diaspora.

My thesis will examine the situation from economic, social, cultural and religious perspectives and, in particular, will consider whether the enviable record of individual success has in fact had a negative affect on communal cohesion. It will also focus on the various characteristics that make up Parsi identity. Has one of these characteristics, the drive for individual success, caused disharmony and division within the community? If so, what if any have been the consequential affects? For example, has disaffection within the community resulted in an accelerated outflow of migrants? Alternatively, will the global diaspora prove beneficial in the longer term to the survival of Parsiism both in India and world-wide? ${ }^{3}$ Parsis have historically seen themselves as immigrants in India, separate from the indigenous Indian population. Has this perception now translated into a greater impulse to migrate again?

Although the Indian Parsis, who are directly descended from Persian Zoroastrians who migrated to India as refugees in c. $786 \mathrm{CE}$, speak Gujarati as their native language and are well-integrated into Indian society, they see themselves as quite separate from the ethnic Indian population with their own religious practices, priestly and communal authorities and social structures. ${ }^{4}$ Whilst numerically miniscule at less than 0.007 percent

\footnotetext{
${ }^{3}$ By Parsiism I meaning 'the Parsis collectively and their religion'; the term is used by Parsis themselves and is similar in scope to Judaism as 'the Jews collectively and their religion'. Parsiism is the ethnicity and culture of the descendants of those Zoroastrians who migrated to India from Persia after the Muslim conquest. It also usually but not always implies being a follower of Zoroastrianism. See "Zoroastrianism and Parsiism", The New Encyclopaedia Britannica: Macropaedia, vol. 29, $15^{\text {th }}$ ed. (Auckland: Encyclopaedia Britannica, Inc., 1990), 1116; Parsiism, Wiktionary, accessed July 26, 2011, http://en.wiktionary.org/wiki/Parsiism.

${ }^{4}$ David L. White, Competition and Collaboration: Parsi Merchants and the English East India Company in 18th Century India (New Delhi: Munshiram Manoharlal Publishing Pvt. Ltd., 1995), 34.
} 
of the total Indian population, the Parsi community in India has not only contributed historically but is still making a major contribution to Indian culture and the Indian economy. Because of its negligible size $(69,601$ in 2001) when compared with the much larger Hindu, Islamic and other religious communities, together with its very peaceable and acquiescent attitude towards the state and other communities, its history and importance in Indian society is almost unknown outside India. ${ }^{5}$ And yet it has a very proud history, its members bound together by Zoroastrianism, a religion which predates, but influenced Christianity and Islam. Indeed it is commonly thought to date back to the seventh or sixth century BCE and therefore is of a similar antiquity to Vedism, with which it interacted. ${ }^{6}$ It has even been credited with influencing the development of Judaism. $^{7}$

Books about the Parsis often refer in glowing terms to their achievements, past and present. For example, John Hinnells and Alan Williams open the introduction to their collection of studies, Parsis in India and the Diaspora, with the words: "The Parsis of India are a community which can often only be described in terms of superlatives. They belong to one of the oldest religious traditions and they are now India's smallest community, yet they are among those who have exercised the greatest influence on the subcontinent". 8 Eckehard Kulke, the eminent German sociologist and Indologist, in the Preface to his book The Parsees of India, refers to "the Parsees' remarkable impact on society, economics and politics" in the nineteenth and twentieth centuries. ${ }^{9}$

What stands out as unusual, and is so far unexplained, is why this impact has not been accompanied by communal stability and growth. Examples of outstanding individual achievement abound, particularly amongst the professions, as industrialists and as senior commanders in the Indian armed forces. ${ }^{10}$ For instance, two of India's largest conglomerates, Tata and Godrej, were founded by Parsis; Indira Gandhi’s

\footnotetext{
${ }^{5}$ Hinnells, Hinnells and Williams, eds., 272.

${ }^{6}$ R. C. Zaehner, The Dawn and Twilight of Zoroastrianism (London: Weidenfeld and Nicholson, 1975), 19, 39, 50, 71, 102-104, 132-133.

${ }^{7}$ Ibid., 20-21, 51-52, 57-58.

${ }^{8}$ John R. Hinnells and Alan Williams, "Introduction," John R. Hinnells and Alan Williams eds., Parsis in India and the Diaspora (London and New York: Routledge, 2007), 1.

${ }^{9}$ Eckehard Kulke, The Parsees in India: a Minority as Agent for Social Change (Munchen: Weltforum Verlag, 1974), 10.

${ }^{10}$ Hinnells, 256-261.
} 
husband, Firoze Gandhi, an influential politician and member of the Indian Congress Party in his own right, was a Parsi; the world renowned conductor Zubin Mehta is Parsi; the commander of the Indian armed forces during the Bangladesh war in 1971/72, Field Marshall Sam Maneckshaw, was a Parsi. ${ }^{11}$ Whilst there are many other examples of excellence, just those five names are indicative of recent or current levels of achievement by individual Parsis in the economic, political and cultural fields of Indian society.

Tanya Luhrmann, in The Good Parsi: The Fate of a Colonial Elite in a Post Colonial Society, states anecdotally that some Parsis believe the current demographic crisis amongst the Indian Parsi community is because they have become sexually effete due to inbreeding. ${ }^{12}$ Mitra Sharafi points towards strict religious exclusivity as another possible cause for falling population statistics. ${ }^{13}$ Eckehard Kuhle suggests a difficulty with political realignment after Indian independence, together with a failure in religious reform, as major contributing factors to a lack of community cohesion and the declining population. John Hinnells points towards the new communities of Parsis, particularly in North America, as "the future of the world's oldest prophetic/revealed religion" and that the population decline amongst Parsis in India is being at least compensated for if not exceeded by growth in overseas populations resulting from migrations from India. ${ }^{14}$ In other words, he is suggesting that the demography of the global Parsi community is changing rather than indicating an overall decline in population size. Although there are no reliable worldwide statistics, there is an ongoing global diaspora. There are now Zoroastrian/Parsi communities in more countries than ever before, spread throughout Asia, Australasia, much of Africa, Europe and North America. ${ }^{15}$

In order to complement these scholarly studies, I intend to research the important question as to why a community, which has such an illustrious record of individual

\footnotetext{
${ }^{11}$ Hinnells, 256-261.

12 T. M. Luhrmann, The Good Parsi: The Fate of a Colonial Elite in a Post Colonial Society (Cambridge, Massachusetts: Harvard University Press, 1996), ix, 132-133 \& 222. Reviewed by Michael Stausberg of Heidelberg University's Institute of Religious Studies. As an aside, her findings do not accord at all well with my own personal experience of the perfectly normal family lives led by all those Parsi families with whom I had contact whilst working in India from 1971 to 1976.

${ }^{13}$ Mitra Sharafi, "Judging conversion in Zoroastrianism: behind the scenes of the Parsi Panchayat case (1908)," John R. Hinnells and Alan Williams eds., Parsis in India and the Diaspora (London and New York: Routledge, 2007), 159-180.

${ }^{14}$ Hinnells, 2, 6.

${ }^{15}$ Hinnells, Hinnells and Williams eds., 2, 3, 10.
} 
successes, has not grown but has numerically regressed during the later half of the twentieth and early twenty-first centuries. Hinnells, quoting from official decadal censuses, shows the total Parsi population in India to have fallen from 114,490 in 1941 to 69,601 in 2001, a massive decline of $39.2 \% .{ }^{16}$ Apart from what appears to be an unexplained aberration in 1991, when the total Parsi Indian population was shown to have increased by nearly 5000 over the 1981 figures, between 1941 and 2001 there has been a decline each decade, with the largest fall, almost 20,000 or $20 \%$, being registered between 1971 and 1981. ${ }^{17}$ Nani A. Palkhivala, the eminent Indian Parsi politician, writing a paper to be read at a seminar on Zoroastrianism and the Parsi Community held in Madras in 1983, used similar demographic data when he stated:

A hundred years ago the fertility rate among Parsis was the highest in India. ${ }^{18}$ The highest figure of the Parsi population in India was 114,890 recorded in the Census of 1941. But over the last 40 years, the number has been dwindling. Today the total number of Parsis or Zoroastrians throughout the world is only about 120,000. Of this number 91,000 live in India, 18,000 in Iran, a little over 5,000 in Pakistan, with another 5,000 scattered over Europe, America, Africa and the Far East. ${ }^{19}$

As Hinnells suggests, not too much credence should be given to any one set of figures, but there can be no gainsaying the overall decline, decade on decade, between 1941 and 2001. ${ }^{20}$ The Federation of Zoroastrian Associations in North America is quoted by Hinnells as suggesting that over the same period of time 20,000 to 22,000, mainly young, Parsis emigrated, accounting for about $50 \%$ of the overall decline. ${ }^{21}$

Undoubtedly, emigration has and is still affecting the demographic shape of the Parsi community in India, but is there any sign of a counter migratory stream, perhaps of older Parsis wanting to return to their roots in India, to retire there within the Parsi community or for religious reasons?

\footnotetext{
${ }^{16}$ Hinnells, Hinnells and Williams eds., 272; Hinnells, 45.

${ }^{17}$ Hinnells, 45.

${ }^{18}$ A somewhat ambitious statement that I am unable either to refute or substantiate.

19 Nani A. Palkhivala, "The Role of Parsis in India", The Sugar in the Milk: The Parsis in India, Nancy and Ram Singh eds. (Delhi: I.S.P.C.K., 1986), 125.

${ }^{20}$ Hinnells, 45.

${ }^{21}$ FEZANA 2004, "The Zarthushti World a Demographic picture”, FEZANA Journal Winter 2004: 24, Hinnells, Hinnells and Williams, 272.
} 
My hypothesis is that the drive for individual achievement and success, both intrinsic to Parsi identity, has directly affected the cohesion and therefore the internal stability of the Parsi community, both historically and currently. I will show that the constant drive for individual success and to be perceived as successful within the community has directly and adversely affected marriage percentages and the size of Parsi families. This, combined with the likelihood of a very small ethnic group tending to be subsumed under the wider Indian identity, will be shown to be the major reason for the community's failure to prosper numerically. Furthermore, I will seek to show that, whilst the search for individual success has certainly led to accelerated migration, this migratory drive may also lead to a global renascence of the Parsi community and to its longer-term health and survival in India.

Whilst later in my thesis I will document in much greater detail my research into the main causes for population decline and loss of communal drive amongst Parsis in India, my initial interest was aroused by three well documented examples, each one exemplifying one major cause for the current situation. They are the life and career of Sir Mancherjee Merwanjee Bhownaggree, the wealthy late nineteenth century Parsi businessman and philanthropist, the Parsi Panchayat Case of 1908 and the political career of Firoze Gandhi.

Sir Mancherjee used his wealth and the traditional Parsi custom of giving charitable donations in memory of a loved one, in his case a beloved sister, to gain favour with the British Government in Bombay. When this failed because of local disagreements, he moved to London, where he became a major sponsor in the construction of the Imperial Institute. He was subsequently elected a Member of Parliament at Westminster and made London rather than Bombay his permanent home. ${ }^{22}$ His case is an example of frustration at home in India, resulting in permanent migration overseas. Whilst amongst the first to take such action, he would be by no means the last.

The Parsi Panchayat court case of 1908 involving the marriage of a member of the immensely powerful Tata family to a French woman, who had converted to Zoroastrianism prior to her marriage, is an excellent illustration of early twentieth

\footnotetext{
22 John McLeod, "Mourning, Philanthropy and M. M. Bhownaggree's Road to Parliament,” John R. Hinnells and Alan Williams eds., Parsis in India and the Diaspora (London and New York: Routledge, 2007), 136-152.
} 
century Parsi wealth and worldliness causing a major schism within the Parsi community in Bombay. ${ }^{23}$ The court case was concerned with whether, as a convert, she was entitled to the full benefits of being a Parsi. ${ }^{24}$ In fact it also served to polarise those who believed that, to be a Zoroastrian Parsi, one had to be born of Parsi parents and those who accepted conversion to Zoroastrianism as an alternative pathway. These are still burning issues to this day, together with whether or not the progeny of intermarriage can be Parsi.

Firoze Gandhi is an example of an eminent Parsi becoming subsumed under the wider Indian identity. His life, both before and after Independence, revolved around the Indian Congress party and therefore Hindu politics. ${ }^{25} \mathrm{He}$ married into the Nehru dynasty, which was Hindu, and his sons, instead of becoming Parsis, were brought up as Hindus. ${ }^{26}$ As will be shown later, such ethnic dilution through intermarriage was to become a major issue as the diaspora gained pace.

\section{Thesis Outline}

I have organised the thesis in four parts:

Part 1: Orientation. This will include a chapter on the history of the Parsis in India and a chapter on the Parsi community in New Zealand.

Part 2: The Parsi Identity. This will examine in detail those characteristics which give the Parsi community its special identity.

Part 3: Individuality and the Future for Parsis in New Zealand and Worldwide; a New Zealand perspective. This will bring together the collective thoughts and aspirations of the Parsi community in New Zealand, both for their community in New Zealand and for the future of the Parsi community in India and world-wide.

Part 4: Overview and Conclusions.

\footnotetext{
${ }^{23}$ Sharafi, 159.

${ }^{24}$ Ibid., 159-161.

${ }^{25}$ Hinnells, 257

${ }^{26}$ Ibid.
} 


\section{The Interview Process}

As my thesis is intentionally based on a uniquely New Zealand perspective, it has been critically important for me to obtain reliable primary source material through the collation of accurately documented and broad-based opinions from a cross-section of the New Zealand Parsi community, most of whom are located in Auckland. My purpose has been to become familiar with aspects of their cultural and religious practices now that they live in New Zealand. My enquiries have included why they emigrated and why they chose New Zealand as their destination of choice, how they perceive their future here in New Zealand and how they view the future for their community, not only here in New Zealand but also in India and worldwide.

To achieve this I interviewed twenty-six people from as broad a spectrum of representation as possible in terms of age, education, gender and socio-economic backgrounds. Interviews were conducted both on a one-to-one basis and as small group discussions. My initial approach to making contact with the Parsi community was partly formal and partly serendipitous. The formal approach was via the Indian High Commission in Wellington, which was able to furnish me with the name of a member of the New Zealand Parsi community who lived locally in Wellington. After some early difficulty in making contact, I arranged an introductory meeting at which I explained the purpose of my project and we had a brief general discussion about it. As this was just a preliminary meeting, no recordings were made, but there was a tentative agreement for a further more formal meeting to take place, which would be recorded. This never took place, as the person in question subsequently withdrew from participation for personal reasons. At the same time, through casual discussions with friends and acquaintances on the subject of my thesis, the names of other possible contacts began to emerge. Most of these turned out to be false trails but one was not and opened the way for me to contact the entire practicing Parsi community in Wellington and interviews with nine people.

I knew that the majority of the New Zealand Parsi community lived in Auckland, but at that time I had no leads into the Auckland community. ${ }^{27}$ I decided to surf the Internet and was immediately rewarded by the name of the Zoroastrian Community Trust

\footnotetext{
${ }^{27}$ Hinnells, Hinnells and Williams eds., 271.
} 
of New Zealand (ZCT), which amongst other information given, listed the names and phone numbers of all the Trustees. ${ }^{28}$ Taking the first name on the list, Mr Tehmus Mistry, I was again lucky. When I rang him, Tehmus turned out not only to be interested in what I was attempting to do and a very willing interviewee, but also to be happy to introduce me to other Parsi contacts in Auckland and to provide me with the history of both the ZCT and of its parent organisation, the Zarathustrian Association of New Zealand (ZANZ), which he had been instrumental in setting up in 1996 (see Chapter 3). Shortly after that first contact, I arranged to visit Auckland to meet Tehmus for a first informal meeting, most of which, unlike other initial meetings, was, at his suggestion, recorded. An added bonus of this visit was that it coincided with one of ZANZ's fortnightly meetings, which Tehmus very graciously invited me to attend. This provided me with the opportunity to meet other members of the Auckland Parsi community, to give a brief account of my project's objectives and to write down some names and addresses as potential contacts. The initial problem of how to make contact with suitable interviewees in Auckland had evaporated in the space of a single weekend.

Right from the start it was my intention to limit the number of interviews that I would undertake, whilst ensuring that each interview was carried out in depth. Whilst I recognised that this procedure would not give me a statistically significant database to work from, I felt that the empirical evidence that it would garner would be more relevant to a better understanding of the New Zealand Parsi community and so be more useful to my research. The methodology that I adopted, and which worked well for me, was to arrange an introductory meeting, at which I spent time introducing myself, talking about my project and making general enquiries about the interviewees' circumstances. Before leaving I gave out copies of the relevant sections of my thesis Introduction, the Victoria University approved Information Sheet for Participants and my approved Questionnaire. I asked them to read these and then consider if they would be prepared to let me return for a formal, recorded interview. These introductory meetings lasted between one and one-and-a-half hours and were not recorded, although on most occasions I made brief meeting notes subsequent to the meeting.

\footnotetext{
${ }^{28}$ See Abbreviations.
} 
Because all but one of my interviewees was engaged in some form of external activity such as study or work, most meetings took place at weekends with a few taking place in the evening on a normal working day. On all occasions, both the preliminary and formal meetings took place at the home of the interviewee(s).

Having ascertained in advance that my prospective interviewee(s) were happy to proceed, I next arranged a time and date to meet for the formal, recorded interview. These were carried out, utilising a small digital voice recorder, after the interviewee(s) had read and signed the appropriate Victoria University approved Consent to Participate in Interview Form. Meetings varied in length between forty minutes and one-and-a-half hours. On each occasion, the same questions were asked in the same order to ensure comparability across all interviews (see Appendix A for the questionnaire used). On one occasion, the interviewee chose to provide a written answer to the questionnaire in place of being interviewed and on another occasion, one of the interviewees provided a written response to supplement his verbatim responses during a group discussion. Amongst their many other courtesies, I was frequently offered additional help with my research in the form of books, newspaper articles and magazines. Recordings of all the formal meetings, along with one preliminary meeting, which had the interviewee's approval to be recorded, were transcribed into computer generated descriptions.

In total, I interviewed twenty-six people at seventeen separate interviews. Of these, eight were individual interviews, six were group discussions with couples and two were group discussions with three people; on four occasions, interviewees invited other(s) to participate in our discussions. Fifteen of the interviewees were male and eleven female, with ages ranging from sixteen to eighty; the majority were in their forties. Three of the interviewees were retired and three were still studying at school/university full-time. Most had lived in New Zealand for ten years or less, with some having been here in excess of twenty years and one family for less than three months. There was a cluster of arrivals around the year 2000 .

Whilst answers to the standard questions were many and varied, reflecting a considerable diversity of individual opinions, there were also important universal practices, common to all the interviewees, which gave the Parsi community a uniqueness in its own right and therefore worthy of careful recording as an indicator of Parsi culture. 
In every interview, I was warmly welcomed and given all the information that I sought without any hint of defensiveness. Quite the opposite from wanting to know why an outsider and a stranger would be asking a number of personal questions, my questions were all answered carefully, thoughtfully and openly. Everyone seemed to welcome what I was doing with comments such as how pleased they were that someone was so interested in their culture. All of those interviewed were interested in the final outcome and wanted to be kept informed of my progress. Some went so far as to say how appreciative they were that I had undertaken this task and looked forward to the thesis as providing them with a useful record. My concern that some would be put off from participation in the formal, recorded interviews through a reluctance to sign the consent forms, as I conjecture might occur in similar projects with other communities, proved to be totally unfounded. Many were familiar with the routine through their work situations as professional people. No one queried the necessity for the forms.

As part of the warm reception to my project, I was rapidly made aware of traditional Parsi hospitality. Small gifts of appreciation for allowing me to intrude on their lives were graciously accepted but with expressions of reluctance, whilst I was pressed, wherever I went, to accept hospitality such as drinks, small eats and even complete meals. Parsis are famous, not only for their hospitality but also for their joie de vivre and I was constantly reminded of this during interviews with not infrequent recourse to laughter, creating a warm and relaxed atmosphere

\section{Literature Review}

Given the diminutive size of the global Parsi population, past and present, it is perhaps of little surprise that there is a limited number of published academic works specifically concerned with Parsi identity and history. This is in sharp contrast to the significant bibliography dedicated to Zoroastrianism, the religion of the Parsis. There are no published works about the Parsis of New Zealand and only a passing reference to them in two books by John Hinnells. ${ }^{29}$ It is my intention in this thesis to fill this gap in academic research, by recording the views of Parsis now resident in New Zealand and

\footnotetext{
${ }^{29}$ John R. Hinnells, The Zoroastrian Diaspora: Religion and Migration (Oxford: Oxford University Press, 2005), 8 \& 600; John R. Hinnells and Alan Williams eds., Parsis in India and the Diaspora (London and New York: Routledge, 2007), 3 \& 271.
} 
placing those views within the wider perspectives of Paris in India and worldwide.

Academic works regarding past Parsi identity and history are comparatively rare and hard to access, on occasion just one copy being located, sometimes in an archive, or in just one university library overseas. Relevant primary source material is limited to one late sixteenth century Zoroastrian poem, the Qesse-ye Sanjān or Qissa-i Sanjan and journals such as Parsiana and Jam e Jamshed. The Qissa-i Sanjan, written in Persian, describes the arrival of the Zoroastrian migrant refugees at Sanjan in Gujarat and chronicles their early development in India. ${ }^{30}$ Alan Williams describes it as a folk chronicle and quotes S. H. Hodivala as saying it is "the only source of our knowledge of the early history of our people". ${ }^{31}$ Of the two journals referred to above, Parsiana is issued fortnightly and is the more widely read amongst New Zealand Parsis. Both contain significant amounts of correspondence directed at domestic Parsi affairs. Parsiana is published by Parsiana Publications Pvt Ltd in Mumbai and covers a wide area of interests from politics and religious matters to sporting activities, art and commerce. In particular it is a vehicle for debating important subjects via its Editorial Viewpoint and letters from correspondents. It always contains a strong section on Parsis living overseas and has a companion website titled "Parsiana Online, The global Zoroastrian link medium". ${ }^{32}$ In this, it states:

"Published in 1964, Parsiana is the international Zoroastrian community's leading semimonthly magazine". ${ }^{33}$ I have used examples from Parsiana, where appropriate, to reflect current Parsi opinion on some important issues.

Secondary source books can be divided into two groups: those that have been written by Western scholars about a particular aspect of Parsi culture or history and those that have been written by Parsi scholars. The latter are augmented by relevant extracts from Parsi books written for a purpose other than scholarly research into Parsi history or identity. Turning first to the former, Mary Boyce, who is widely respected as an expert on Zoroastrianism, touches only briefly but definitively on early Parsi history and culture

\footnotetext{
${ }^{30}$ Alan Williams, "The structure, significance and poetic integrity of the Qesse-ye Sanjan," John R. Hinnells and Alan Williams eds., Parsis in India and the Diaspora (London and New York: Routledge, 2007), 15-34.

${ }^{31}$ Ibid., 18.

${ }^{32}$ Parsiana Online, The global Zoroastrian link Medium, accessed October 19, 2011, http://parsiana.com/general/aboutus.asp.

${ }^{33}$ Ibid.
} 
in her book, Zoroastrianism: Their Religious Beliefs and Practices. ${ }^{34}$ The most wideranging and detailed publication on Parsi identity is The Parsees in India: A Minority as Agent of Social Change by the German scholar, Eckehard Kulke. ${ }^{35}$ It is a very detailed study of Parsi social, political and cultural identity from their arrival in Sanjan until after Indian independence and contains useful statistics regarding many aspects of Parsi life in India. Dr Kulke spent from 1966-1969 researching the Parsi community in Bombay. For my purposes however, the two most relevant and authoritative works are The Zoroastrian Diaspora: Religion and Migration by John R. Hinnells and Parsis in India and the Diaspora edited by John Hinnells and Alan Williams. ${ }^{36}$ In the former, Hinnells not only covers Parsi identity and life-styles in post-independence India but the global Parsi diaspora, country by country. In the latter, Hinnells combines with Williams to bring together a group of experts on Parsi history and culture covering various important aspects of Parsi history from their arrival in India until the twenty-first century. Whilst these academic works provided useful background information of a generalist nature regarding Parsi identity and culture, the main thrust of my thesis differs from them in that it focuses in depth on just one community, the Parsi now domiciled in New Zealand. Of particular significance is the data which I provide regarding Parsi migration to New Zealand and the relationship between that migratory drive and the urge to achieve individual success.

Of works written by Parsi academics two stand out as being particularly authoritative. The first is The Parsis of India: Preservation of Identity in Bombay City by Jesse S. Palsetia. ${ }^{37}$ This book is particularly important in its detailed analysis of Parsi identity and for its records of notable legal cases concerning Parsi ethno-religious disputes. The Sugar in the Milk, edited by Nancy and Ram Singh is a valuable collection of writings presented by various Parsi authors at a Seminar on Zoroastrianism and the

\footnotetext{
${ }^{34}$ Mary Boyce, Zoroastrians: Their Religious Beliefs and Practices (London, Boston and Henley: Routledge and Kegan Paul, 1979).

${ }^{35}$ Eckehard Kulke, The Parsees in India: a Minority as Agent for Social Change (Munchen: Weltforum Verlag, 1974).

${ }^{36}$ Hinnells; Hinnells and Williams.

${ }^{37}$ Jesse S.Palsetia, The Parsis of India: Preservation of Identity in Bombay City (New Delhi: Manohar, 2008).
} 
Parsi Community held in Madras on November 12-13, 1983. ${ }^{38}$ It encompasses various Parsi topics ranging from "Parsi women: Their Contribution to Indian Public Life" by Piloo Nanavutty to "The Role of Parsis in India" by the famous Parsi politician and diplomat, Nani A. Palkhivala. An excellent example of a book not written expressly about Parsi identity but which contains valuable commentary on a range of related subjects is the two volumes of Parsi Fiction, edited by Navi Kapadia, Jaydipsingh Dodiya and R. K. Dhawan. ${ }^{39}$ It includes critical commentaries on works by such eminent Parsi authors as Bapsi Sidhwa and Rohinton Mistry but more apposite to my thesis, it also contains informative papers such as "The Parsis and Their Religion" and "Causes and Effects of Decline in Parsi Population”. In the latter, Rustom Gae raises two points of interest. ${ }^{40}$ Firstly, as a clearly identifiable Indian-oriented Parsi, he suggests that there are just as many attractive appointments currently available to Parsi youth in India as overseas. ${ }^{41}$ Secondly, he says that the decline in the Parsi population would take a turn for the better if only Parsi youth would return to "prosper in our own country", India. ${ }^{42}$ My own research indicates that the majority of New Zealand Parsis would neither subscribe to the former viewpoint nor ever return to India permanently. It just will not happen.

One problem associated with such a small pool of relevant, published academic works is the degree of cross-referencing which occurs. So for example, Hinnells quotes Boyce, Kulke and Palsetia. Hinnells and Williams include an essay written by Palsetia, "Partner in empire: Jamsetjee Jejeebhoy and the public culture of nineteenth-century Bombay," in Parsis in India and the Diaspora. ${ }^{43}$ Palsetia quotes extensively from Hinnells and also from Kulke and T. M. Luhrmann. ${ }^{44}$ Luhrmann quotes extensively from Hinnells and also from Boyce and Kulke. Overall however, although the quantity of

\footnotetext{
${ }^{38}$ Nancy and Ram Singh eds., The Sugar in the Milk: The Parsis in India (Delhi: I.S.P.C.K., 1986).

${ }^{39}$ Navy Kapadia, Jaydipsinh Dodiya, R. K. Dhawan eds., Parsi Fiction, Vols. 1 and 2 (New Delhi: Prestige Books, 2001).

${ }^{40}$ Rustom S. Gae, "Causes and Effects of Decline in Parsi Population," Navy Kapadia, Jaydipsinh Dodiya,

R. K. Dhawan eds., Parsi Fiction, Vol.1 (New Delhi: Prestige Books, 2001), 69.

${ }^{41}$ Ibid.

42 Ibid., $69 \& 72$.

${ }^{43}$ Jesse S. Palsetia, "Partnership in empire: Jamsetjee Jejeebhoy and the public culture of nineteenthcentury Bombay," John R. Hinnells and Alan Williams eds., Parsis in India and the Diaspora (London and New York: Routledge, 2007), 81-99.

${ }^{44}$ T.M. Luhrmann, The Good Parsi: The Fate of a Colonial Elite in a Postcolonial Society (Cambridge, Massachusetts, London, England: Harvard University Press, 1996).
} 
appropriate, academic works is limited, what is available is both informative and authoritative.

\section{Summary}

Utilising the Parsi community in New Zealand's interviews as my primary source material, my thesis has sought reasons why, in spite of the outstanding qualities of many of its individual members, the Parsi community in India has not prospered demographically and indeed has declined in numbers during the post-Independence period. I shall also explore the trends that are likely to impact on the future for Parsis, both in India and worldwide. The conclusions are intended to make a contribution to the scholarly debate on the dynamics of the Parsi community in India and abroad, in particular the negative aspects of individual success and consequential acceleration of migration. 


\section{Chapter 2 A Brief History of the Parsi Community in India}

\section{The Historical Imperative}

It is necessary to set the main theme for this thesis within the context provided by an understanding of the Parsi community in India, its historical background and achievements. In this regard, I have found myself in accord with Susan Manek, who mentions in the Preface to her book, The Death of Ahriman: Culture, Identity and Theological Change Among the Parsis of India: "In order to present a proper picture of the process of modernization I needed a clear picture of what had preceded it". ${ }^{45}$ In a similar vein, in the Preface to his book, $O$ Whither Parsis? Placate and Perish or Reform and Flourish? Homi Homji writes:

As the author himself delved into this historical literature, he got so fascinated by it, that unlike the original objective of writing only a sociological analysis, he has added to this book a wider historical perspective, thus serving a double purpose. Chapter 1 accordingly is presented as the historical, from which, some later conclusions are drawn. It is also indicative of the illogical stand some elements in the community tend to take in the name of history, culture and religion. ${ }^{46}$

Whilst researching the dynamics of the Parsi community, I was constantly made aware of the relevance of their history in the formation of their culture and perception of themselves in the modern world. Without an understanding of their history, it would be difficult if not impossible to comprehend their current situation and associated problems.

\section{Origins}

According both to Kulke in his book, The Parsis in India, and to James Boyd and F. M. Kotwal in their paper, "The Indian Parsis in New Zealand", the Parsis of India derive their name from the Persian province of Fars. ${ }^{47}$ They fled from Fars to the North

\footnotetext{
${ }^{45}$ Susan Stiles Manek, The Death of Ahriman: Culture, Identity and Theological Change Among The Parsis of India (Bombay: K.R. Cama Institute, 1997), vii.

${ }^{46}$ Homi B. Minocher Homji, O Whither Parsis? Placate and Perish or Reform and Flourish? (Karachi: The Mirror Press, 1978), xv-xvi.

${ }^{47}$ Kulke, 13 and 27; James W. Boyd and F.M. Kotwal, "The Indian Parsis in New Zealand," Kapil. N. Tiwari, ed., Indians in New Zealand: Studies in a sub culture (Wellington: Price Milburn, 1980), 163.
} 
West coast of India, probably during the eighth or tenth centuries CE, in order to protect and preserve their Zoroastrian heritage and religion from the onslaught of Arabic Islam. To this day, more than twelve hundred years later, they still regard Persia as their ancestral home.

The exact arrival date in Gujarat of the "founding fathers of the Parsi community" is the subject of some dispute. ${ }^{48}$ According to Mary Boyce it was either $716 \mathrm{CE}$ or 976 $\mathrm{CE}$ depending on how the local script of the time is interpreted; $786 \mathrm{CE}$ according to David L. White. ${ }^{49}$ Also disputed is "the time of Zoroaster's actual historical appearance". ${ }^{50}$ According to Kulke:

Western Iranists date Zoroaster's activities mainly in the $5^{\text {th }}$ and $6^{\text {th }}$ Centuries B.C. ... or between the $9^{\text {th }}$ and $6^{\text {th }}$ Centuries B.C.... There is, however, also the opinion derived from Greek historiographers and widely held among the presentday Parsees in India that Zoroaster lived and taught between 4000 and 6000 B.C. ... This opinion is in no way impaired by an historic gap of several thousand years. It is of enormous psychological relevancy because it helps the Parsees to that feeling of religious exclusivity necessary for the existence and survival of the community. ${ }^{51}$

As will be demonstrated later, this characteristic of uniqueness is a fundamental cornerstone of Parsi identity, rather as the Jews see themselves as the 'chosen ones of God'. It was to stand them in good stead when, in the eighteenth century CE, the community emerged from the lower strata of Gujarati society and made itself indispensable to the burgeoning British commercial interests in Western India.

Prior to the onset of Islamic persecution in their Persian homeland in the seventh century CE and their subsequent flight to Gujarat, Zoroastrians had enjoyed centuries of benign existence going all the way back to the time of Cyrus the Great and the Achaemenid Empire. ${ }^{52}$ There is also evidence of trading by Zoroastrians in India and in particular in Gujarat prior to their exodus from Persia. ${ }^{53}$ As life under Islam became increasingly intolerable for the Zoroastrian community, it was perhaps logical that some

\footnotetext{
${ }^{48}$ Boyce, 166.

${ }^{49}$ Ibid.; White, 34.

${ }^{50}$ Kulke, 14.

${ }^{51}$ Ibid., 14-15; the emphasis is mine.

${ }^{52}$ Ibid., 13-14.

${ }^{53}$ Rukshana Nanji and Homi Dhalla, "The Landing of the Zoroastrians at Sanjan: The archaeological evidence," John R. Hinnells and Alan Williams eds., Parsis in India and the Diaspora (London and New York: Routledge, 2007), 52-53.
} 
of the dwindling community should seek refuge by fleeing eastwards to another land, one which was already known to them through their trading contacts.

By good luck or by design, the first Zoroastrian migrants, who, en route to Gujarat had spent the previous 20 years on the island of Div, where Gujarati was also spoken, landed in Gujarat at a place ruled over by the Silhara dynasty, "famed for their tolerance and encouragement to foreigners to trade and settle". 54 The local raja granted them land on the seashore, where they founded a settlement and named it Sanjan after their home town in Khorasan. ${ }^{55}$ According to the Qissa-i Sanjan - a narrative poem that is the main source for the history of Sanjan, composed in 1600 CE by a Parsi priest named Bahman - they also established the first Atash Bahram, or fire temple, utilising ritual objects such as 'nirang' (bulls' urine) and ash imported from an existing Atash Bahram in Persia. ${ }^{56}$ Also according to the Qissan, over the next three hundred years the Parsi community adopted Gujarati as their lingua franca and Indian clothing with minor distinguishing differences such as the kerchiefs worn by women to cover their hair under their saris and the white robes of the priesthood. ${ }^{57}$ During this period, the community prospered, expanded and spread out through Gujarat, whilst maintaining its links with Persia, mainly through the importation of priests. ${ }^{58}$

Rukshana Nanji and Homi Dhalla suggest that the pattern of expansion and spreading out to other sites indicates that the early settlers were traders rather than agriculturalists. ${ }^{59}$ In later years the Parsi community in Gujarat would become farmers, weavers and toddy producers. ${ }^{60}$

Of equal importance to the Parsi community as the history of their origins, has been and remains their distinctive religious belief. Zoroastrianism or the teachings of Zoroaster also known as Zarathustra, their founding prophet, was the state religion of Persia during the Achaemenid Empire (550-330 BCE). But Zoroaster was never accorded the position of a mediator between the Emperors and Ahura Mazda, 'Wise

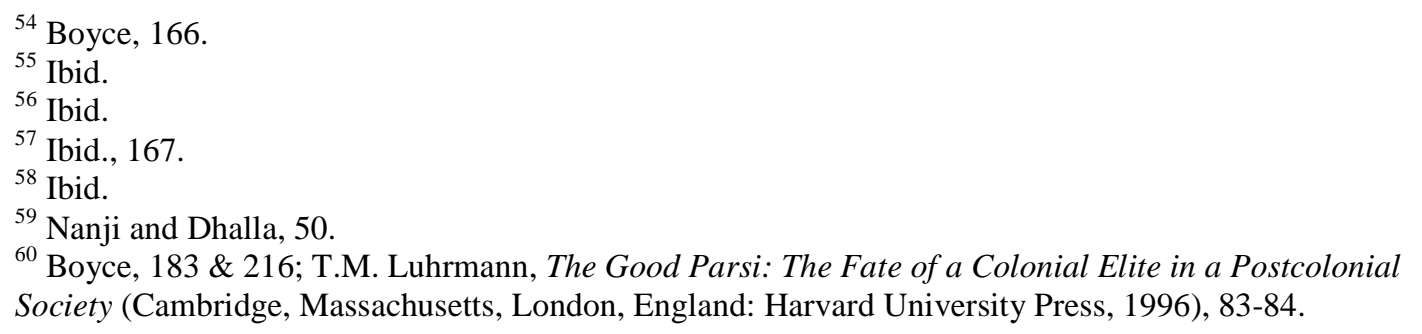


Lord', whom "Zoroaster proclaimed the sole absolute, omnipotent, eternal God". ${ }^{61}$ Herein lay two fundamental cornerstones of Parsi Zoroastrian religious belief. Firstly it is an expression of monotheism, although, as will be explained below, some doubt on this point was to arise later. Secondly was the development of the concept of there not being any direct intermediary between the individual and his God. This in turn was to lead to a lack of emphasis on doctrine, and a general lack of regard for the priesthood. "Rites in Parsism [sic] are less important than ethical dimensions." ${ }^{.62}$ It also explains at least in part the emergence of individualism as a typical Parsi trait. This important characteristic will feature significantly in later chapters.

Ahura Mazda rules this world, a world which contains both good spirits (Spenta Mainyu) and evil spirits (Angra Mainyu) and it is confusion over this point which has given rise to the later claims by Western theologians that Zoroastrianism is a dualist religion rather than monotheistic - an interpretation which is vehemently denied by Parsis themselves. ${ }^{63}$ But the concept of good versus evil is all-important to an understanding of Parsi behaviour and is directly related to the central theme of Parsi culture: "The moral demands on the individual meet in the formula: 'good deeds, good words, good thoughts'. They also, however explicitly include truthfulness, righteousness, faithfulness, purity, diligence, peaceable-ness and charity". ${ }^{64}$ Earthly renunciation and asceticism, as practised in particular by Hinduism and Buddhism, were condemned by Zoroaster. ${ }^{65}$ Life in this world is all important and is to be lived to the full without concern for any life hereafter.

When the Parsis negotiated with the local raja for permission to settle at Sanjan, they agreed to five conditions. These were: explaining their religion to the raja, adopting Gujarati as their language, wearing Gujarati rather than Persian dress, not carrying arms and not flaunting their religion in public as exemplified by their wedding processions taking place after dark. ${ }^{66}$ By and large these conditions have been adhered to through the centuries. In particular the one regarding not carrying arms has translated into respect for

\footnotetext{
${ }^{61}$ Kulke, 15-17; see Glossary.

62 Ibid., 19.

${ }^{63}$ Ibid., 92-93.

${ }^{64}$ Ibid., 18.

65 Ibid.

${ }^{66}$ Ibid., 28.
} 
and obedience to the governance of the day, regardless of who that might be. ${ }^{67}$ This characteristic was to become of great significance at the time of Indian independence. Indeed, as will be shown, Parsis have traditionally acquiesced quietly to the decisions of their political masters, only unflinchingly defending their right to practise their religion through their own religious structures and hegemony. "The only condition for their loyalty was that they were not hindered in the practice of their religion". 68

It was these principles of loyalty to those in charge, combined with their other ethics of hard work, thrift, honesty, integrity and charity that would see the Parsi community emerge in the eighteenth century from the obscurity of small-time merchants, weavers and agriculturalists to a dominant position in the leading commercial city in Western India - Bombay. Their progress was assisted massively by the security and encouragement afforded them by the British Raj. ${ }^{69}$

\section{The Sugar in the Milk}

In addition to the five conditions agreed to by the initial settlers on their arrival in Sanjan referred to above, there is an important, albeit legendary, story relating to the same occasion. This is constantly referred to in Parsi literature as the 'Sugar in the Milk' ${ }^{70}$ Although only a fable, it is a significant marker for the Parsi community as a whole through its relevance to their attitude to their host countries, historically India but now world-wide. There are slight variations in how the story is told, but the essence always remains the same. ${ }^{71}$ When the original settlers went before Jadi (or Jadav) Rana, the local raja, to seek permission to stay in Sanjan, Jadi Rana called for a bowl brimful of milk to indicate that there was no room for the new arrivals. In response, the leader of the migrants, an elderly dastur, a Parsi priest, took a gold coin and slipped it into the jug without spilling a drop of the milk, to indicate that they would disappear into the local community without being noticed. The raja then said that was all very well, but how

\footnotetext{
${ }^{67}$ Kulke, 28.

${ }^{68}$ Ibid., 133.

${ }^{69}$ White, $81 \& 162$. Kulke, 134.

${ }^{70}$ Luhrmann, n.46, 259-260; Manek, 19-20.

${ }^{71}$ Maneck, 20; Nivedita Mehta, "Parsi Contributions to the Art and Cultural Life of India," Nancy and Ram Singh eds., The Sugar in the Milk: The Parsis in India (Delhi: I.S.P.C.K., 1986), 31.
} 
would the migrants repay his hospitality? The dastur, in reply, took a pinch of sugar and dropped it into the milk, saying: "As the sugar sweetens the milk, so shall we endeavour to sweeten your lives with our industry". ${ }^{72}$ True or false this story neatly sums up the way that Parsis have traditionally behaved towards their hosts through the centuries, not making a nuisance of themselves through excessive demands but always striving to make a positive contribution to society through their efforts, particularly in the economic, social and political fields.

\section{Parsi Emergence in the Eighteenth Century}

The first Parsis to demonstrate prowess as intermediaries between foreign purchasers and indigenous producers for Gujarati goods were a certain Rustum Manock and his family during the first half of the eighteenth century. As David White states:

Within this group of shopkeepers and small merchants appeared one Rustum Manock, who was to lay the foundation for the long and fruitful Parsi connection with the English in India, and whose descendents were to build on this foundation to establish Parsi mercantile and industrial successes. ${ }^{73}$

During this time, Rustum Manock created a powerful link with the East India Company and at the same time moved from the role of risk-taking upstart in Surat (at that time Surat was a very important West Indian entrepôt, a collection point for goods from all over India destined for export) to head of a family of immense wealth, respectability and prestige in Bombay. ${ }^{74}$ They were to be the model for future Parsi successes during the nineteenth and twentieth centuries. Whilst they typified the major Parsi characteristics in most respects, they stretched the one regarding honesty well beyond the normal meaning of the word. For example, when Manock lost the position of broker to the East India Company in 1739 , he was able to maintain his position as their principal supplier by bribery and coercion of those who might have competed with him. ${ }^{75}$

The Manock family were the first, the trail blazers, in a long line of Parsi entrepreneurial dynasties. It was, however, to be several decades before another such

\footnotetext{
${ }^{72}$ Luhrmann, 78-79.

${ }^{73}$ Ibid., 39.

${ }^{74}$ Ibid., 22 \& 126-127.

${ }^{75}$ White, 173.
} 
family would emerge in the form of Sir Jamsetjee Jeejeebhoy and his descendants. ${ }^{76}$ As White states:

The Rustum Manock family created their success by combining two sets of characteristics: one located within Parsi ethical structure and one set within entrepreneurial techniques. As Parsis, the Rustum Manock family manifested an ability to acculturate, to emphasise living well in this world, and to serve the Parsi community.... As entrepreneurs the Parsi family became an indispensable source of expertise, funds, and access to the products of India for the East India Company and private traders. ${ }^{77}$

Whilst these Parsi entrepreneurs provided the bridge between the producers of indigenous products and the East India Company and private traders, their Achilles heel was their lack of security in a land where they were 'different' to the majority. These feelings of insecurity would increase dramatically as India moved from living under the British Raj to independence in the middle of the twentieth century. ${ }^{78}$ Prior to that, the British Raj provided the security that they craved and under which they were able to thrive both as individuals and as a community. Perhaps the most important trait exhibited by the Parsi community at this time was their adaptability, their ability to change with the times and as the needs of their foreign masters changed. ${ }^{79}$ "The Parsees called to mind that even the Greek historians had already described the ancient Iranians as a people with the greatest adaptability to foreign habits and customs". ${ }^{80}$

\section{The 'Golden Age' 81}

The nineteenth century saw the Parsi community consolidating its position as the principal agents and commercial lieutenants of the British Raj in Western India. This development was accompanied by the general transfer of the Parsi community from Gujarat to Bombay. At the same time, the centre for their religious and commercial

\footnotetext{
${ }^{76}$ Kulke, 126; Hinnells, 160.

${ }^{77}$ White, 175.

${ }^{78}$ Ibid., 177.

${ }^{79}$ Ibid.

${ }^{80}$ Kulke, 106.

${ }^{81}$ A term used by some academics and by older members of the Parsi community to describe the period between the late eighteenth and early twentieth centuries when Parsi influence in Bombay and Western India was at its height. Michael Stausberg, "Parsis of India: Two Recent Publications," Review articles, Numen Vol. 49 No. 2 (2002), 219.
} 
activities moved from Surat to Bombay. It also saw the emergence of those profiles for which Parsis have justifiably become famous - success as entrepreneurs, political, military and industrial leaders, and, in the professions, as doctors, lawyers, scientists and teachers. Their level of secondary and tertiary qualifications, both actually and on a per capita basis, was way ahead of any other ethnic group in Bombay. For example, according to Kulke, in 1860, 1341 Parsi boys and 485 Parsi girls were enrolled in Bombay's schools against a total of 1089 Hindu boys and no girls; numbers for all other groups such as Muslims and Christians of both sexes were lower than for the Parsi girls. ${ }^{82}$ By 1909, the figures for Hindus were exceeding Parsis for both boys and girls in absolute terms but were still far behind on a per capita basis. ${ }^{83}$ All this excellence translated into a disproportionately high representation amongst the professions, the governance of Bombay and in a wider context throughout India. ${ }^{84}$ It also saw the emergence of what became known as the "brown sahib'. ${ }^{85}$ Much of the Parsi community tried to follow British customs and behaviour rather than adhering to Indian ways. ${ }^{86}$ Indeed, as the day for Indian independence drew closer, those Parsis who perceived a future without the British Raj as a threat were to become sharply divided from those few, such as Firoze Gandhi, who were clearly in favour of independence. It was to prove a major cause of division within the Parsi community.

As has been mentioned earlier, an integral part of Zoroastrian and therefore Parsi philosophy was the importance of charity and charitable gifting (see The Importance of Charity in Chapter 5). As wealth grew within the Parsi community, so did the concept of charitable trusts, which, as will be explained later, would become two-edged swords as the economic influence of the Parsi community in Bombay passed its zenith and started to decline after Independence. During their 'golden age', these charitable trusts provided the base for family wealth and power as well as financial help and welfare to the needy within the community.

The role played by these trusts was to gain in significance as the Parsi population became more urbanised. According to Boyce: "In the 1930s there was a boycott of Parsi

\footnotetext{
${ }^{82}$ Kulke, 86.

83 Ibid.

${ }^{84}$ Kulke, 147-167; Luhrmann, 39-40.

${ }^{85}$ Luhrmann, 49.

${ }^{86}$ Ibid., 118-120.
} 
farms in Gujarat, which forced their owners to sell. Others suffered through prohibition (introduced in Gujarat in 1937), for some Parsi villages were given over to growing the toddy-palm". ${ }^{87}$ This antagonism led to many of those rural-dwelling Parsis still living in Gujarat moving to Bombay in search of work and new livelihoods. But Parsi influence was on the wane in Bombay as well. This exodus from rural Gujarat to urban Bombay brought the Parsi ethic of charity forcibly into the foreground, for better and worse.

Trusts, funded and administered by the Bombay Panchayat, initiated training schemes for the new arrivals and subsidised baags, communal housing complexes, for them. ${ }^{88}$ Whilst both initiatives were initially very successful, in post-Independence days these charities were to create something of a millstone for the community in the form of a ghetto mentality and a loss of self-reliance. ${ }^{89}$ As suggested by Luhrmann and Kulke and confirmed by responses to my interview question on reasons for emigration (see Part 3), the more individualistic and therefore more enterprising products of the baags wanted to get away from the closed and confining influence of their surroundings. ${ }^{90}$

\section{Historical Importance of Religious Issues}

Of considerable historical importance are the distinctive religious beliefs and practices of the Parsi community and how these have directly affected the community's social, economic and cultural circumstances. Whilst these will be discussed in much greater detail in Chapter 5, one issue of particular historical importance has been the socio-religious impact resulting from the lack of any formal religious hegemony, relegating the priesthood to a relatively minor role, exercising little if any real community leadership. The impact of a lack of any cohesive, religious authority has been that it has led to schisms and disputes between sects, groups and centres such as that between the Sanjanas of the Wadia Atash Bahram and the JamaspAsas of the Anjuman Atash Bahram, two competing fire temples. ${ }^{91}$ For decades during the nineteenth century these

\footnotetext{
${ }^{87}$ Boyce, 216.

${ }^{88}$ Ibid., 216-217.

${ }^{89}$ Luhrmann, 116, 149-150 \& 170; Hinnells, 71-72; Kulke. 76-77.

${ }^{90}$ Luhrmann, 171; Kulke, 109-110.

${ }^{91}$ John R. Hinnells, "Changing perceptions of authority among Parsis in British India," John Hinnells and Alan Williams, eds., Parsis and the Diaspora (London and New York: Routledge, 2007), 106-108.
} 
two important religious centres argued over seniority, priestly initiations, the distribution of offerings, the performance of navjotes for the children of mixed marriages and much else, leading ultimately to a series of acrimonious court cases in $1882-1884 .{ }^{92}$ One of these concerned the navjote of a French woman named Suzanne Brière, performed in 1903 by Dastur Kaikhroo Jamaspji, prior to her becoming Mrs Tata. ${ }^{93}$ This was to trigger the famous Parsi Panchayat case referred to below. These disputes have been and still are extremely harmful to communal cohesion. Loss of respect for the priesthood resulted in their standard of education being extremely low and consequently priests often being despised by the better educated laity. ${ }^{94}$ It was also to lead, in the nineteenth century, to a lacuna in communal authority which was only partly filled by the creation of lay councils called Panchayats. ${ }^{95}$ In their turn these organisations, particularly the main one in Bombay, had mixed fortunes due to internal wrangling and by the latter pat of the nineteen century were reduced to: "The administration of charitable foundations and public welfare activities which are still in its hands to this day". 96

The socio-religious characteristic that has had the greatest impact on the Parsi community and its demography has been the development through the centuries in India of the importance of religious and ethnic purity. In orthodox terms, to be a Parsi, it is necessary to be born of a Parsi mother and a Parsi father without any exceptions. ${ }^{97}$ Whilst this tenet does not seem to have applied to the original Zoroastrian religion imported into India with the first arrivals from Persia in the eighth century CE, it has led, as will be shown in great detail later, to a major schism between orthodox Parsis and modern or reformist Parsis, referred to more generally as conservatives and liberals respectively (see Chapter 7). ${ }^{98}$ Although this applies particularly amongst those who have migrated to other countries such as New Zealand, there are also those remaining in India who passionately believe that the only way the Parsi community will survive is

\footnotetext{
${ }^{92}$ Hinnells, Hinnells and Williams, 107-108.

93 Ibid., 109.

${ }^{94}$ Kulke, $77-78$

95 Ibid.

${ }^{96}$ Ibid., 69. Palsetia, 228.

${ }^{97}$ Luhrmann, 166; Sharafi, 159.

${ }^{98}$ Luhrmann, 79; Rusheed R.Wadia, "Bombay Merchants in the eighteenth and nineteenth centuries," John R. Hinnells and Alan Williams eds., Parsis in India and the Diaspora (London and New York: Routledge, 2007), 129.
} 
through a relaxation of the marriage rules to permit mixed marriages. Strangely, one of the principal objections, historically, to marrying out was based on fear of charitable trust funds being diluted by mass conversion of low-caste Hindus to Zoroastrianism, rather than solely for reasons of ethnic purity. ${ }^{99}$ Even more quixotically this reason was used in the famous 1908 Bombay High Court case of Petit v. Jijibhai, which denied Suzanne Brière, the French wife of Sooni Tata, of the immensely wealthy Tata dynasty, access to Parsi rites and charities, although she had converted to Zoroastrianism prior to her marriage. ${ }^{100}$ This case was to become a cause célèbre in subsequent arguments between orthodox and reformist Parsis over whether or not one could ever become Parsi or even Zoroastrian by any means other than by birth.

\section{Post-Independence}

Many Parsis foresaw the end of British rule as a cataclysmic event, which would endanger their survival as an independent community. Others were prepared to throw in their lot with the new post-Independence regime, thereby reiterating the ancient Parsi ethic of support for the ruling authority regardless of its political make-up. ${ }^{101}$ But it also resulted in yet one more cause of communal disharmony, in this instance between those supportive of the new Indian regime and those bitterly opposed to it. From amongst the latter would emerge a steady and burgeoning diaspora, seeking perceived greener pastures for individual socio-economic advancement, initially to England, Canada and the USA, more recently to many parts of the world including New Zealand. ${ }^{102}$ According to John Hinnells: “A growing centre for Zoroastrian [Parsi] migration is New Zealand with approximately 860 [migrants]". ${ }^{103}$

Meanwhile, those who threw in their lot with the new post-Independence sectarian state of India, far from being persecuted as outsiders, were accorded positions of major significance as politicians, leaders of the armed forces, scientists, industrialists, doctors and lawyers; positions that many Parsis continue to enjoy up to the present time.

\footnotetext{
${ }^{99}$ Sharafi, 165 .

${ }^{100}$ Ibid., 159.

${ }^{101}$ Boyce, 223.

${ }^{102}$ Hinnells, Hinnells and Williams eds., 2-3.

${ }^{103}$ Ibid., 271.
} 
Examples include Homi J.H. Tayarkhan, General Secretary of the Congress Legislative Party and Parliamentary Secretary to the Chief Minister 1957-60, Sir Homi Mody, Governor of Bombay after Independence, Nani Palkivala, appointed Indian Ambassador to the USA in 1977, Sam Maneckshaw first Indian to be appointed a Field Marshall (1973), the Tata and Godrej conglomerates and not least Homi Bhabha, the father of the Indian atomic energy and space programs. ${ }^{104}$ But the days of over-weighted political influence that they had enjoyed as a community under the British Raj, especially in Bombay, were over, never to return. ${ }^{105}$

During the years leading up to Indian independence, the Parsi community had developed readily identifiable characteristics that set them apart from the main Indian population, some positive and some negative. On the positive side, firstly and foremost was the emphasis on the acquisition of tertiary qualifications. ${ }^{106}$ Secondly was the stress on high levels of individual achievement particularly in the public arena as local political leaders. As Mary Boyce says: "Public service had long been regarded by Parsis as a religious obligation, a part of their duty, each according to his ability, to care for their fellow-men". ${ }^{107}$ Thirdly was the general acclaim accorded to worldly success. Not only was the acquisition of wealth highly desirable but likewise its demonstration through material possessions such as large houses, good English furniture, fine clothes and large charitable donations. Well known examples of this included such famous Parsi names as Sir Jamsetjee Jeejeebhoy, "the first Indian knight [and later baronet] in recognition by the British of his many acts of charity and public-spiritedness", Sir Mancherjee Merwanjee Bhownaggree, who funded significant charitable organisations both in Bombay and in London as a memorial to his beloved daughter, Ave, the Tata Group and the Godrej Group. ${ }^{108}$ Fourthly and, as will be shown of very considerable importance to the general health of the community, was the emphasis on gender equality, not only the education accorded to girls but also in terms of their freedom of action. ${ }^{109}$

\footnotetext{
${ }^{104}$ FEZANA Journal Winter 2004: 75-78; Hinnells, Hinnells and Williams eds, 256-262.

${ }^{105}$ Kulke, 263-264.

${ }^{106}$ Ibid., 85-91.

${ }^{107}$ Boyce, 223.

${ }^{108}$ Palsetia, Hinnells and Williams eds., 92; McLeod, 136; Hinnells, Hinnells and Williams eds., 259-260.

${ }^{109}$ Kulke, 104-105; Palsetia, 137-139.
} 
In equal measure, those formative years were to throw into stark relief some negative aspects such as the propensity to hold strong individual opinions which created rifts within the community as exemplified by the religious disputes of 1882-1884 and the 1908 Bombay High Court case of Petit v. Jijibhai, already referred to in Chapter 2. The community was often subject to jealousies and rival factions which tended to weaken communal cohesion. This lack of communal cohesion was compounded by the lack of a viable religious leadership and the weakness of the lay leadership, the Panchayats. ${ }^{110}$ As already stated at the beginning of this section, excessive commitment to the British as their role model and protector was in turn to create a sense of uncertainty and insecurity at the prospect of losing the British political umbrella and how best to react to their new circumstances. In stark counterpoint to the Parsi facility for acculturation were the feelings of cultural and racial separateness and alienation from the indigenous population. The Parsi community, by its very successes in the political, commercial and professional fields, had set itself apart from its host community. ${ }^{111}$ Heightened feelings of separateness would have accompanied any sense of superiority caused by their socioeconomic success. Also, as John Hinnells says: "Indian Parsis are, of course, a diaspora, having migrated from Iran to India..., and despite their successful settlement and commitment to India they retain a strong emotional link with their ancestral land". ${ }^{112}$ This created a feeling of being transitory rather than permanent inhabitants amongst many within the Parsi community and a sense of readiness to move on if the need arose. $^{113}$

Female emancipation, within the wider context of traditional Indian inequality for women was, as will be dealt with at some length later, to create unforeseen problems for the community, in the form of a conflict between careers and marriage. ${ }^{114}$ So, too, would be the importance of the growing debate on the future ethnic purity of the community and the need for reforms if the demographic imperatives of contraction were to be reversed.

\footnotetext{
${ }^{110}$ Hinnells, Hinnells and Williams eds., 115-116; Kulke, 69.

${ }^{111}$ Kulke, 234 \&265.

${ }^{112}$ Hinnells, Hinnells and Williams eds., 265.

${ }^{113}$ Hinnells, 726.

${ }^{114}$ Luhrmann, 169.
} 


\section{Summary}

This brief history of the Parsi community of India gives not only an insight into their religion and way of life, but is also an essential backdrop for understanding the strengths and weaknesses, opportunities and threats, which the community is facing in the twenty-first century. It reveals their strengths as individuals in whatever is their chosen profession or way of life alongside the weaknesses which those very strengths have tended to create within the Parsi community in the form of disagreements and schisms. It touches on the opportunities for success both amongst those Parsis who chose to throw in their lot with India post-Independence and those who, fearing submergence within the wider Indian culture, chose to take part in a world-wide diaspora, for better or worse embracing a totally strange culture in a foreign land far from either their Persian origins or their adopted home in India. In recent years, this diaspora has spread to New Zealand.

Alongside those opportunities, the threats to their very existence as an ancient and unique community are thrown into stark relief. The very closeness and closed nature of their culture together with the insistence on ethnic purity have, through the years since Indian independence, become major factors in their future survival. 


\section{Chapter 3 The Parsi Community in New Zealand and Diaspora Comparisons}

Still very modest in size by comparison with the numbers of Parsis that have migrated to such places as the United Kingdom and North America, the last twenty years has seen a dramatic increase in the number of Parsis taking up permanent residence in New Zealand. Although Parsi figures are also very modest by comparison with other migratory groups to New Zealand from South-East Asia, it is interesting to make some comparisons between the migratory streams of Parsis and Indians to New Zealand over the years. Whilst differences far outweigh similarities, there are a few intriguing common threads. The most obvious differences are concerned with timing and numbers. In the 2006 NZ census, 64,392 people identified themselves as Hindu Indians, 9,507 as Sikhs and 17,268 as Christian Indians, whilst the number of Zoroastrians, mainly Parsis, was only 1,071. ${ }^{115}$ The earliest Indian communities in New Zealand came from Navsari and Surat in Gujarat, the traditional home villages for the Parsis, where they first settled after their arrival from Persia. ${ }^{116}$ These early Gujarati settlers were mainly Hindus from the Koli and Kanbi jatis, but also included some Harijans. ${ }^{117}$

Although the initial arrival in New Zealand of both Indians and immigrants of Parsi birth is separated in time by about 70 years, both communities started in a very small way; the earliest Indian settlers, in 1809 and 1816, were lascar (Indian seamen) deserters, followed mainly by servants who accompanied wealthy English families migrating from India. ${ }^{118}$ The first known Parsi settler was a certain Hormuzji Ratanjes Shroff, who had a degree from Oxford and several business disasters in the UK to his name before arriving in NZ in 1877. ${ }^{119}$ After an unsuccessful foray into farming, he founded the well-known Auckland hardware shop of Shroff and Sons Ltd, which celebrated its centenary in 1986, when it was still being run by a member of the Shroff

\footnotetext{
${ }^{115}$ Statistics New Zealand, 2006 Census of Population and Dwellings, 2006, accessed January 05, 2011, http://www.stats.govt.nz/Census/2006CensusHomePage/QuickStats/quickstats-about-a-subject/culture-andidentity/religious-affiliation.aspx. There are a small number of Iranian Zoroastrians living in New Zealand. ${ }^{116}$ Jacqueline Leckie, "New Zealand," Bij V. Lal, General ed., The Encyclopedia of the Indian Diaspora (Honolulu: University of Hawai'i Press, 2006), 389.

${ }_{117}^{11}$ Ibid.

${ }^{118}$ Ibid.

${ }^{119}$ NZ Herald, Tuesday 18 February 1986, section 4.
} 
family. The business closed in 2007. ${ }^{120}$ In the article celebrating the $100^{\text {th }}$ anniversary of the company, which includes an interview with the then current managing director, $\mathrm{Mr}$ Brian Shroff, there is not a single reference to the family's Parsi heritage or origins. ${ }^{121}$ Unfortunately, family records do not provide any clear evidence, but it would seem probable that Hormuzji Shroff was married to a non-Parsi, possibly English, when he arrived in New Zealand and that the family's Parsi identity did not survive beyond him.

Both Parsi and Indian migrants tend to keep close relationships with overseas friends and family, making good use of modern technology (email, internet, Skype) for this purpose. Although there have been a couple of examples of involvement in national and local New Zealand politics, in the main the Indian community has kept a fairly low political profile in their adopted country. Political involvement by the Parsi community is non-existent. ${ }^{122}$ Indian migrants tend to divide up, socially, along regional and religious lines. ${ }^{123}$ Parsis mix socially with anyone, but tend to divide into conservatives and liberals for religious purposes. Both have maintained their individual culinary traditions and their culture. ${ }^{124}$

The numbers of Indian migrants had reached 46 by 1896, escalating into thousands during the twentieth century, whilst it took until 1990 for the number of Parsis in New Zealand to reach 20 individuals. ${ }^{125}$ Although many Indians came directly from India, towards the end of the twentieth century their numbers were significantly enlarged by thousands of political fugitives from Fiji, following the 1987 military coups. ${ }^{126}$ In the earlier part of the century, few Indian migrants to New Zealand had professional qualifications and most took up labouring or domestic work, although significant numbers also went into the retail trade, running and owning small family shops such as dairies. ${ }^{127}$ Whilst the inflow of more qualified Indian migrants has increased since the 1970s, unskilled workers, both from Fiji and India, have continued to flow into the

\footnotetext{
${ }^{120}$ Wayne Thomson, NZ Herald, 2007, accessed June 16, 2010, http://www.nzherald.co.nz/nz/news/article.cfm?c id=1\&objectid=10432034.

${ }^{121}$ NZ Herald, Tuesday 18 February 1986, section 4.

${ }^{122}$ Leckie, 394-395.

${ }^{123}$ Ibid., 392.

${ }^{124}$ Leckie, 393.

125 Ibid., 389.

${ }^{126}$ Ibid., 391.

${ }^{127}$ Ibid.
} 
country, many of them government sponsored under family reunification schemes. ${ }^{128}$ In contrast, the Parsi migration to New Zealand, which has accelerated since the early 1990s, has been individually driven and has consisted of singles or families, all with some technical or professional qualifications and, at least amongst those interviewed, gaining entry through meeting the Skilled Migrant Category requirements. The motivation for Parsis to migrate to New Zealand has not been driven by a group desire to escape an intolerable burden such as poverty or religious persecution but rather, as individuals, deciding to seek a more favourable environment in which to live, work and raise a family. As will be described in greater detail in Part 3, the accelerated migration to New Zealand during the 1990s, whilst due in part to unease about future opportunities in India, was also and more importantly motivated by the easier access, at that time, to career choices in New Zealand when compared with more traditional destinations such as Britain, Canada and Australia. In my interviews with New Zealand domiciled Parsis, several people said that they chose New Zealand because they could obtain work commensurate with their qualifications with minimal retraining or onerous prequalifying conditions such as applied in Australia.

During the twentieth century, particularly the earlier years, the burgeoning Indian population faced significant discrimination, leading to the formation of many Indian associations which provided "crucial social and cultural support". ${ }^{129}$ These in turn have given the Indian community a high local profile, for example the public celebration of Diwali and the success of various Indian sporting clubs. ${ }^{130}$ In complete contrast, the Parsi community in Auckland, the only New Zealand city with a significant number of Parsi residents, makes no attempt to publicise its cultural associations and their activities, preferring to meld into their local communities on an individual basis, continuing their traditional practice of being the 'sugar in the milk' - participating and making a major contribution but not specifically publicising themselves or their distinctive ethnic background. In discussions with individual members of the New Zealand Parsi community, they point directly back in history to their arrival in Sanjan in the eighth

\footnotetext{
${ }^{128}$ Leckie, 391.

129 Ibid., 392.

${ }^{130}$ Ibid., 392 \& 395.
} 
century and their commitment never to proselytise as the principal reason for this reticence. This tenet is supported and augmented by the closed nature of both their religion and their ethnicity. This rigidity is combined with an intense pride in the uniqueness of their origins and the socio-religious drive to be as successful as possible as individuals.

Since Indian independence, some Parsis have firmly aligned themselves with India as their nationality of choice. ${ }^{131}$ But this is not the case with those Parsis whom I have interviewed in New Zealand. They all very clearly make a distinction between themselves and other migrant groups from India, whilst maintaining friendly and often close relationships. This suggests that, at least amongst those who have joined the diaspora, their Zoroastrian religion and Persian origins are taking on an added significance in terms of their self-perceived identity. ${ }^{132}$

\section{Locations}

Whilst exact numbers are hard to come by, as already stated, in the 2006 census 1071 people were recorded as being followers of the Zoroastrian religion. The majority of these would have been Parsis, with a very few being Iranian Zoroastrians. Most of this group are located in Auckland, where current anecdotal data puts the current figure at 1200-1300. Many of the Parsis, now residing in New Zealand, arrived around the turn of the century but they are still coming, albeit more slowly than ten years ago, due, at least in part, to the more stringent New Zealand immigration requirements now pertaining. Although most have settled in Auckland, they are also spread out around the country, either as single families or in very small groups, their locations being job-related. So for example, there are five separate families in the Wellington area, one family until recently living in Hawera (now moved to Auckland), one person in Cambridge, one family with a vineyard in North Auckland and several families in Christchurch and Dunedin. In Auckland, they are not confined to any one area but are spread out around the city from Henderson in the North to Howick and Botany Bay in the South. Several of the wealthier

\footnotetext{
${ }^{131}$ Hinnells, 61- 64.

${ }^{132}$ Ibid., 4.
} 
families live in Howick but are not always aware of each other with little apparent local communal cohesion. Most, particularly those living outside Auckland, are perfectly content with being isolated from other Parsis, interacting and forming friendships within their local communities. Often they are very involved in local community activities such as schools and social groups. The Wellington group all know each other and meet socially, whilst very much carrying on with their own lives. They also maintain some contacts with Parsi families living elsewhere in New Zealand with occasional social gatherings and ad hoc visits Because of its numerical superiority, there has been more opportunity for Auckland to develop formal social and religious structures.

\section{Integration or Separation?}

One does not need to look far to establish the reasons for the differing directions taken by the New Zealand Parsis when compared with other migrant groups such as the Indian Hindu community. The Parsis have migrated to New Zealand from India and elsewhere such as Pakistan, Singapore and Malaysia as individuals and small nuclear family units rather than in social groups. They have a long tradition of excellence in the English language, tertiary qualifications and work habits with little if any history of being discriminated against prior to migrating. Such a background has stood them in good stead for racial integration in their new country of adoption. In sharp contrast to this, as described by Jacqueline Leckie in her chapter on Indian communities in New Zealand, many Indian Hindus arrived in New Zealand with poor English language skills and limited education. Because of their significant numbers and being in competition with others for jobs within the lower socio-economic job market, they met with considerable antagonism and discrimination. ${ }^{133}$ Finding integration difficult led naturally to the formation of ethnically based community groups as protection against and to oppose racism, for example the Auckland Indian Association formed in 1918 and the New Zealand Indian Central Association, "formed in 1927 in response to the White New Zealand League". ${ }^{134}$ By the time the main part of the Parsi community began to arrive in

\footnotetext{
${ }^{133}$ Leckie, 389-395.

${ }^{134}$ Ibid., 391.
} 
New Zealand in the 1990s, circumstances had changed with discrimination against Asian migrants much less overt. To this can be added Parsi ambivalence to being associated with an Indian identity and their enthusiasm for assimilation into the New Zealand way of life. Some Indian organisations have been formed for the specific purpose of preserving their mother tongue, something the Parsi community would find quite superfluous as they have a long history of accepting other languages as their own, historically Gujarati and more recently English. What both communities do have in common is the formation of community associations to try to preserve their cultural and religious heritages. ${ }^{135}$

\section{Associations}

There are two registered Parsi associations in New Zealand, both located in Auckland. The larger of the two is the Zarathustri Association of New Zealand or ZANZ for short. This was incorporated in Auckland in 1996. In its Preamble, it states: Baname Khoda, Baname Yazad, we the ZARATHUSTRIANS of New Zealand aspiring to preserve and foster the rich, religious, cultural, social and historical heritage of our forefathers. Having decided that this may be best achieved through united action, strength and resources, have therefore created this Association as a primary nucleus to execute and promote these and other objectives set forth in the following articles. ${ }^{136}$

Ordinary members are defined as: any ZARATHUSTRIAN over the age of 18 years, who has been initiated into, and is professing, the ZARATHUSTRIAN religion, and who is a New Zealand Citizen or a permanent resident of New Zealand, will have the automatic right to become an Ordinary Member. ${ }^{137}$

Other categories include life members, honorary members, out station members and, significantly, family members defined as: "The spouse or unmarried child (under the age of 18) of an Ordinary or Life Member of the Association, residing in the household of such a Member shall, be entitled to be enrolled as a Family Member". This allows, for example, the non-Zoroastrian spouse or child of an ordinary member to be a contributing

\footnotetext{
135 Leckie, 392.

${ }^{136}$ Zarathushtrian Association of New Zealand (ZANZ), Constitution, 2010, accessed August 16, 2010, http://www.zanz.org.nz/constitution.htm . 
member of the Association although they are explicitly excluded from having any say in its affairs and management. There would also appear to be the facility, under honorary membership, for someone other than a Zoroastrian, who has "rendered meritorious service to the ZARATHUSTRIAN community in New Zealand, or who has contributed significantly in furtherance of the Objectives of the Association" to join the Association. ${ }^{138}$ They too are specifically excluded from having any say in the Association's affairs and management.

The Association is very active with an up-to-date website advertising activities and a newsletter. Although it has no premises of its own and must hire facilities such as community halls for its activities, it has regular fortnightly meetings, which include religious and Parsi history instruction. Ordinary membership is currently 97 with an additional 33 life members. These numbers swell to about 250 for social events, when family members are included.

ZANZ has an associated Trust, the Zoroastrian Community Trust of New Zealand, set up on 27 March 2007 for the express purpose of raising funds and then acquiring its own community and religious centre. ${ }^{139}$ It is estimated that a figure of NZ\$2,000,000 will have to be raised for this purpose. ${ }^{140}$

The second and much smaller organisation is the Traditional Mazdayasni Zarathushtee Anjuman of New Zealand Inc., or TMZANZ for short. It too has a website (although this has not been updated since 2007) and a registered Constitution which states amongst its objectives:

4.01 To preserve and promote the Mazdayasni Zarathushtee religion in its pristine form;

4.02 To provide religious education, conduct research into Mazdayasni

Zarathushtee Religion, and provide lectures by traditional scholars to Mazdayasni Zarathushtees;

4.03 To provide religious and social communication in order to promote solidarity between like minded traditional Mazdayasni Zarathushtees in the community. ${ }^{141}$

\footnotetext{
${ }^{138}$ Zarathushtrian Association of New Zealand (ZANZ), Constitution, 2010, accessed August 16, 2010, http://www.zanz.org.nz/constitution.htm .

${ }^{139}$ Zoroastrian Community Trust of New Zealand, Trust Deed, 2007, accessed August 17, 2010, http://www.zct.co.nz/deed_23March_2007.pdf.

${ }^{140}$ Ibid.

${ }^{141}$ Traditional Mazdayasni Zarathushtee Anjuman of New Zealand Inc. , Constitution, accessed August 19, 2010, http://www.tmzanz.org.nz/.
} 
It also advertises regular meetings for such purposes as religious and historical instruction. Hired premises are used for meetings.

Immediately prior to ZANZ being set up in 1996, a major disagreement arose over association membership with opinions divided between conservatives and liberals regarding the acceptability or otherwise of families from mixed marriage. This disagreement led directly to the formation of TMZANZ whose membership is confined to Parsis who believe in strict adherence to the traditional ethnic purity rules. The two organisations have social contact with each other but keep their religious functions separate. A sad corollary to the split has been a loss of momentum in fund raising for a purpose-built Parsi owned community hall. A more recent development has been talk of a joint community hall, purely for social activities, which could be supported by both groups.

One could argue that the formation of these two organisations provides evidence of communal cohesion and there is no doubt that there is a small and active group of New Zealand Parsis who are striving to provide such cohesion in furtherance of the twin aims of maintaining and upholding their traditional culture and religious beliefs. But the reality is less convincing. In the first place, the fact that such a small community has found it necessary to have two associations rather than everyone getting behind one association must be seen as unfortunate, particularly as the smaller association does not appear to be very active other than in its opposition to the aims of the larger group. Secondly, as the figures in an earlier paragraph demonstrate, only about $25 \%$ of the total Zoroastrian population in Auckland regularly attend social events let alone support the fortnightly meetings, when attendance is considerably lower. This suggests only very lukewarm interest on the part of the majority of Parsis living in the Auckland area. Interest in these associations by those living elsewhere throughout New Zealand is virtually nonexistent.

\section{Religious Facilities}

The current absence of any permanent communal place of worship anywhere in New Zealand is, at least at first sight, to be wondered at, given the importance which 
Parsis themselves attribute to their religion as an integral part of their everyday lives. As will be discussed in detail in Chapter 5 and in Part 3, however, Parsi worship and therefore the facilities for worship are largely a private matter. As a consequence the urgency to progress the construction of communal facilities is perhaps not receiving as high a level of priority as might be the case for other religious denominations, such as Christianity, Hinduism or Islam, where communal worship forms such a central and essential part of their religious dogma. That is not to say that most Parsis, certainly in Auckland, would not welcome communal facilities for both social and religious purposes, if and when the necessary funds can be collected for this purpose. This desire was clearly borne out during my interviews as recorded in Part 3.

There is a small private Zoroastrian fire temple in Pakuranga, which was erected and is maintained by an Iranian Zoroastrian couple, Dolly and Aspi Shahlori, expressly for public use by Parsis and Zoroastrians living in New Zealand. Interestingly, it is frequented by both liberal and conservative members of the Parsi community, along with the few Auckland domiciled Iranian Zoroastrians. ${ }^{142}$ Whilst this facility is much appreciated by individual members of the Parsi community, there is a general desire for something more permanent, owned by the community at large.

\section{Summary}

Since the 1990s the Parsi community in New Zealand has expanded from a mere handful to a small but thriving and well-settled group estimated at 1200-1300. Most live in Auckland although individual families have also spread out all around the country. By comparison with the much larger and much longer established Hindu community, they have found integration with the local population comparatively non-threatening and straightforward. This can largely be attributed to the preponderance of professionals and tertiary-qualified persons amongst their numbers. This contrasts with historical perceptions of the Hindu migrant community as being largely from the lower educated and lower skilled classes. Another factor has been the differing motivations for

\footnotetext{
142 geveN, Zoroastrian Temple in Auckland NZ, accessed July 14, 2010, http://bbs.keyhole.com/ubb/ubbthreads.php?ubb=showflat\&Number=916948.
} 
migration to New Zealand with most Parsis opting individually to apply for New Zealand residency and citizenship because of perceived better opportunities for themselves and their families rather than because of persecution or social barriers to progress in their country of origin, as for example has been the case for Indo-Fijian immigrants. Excellence in the English language combined with their centuries-old ability to acculturate has stood the New Zealand Parsi community in good stead.

A lack of facilities for both devotional and social purposes is not only a serious bar to Parsi communal cohesion, but also symptomatic of that very lack of cohesion, progress towards a resolution being hampered by differing and intractable opinions on how best to proceed. This is unfortunate given the smallness of the total Parsi population in New Zealand. It has led to a split within the community and the setting up of two separate organisations, ZANZ and TMZANZ. In the absence of a more permanent community facility or facilities for social and/or religious purposes, many Parsis of both liberal and conservative persuasion utilise a small private fire temple for devotional purposes. 


\section{Part 2 Parsi Identity}

The history of the Parsi community in India, as described in Chapter 2, in particular their ability to live peaceably for generations in a foreign land, as a very small endogamous group, and not to lose their distinctive Zoroastrian culture and religion through assimilation, has been a remarkable achievement. Part 2 will examine the specific characteristics which have helped the Parsis to survive and prosper in the past and which have contributed to their distinctive identity. These characteristics will be discussed under three headings: individualism, religiosity and socio-economic issues. Whilst each topic may be unremarkable in itself, their interconnection is of considerable significance. The combination of acculturation, without which their individualism would not have flourished, in juxtaposition with Parsi exclusivity in the form of ethno-religious purity, calls for deeper analysis. Do the two emanate from the same source? Certainly, the combination was a formula for socio-economic success between the eighteenth and twentieth centuries, but has it also been a major contributor to the current demographic crisis? My research suggests that it has.

Chapter 4 Individualism and the Parsi Community. How has the one affected the other?

A certain amount of individualism within any community would be regarded as quite normal. What is unusual about the Parsi community is the degree to which it has become a part of Parsi identity. So much so that, historically, it was to be an important part of their survival strategy. As will be shown later, however, the current trend for the community to disperse as a diaspora can also in large measure be attributed to it.

\section{Individualism: the Cause of Success but also of Disharmony and Community Friction}

Historically, Parsi fame was built on the success and notoriety of a succession of powerful entrepreneurial individuals and their families. In their wake, however, these 
powerful individuals and dynasties sometimes left a legacy of friction either within the family or within the Parsi community itself. As Homi Homji says in his assessment of the Parsi community: "We Parsis produce by innovation or emulation, wonderful institutions and operate them with all possible internal conflicts and dissensions". 1

In the eighteenth century, members of the Rustum Manock family stood out as successful individual entrepreneurs, who, whilst leaders of their community, also created friction within it. "Manock used the recognised legitimacy between himself and the East India Company to extort from, pressure and threaten other merchants for his own benefit". 2 The drive towards individual success and dominance by various members of the Manock family led to conflict not only within the community but also within the Manock family itself. The legacy of the very significant enterprise, founded by Rustum Manock, fell to his three sons on his death. Although initially harmonious, this arrangement finished up with the middle son, Nowros, clearly the head of both the family and the enterprise. But just before Nowros died, a major family rift occurred directly as the result of sibling rivalry. As White says: "We can only surmise what the origin of this quarrel might have been: most likely Framji [his elder brother] was jealous of Nowros' triumph over the East India Company and his evident leadership of the family after his return from London". ${ }^{3}$ After the enterprise had passed down to Nowros's son, Manock Nowrosji, there was another family rift, this time with considerable political and economic impact. ${ }^{4}$ This was followed by Manock Nowrosji suing his relations' estates for recovery of debt. ${ }^{5}$ Manock Nowrosji was to become not only head of the family but leader of the Parsi community in Bombay as well. When he died, the surviving members of the different branches of the family disputed his will, leading to the break-up and ultimately contributing to the demise of the business. "Avarice now fragmented the family, divided its capital and impaired its ability to respond to future economic developments". ${ }^{6}$ Their story is a good example of individual success creating family disputes and ongoing inter-family rifts, leading ultimately to disaster.

\footnotetext{
${ }^{1}$ Homji, 98.

${ }^{2}$ White, 141.

${ }^{3}$ White, 106.

${ }^{4}$ Ibid., 128.

5 Ibid., 159

${ }^{6}$ Ibid., 174.
} 
A good nineteenth century example of the juxtaposition between individual Parsis and their community would be the first Sir Jamsetjee Jeejeebhoy and his son Curtsetjee Jeejeebhoy, who bought the family the first Indian baronetcy in 1857. By doing this, they accepted the English law of primogeniture in direct opposition to the Parsi community's rejection of English laws of succession in the construction of their own laws in 1865 . $^{7}$

As mentioned previously, in 1908 came the notorious and bitter court case of Petit v. Jijibhai, more popularly known as the Parsi Panchayat case by which "juddins or nonParsis were excluded from enjoying the benefits of Parsi trusts, the legal instrument governing Zoroastrian religious properties and funds". ${ }^{8}$ Whilst of major significance to the Tata family, "the Parsi 'royalty' of mercantile-industrial Bombay", it also set an important legal precedent, which divided and still divides the Parsi community over the question of admission or non-admission of converts. ${ }^{9}$ The resulting schism is documented by Luhrmann as a part-victory for reformists, when she states that:

The suit arose because the Panchayat, after some dithering, forbade the use of all their funds and properties - including the agiaries, fire temples, and dokhmas, towers of silence - by people who had not been born Parsi ... and yet he [the presiding Parsi judge, Davar] made what appears to be a new and significant concession which was accepted by the Panchayat: that while Tata's wife could not have access to Parsi institutions, her children could. ${ }^{10}$

Other Parsi scholars such as Rashna Writer, Jesse Palsetia, Michael Stausberg and John Hinnells, take a different view, claiming that the outcome was a total victory for orthodoxy. Whichever viewpoint is correct, a major marker was created in the ongoing struggle between orthodoxy and reformists. ${ }^{11}$

In researching the Parsi community in India, I was often made aware of groups of important individuals, leaders within the Parsi community, airing intractable and irreconcilable differences on such important communal issues. A more recent example of the actions of prominent individuals affecting the whole community was the debate in 1981 over the non-voting rights of Parsi women who had married outside the community.

\footnotetext{
${ }^{7}$ Palsetia, 197-226; Palsetia, Hinnells and Williams eds., 93-94; Kulke 67- 68.

${ }^{8}$ Sharafi , 159.

${ }^{9}$ Ibid.

${ }^{10}$ Luhrmann, 164.

${ }^{11}$ Sharafi, 161.
} 
This pitted the BPP (the Bombay Parsi Panchayat) headed by the then president, BomanBehram and other prominent orthodox Parsi religious figures such as Dastur Dr Firoze Kotwal, against leading Parsi figures such as the eminent lawyer and politician, Nani Pulkhivala and the editor of Parsiana, Jehangir Patel, representing the Committee for Electoral Reform. ${ }^{12}$ Again this became an issue between orthodoxy and reformists finishing up with a high court battle, won by the latter. ${ }^{13}$ Not only was it yet another milestone in the ongoing dispute between orthodoxy and reformism but it also gave further prominence to the internal debate regarding the overall rights of Parsi women who had married outside the community.

A modern example of dissent between a diaspora community and priestly authorities in Bombay is documented by Hinnells in his chapter on Zoroastrians in Australia and concerns a certain eminent Australian Parsi, Dr Purvez Kolswalla, who was active in the 1980s, encouraging the study of Zoroastrianism amongst adult Australian Parsis:

Certain Bombay priestly authorities have denigrated some of the AZA (Australian Zoroastrian Association) activities, in once [sic] case questioning the validity of Kolswalla's doctorate. On another occasion the AZA was attacked in the Bombay press because it debated changing the name from Zoroastrian to Zarathushtrian .... Both attacks were hurtful and provoked the protest from Kolswalla... ${ }^{14}$

In itself this dispute might seem unimportant and somewhat parochial by comparison with the more communally important disagreements discussed earlier in the chapter. It does however demonstrate how the tradition of airing disagreements between individuals in public has accompanied the diaspora. A self-deprecating joke amongst Parsis concerns the last Parsi left on earth and how he would argue with himself in the mirror every morning! As will be shown in Part 3, the New Zealand Parsi community is by no means immune to the intensity of such public displays of individual dissent.

\footnotetext{
${ }^{12}$ Hinnells, 75.

${ }^{13}$ Ibid., 76.

${ }^{14}$ Ibid., 581.
} 


\section{Internal Family and Gender Dynamics.}

The building blocks of every society are the family unit and, of course, Parsi society is no different. In this section, I aim to show how the development of Parsi family dynamics has impacted on the community, in particular the fundamental importance of being independent and successful. As an example, there is an interesting vignette described by Luhrmann regarding a middle-class working family in Bombay, post-Indian independence. ${ }^{15}$ The father was brought up as a very religious, orthodox Parsi. He had two sons; the eldest was very bright and had a good job at the same firm that had previously employed the father. In 1984, this son married out of the community in direct disobedience to his father's wishes. The second son, although still living at home, had not come up to his father's expectations as a hardworking and successful son. The eldest son had been disowned. The father describes the second son as useless, because he failed his B. Com and would not retake it, only earned a very modest wage and stayed out late. ${ }^{16}$

Both his sons are, to Cyrus [the father] destroying their ancestry and insulting their parents. One humiliates him by marrying out - not only a non-Parsi, but a dark skinned woman .... The other humiliates him in a more Parsi, less Indian manner: he fails to achieve and Cyrus suspects him of being immoral. ${ }^{17}$

Luhrmann backs up her vignette by saying: "Parsis have been arguing for years, with trauma and ambivalence, about how to fix the boundary around their religious community". ${ }^{18}$ To be a worthy Parsi, one must not only abide by the purity rules but one must make a success of one's life. Failure to achieve these requirements, on both counts, has destroyed this twentieth century family as surely as avarice destroyed the Rustum Manock dynasty in the eighteenth century.

Turning to the impact of gender equality on Parsi demographics in India, Paul Axelrod, in his article published in 1990, makes a direct connection between the Parsi emphasis on equality of the sexes, their historical insistence on education for women and the community's population decline, tracing the commencement of the decline back to

\footnotetext{
${ }^{15}$ Luhrmann, 153-155.

${ }^{16}$ Ibid., 153-154.

${ }^{17}$ Ibid., 154-155; the emphasis is mine.

${ }^{18}$ Ibid., 158.
} 
the late nineteenth century. ${ }^{19}$ As will be shown, this provides further confirmation that the Parsi emphasis on individual achievement, regardless of their chosen vocation or profession, has directly and adversely affected the numeric growth of the Parsi community in India. In his discussion, Axelrod suggests that, as Indian independence approached, other upwardly mobile Indian groups began to compete more vigorously for positions that had traditionally been held by Parsis. ${ }^{20}$ "In the increasingly rationalised economy, Parsi aspirations and goals for a distinctive lifestyle continued in the face of diminishing opportunities... Parsis, as a group, chose to delay marriages, remain celibate, and have fewer children". ${ }^{21}$ In other words, the importance of marriage and having children became secondary to maintaining Western standards of living. In arriving at this conclusion, Axelrod traces a direct connection between low fertility, low marriage rates and female emancipation. ${ }^{22}$

Of the various Parsi mores, perhaps the most important, in terms of its long-term impact on the community since the nineteenth century, has been this emphasis on gender equality and the education of women. ${ }^{23}$ "The pursuit of education for Parsi women had more profound effects on fertility than merely delaying marriage for a few years.

Educated Parsi women were pioneers in seeking employment outside the home which often postponed childbearing after the completion of education". ${ }^{24}$ It was to lead directly to Parsi women being much more self-confident then their Hindu or Muslim counterparts and consequently keen to seek employment and greater exposure to the wider world outside the narrow confines of their family and indeed of their Parsi community. In turn, this had a direct effect on nuptiality; girls earned their own money and therefore expected to live and be kept in comfort, aspiring to Western standards of living. By going outside the family to work, they became exposed to other cultures and a wider circle of friends and acquaintances, making them more selective when choosing a partner. ${ }^{25}$ In the early

\footnotetext{
${ }^{19}$ Paul Axelrod, "Cultural and Historical Factors in the Population Decline of the Parsis of India," Population Investigation Committee, Population Studies, vol 44, No. 3 (Nov., 1990), 402, accessed June 06, 2009, http://www.jstor.org/stable/2174460 .

${ }^{20}$ Ibid., 419.

21 Ibid.

${ }^{22}$ Ibid., 402 \& 416.

${ }^{23}$ Ibid., 407 \& 416; Kulke, 84 \& 86; Luhrmann, 113.

24 Axelrod, 416.

${ }^{25}$ Hinnells, 83.
} 
twentieth century, this tendency was reinforced by the gradual change amongst Parsi families from arranged marriages to love marriages. ${ }^{26}$ As Axelrod shows, the percentage of arranged to love marriages reversed from two thirds/one third at the beginning of the twentieth century to one third/two thirds by $1950 .^{27}$

Whilst the adverse affect of female emancipation and education on nuptiality and consequently on average family size is starkly relevant to the current debate on population decline within the Indian Parsi community, the decline is by no means confined to this cause. The Parsi emphasis on striving for wealth and perceived Western standards of living also applies to the men, although, according to Luhrmann, there is a common belief that boys are: "Not as clever as Parsi girls. Parsi girls are hard-working, ambitious and well-educated. Parsi boys are spineless and undriven. Parsi girls are independent, strong-minded and determined. Parsi boys are dominated by their mothers". ${ }^{28}$ On the other hand, Luhrmann also quotes from an eminent lawyer, who states that: "I have personally inspected each application to work in my office, and I tell you, the boys are every bit as well qualified as the girls". ${ }^{29}$ Luhrmann goes on to say that the perception of female superiority is false and that in fact Parsi women do not earn more, work longer hours nor acquire more education, supporting this with statistics from a 1982 survey by M. Karkal. ${ }^{30}$ Such perceived stereotyping of female superiority, however, deserves recognition as being unusual, not only in India but also worldwide. What is certainly very significant is the trend in delayed marriages, quoted by Axelrod, which shows a move in the median age range of marriages from 11-15 years for girls in 1871 to $16-20$ years in 1901 to $21-25$ in 1946 and from 16-20, to 26-30 and 26-30 for men over the same period. ${ }^{31}$

A further disincentive to early marriage has been the Parsi desire to live in nuclear rather than extended families, whilst still living close to their parents and relations "Patterns of nuptiality were most directly influenced by the shift from arranged to what are described in India as 'love' marriages and values concerning ideal household

\footnotetext{
${ }^{26}$ Axelrod, 408-409; Luhrmann 170-171.

${ }^{27}$ Axelrod, 408-409.

${ }^{28}$ Luhrmann, 134-135.

${ }^{29}$ Ibid.

${ }^{30}$ Ibid., 135.

${ }^{31}$ Axelrod , 405.
} 
structures in the community: Parsis prefer to find their own partners and live neolocally" ${ }^{32}$ The need to live as nuclear families and its impact on delayed marriage and therefore lower birth rates and non-marriage is important. Marriage is delayed until the family income is sufficient to provide an independent dwelling, rather than the lower initial costs of living in an extended family as has been normal for most other Indian communities. The desire to live 'neo-locally', particularly in Mumbai, where traditional Parsi enclaves are located near the city centre and therefore are very crowded, of limited availability and expensive, rather than moving out to the outskirts, where accommodation is more affordable, has exacerbated the situation. ${ }^{33}$

All these points - education and emancipation of women, the desire for nuclear families, location and availability of affordable housing - have their genesis in the very fundamental Parsi values of being and being seen to be both independent and successful:

Education... is directly connected with Parsi expectations about their position in Indian society; indeed, this is cited as a primary motivating force for having fewer children. This is more than the ordinary desire to improve one's lot in life; it is tied to the Parsi self-perception of the gold in the cup of milk.... Western education, British-style residences and tastes meant financial commitments that made the large extended families of the mid-nineteenth century infeasible. This led to late marriage and fewer children. ${ }^{34}$

It all ties back to Parsis seeing themselves as both a unique and a superior community, almost the equal of the British in pre-independence terms: "It has often been called to my attention that 'those Gujaratis and Maharastrians don't mind sleeping on the floor in one room; but we Parsis like to have a bed, and we are used to privacy. We have a higher standard of living than the other communities" ".35 Whilst Parsis may have been subject to centuries of Gujarati and Marathi acculturation, their traditional Parsi culture has remained firmly imbedded in their sense of identity.

\footnotetext{
${ }^{32}$ Axelrod, 408.

${ }^{33}$ Ibid., 410.

${ }^{34}$ Ibid., 416.

${ }^{35}$ Luhrmann 169-170, quoting from P. Axelrod, "A social and Demographic Comparison of Parsis. Saraswat Brahmins and Jains in Bombay." Ph.D. diss. (Chapel Hill: The University of North Carolina, 1974), 86.
} 


\section{Loss of Individual Opportunity and Migration}

In India, since Independence and the departure of the British, opportunities for success have diminished as the Parsi community's political influence has waned and competition from other communities has risen in line with increasing levels of education, self-reliance and widening emancipation. ${ }^{36}$ The consequential loss of opportunities for advancement supports my argument that the need to be and to be seen to be successful in material terms has directly and adversely impacted on the demography of the Parsi community in India. Furthermore, admiration for material success is not confined to a relatively few high-profile examples, but runs right through the community at all levels. It has directly fuelled the not inconsiderable and accelerating numbers of Indian Parsis migrating to other parts of the world, including New Zealand, in search of enhanced opportunities for a better quality of life and greater material success for themselves and their families. ${ }^{37}$

\section{Summary}

This chapter has highlighted the importance of individualism in the make-up of the Parsi identity. Although, to the outsider, the Parsi community has survived as a close knit united group, in fact it has been driven upwards and outwards by the absolute imperative to survive and succeed at the individual level. Whilst individual success has led to wealth and wealth has led to power and leadership, both within the community and at the wider, state and national levels, it has also led to internal friction and schisms, within the community and within families. This has been damaging to the internal health of the community, has adversely affected the community's long-term chances of growth and, ultimately, as individual opportunities for success have diminished in India, has created an atmosphere that has favoured migration.

\footnotetext{
${ }^{36}$ Luhrmann, 135; Kulke, 236.

${ }^{37}$ Hinnells, 703-704.
} 


\section{Chapter 5 The Impact of Religion on Parsi Identity}

The Zoroastrian religion is at the very heart of Parsi identity. All those characteristics which make Parsis special and different from other communities emanate from their religious beliefs. Zoroastrianism pervades the everyday lives of Parsis. John Hinnells, in debating the issue of conversions, raises the question "whether Zoroastrianism is a religion or racial marker?" ${ }^{, 38}$ In my discussions with a committee member of ZANZ (Zoroastrian Association of New Zealand), the same question arose and he was quite emphatic that it was both and that both interpretations were essential and interwoven.

\section{Religion as the Community's Traditional Driving Force}

It could well be argued that religion has traditionally been the principal driving force behind all major world communities. What makes Zoroastrianism somewhat different has been its open and worldly, even materialistic, doctrinal structure. Also of immense importance has been and still is its continual impact on the daily lives of its adherents. S. D. Nargolwala states in his essay, "Zoroastrianism and Parsis in India": Zoroastrianism is not a religion in the sense in which the term is commonly understood. Zoroastrianism does not contain the ingredients which are ordinarily supposed to form part of religion viz. dogmatism, compulsions from without, blind faith, the fear of punishment and the expectation of future reward as the impelling forces of our daily life. Zoroastrianism is rather a scientific and rational explanation of existence, of reality as a whole, of man's place in it, his duties while in this life and the high destiny which he can achieve by establishing his conduct in accordance with the eternal and immutable law of Nature which Zarathustra called the Law of Asha. ${ }^{39}$

If one looks back through Parsi history in India, one can say without equivocation that their religion has been the driving force behind the community's determination to achieve worldly and material success. Expressions reflecting this abound in their literature, for example, in the essay compiled by the Zoroastrian Association of Metropolitan

\footnotetext{
${ }^{38}$ Hinnells, 729.

${ }^{39}$ S. D. Nargolwala, “Zoroastrianism and Parsis in India,” Navy Kapadia, Jaydipsinh Dodiya, R. K. Dhawan eds., Parsi Fiction, Vol., 1 (New Delhi: Prestige Books, 2001), 51.
} 
Washington, Jashan, "Getting to know Parsi Zoroastrians," it says: “As a practical guide in daily life, his [Zarathustra's] prescription was very simple. Think good thoughts, speak good words, do good deeds". ${ }^{40}$ Nargolwala, later in the same essay quoted above, writes about the active, heroic aspects of the Zoroastrian religion reflecting the character of the people themselves - their zest for life and their confidence in their own strength. ${ }^{41}$ But, perhaps most significantly of all, given the importance of fire within the Zoroastrian religion, Pesi Muncherji, in his paper, "the Zoroastrian Association of Metropolitan Washington, Jashan," writes:' "To the modern Zaroastrian [sic], the 'sacred fire' is the fire within oneself with a burning desire to always succeed." 42

In answering the question, "What are the most important Zoroastrian [therefore Parsi] values?" the Zoroastrian Association of Metropolitan Washington, Jashan, highlights truthfulness, charity, purity and hard work. ${ }^{43}$ Interestingly, although these are the values emphasised by Zoroastrians in contemporary USA, they closely follow the sentiments expressed by an eminent Parsi in India many decades earlier. J. R. B. Jeejeebhoy, writing in the Introduction to Parsi Lustre on Indian Soil by H. D. M. Darukhanawala, writes:

They [the Parsis] lived in purity of heart conscious of their strength, they lived humbly, soberly and happily, they forgot pride of self, ...they were honest, frugal, hard-working and persevering, they identified themselves with all the beneficial reforms, and far-reaching influences of Western culture, they kept their purse strings loose and lightened the burden of their neighbours, they swerved not, even in the midst of slaughter and fury, from their ancient creed. ${ }^{44}$

Whilst a bit self-congratulatory, this statement by Jeejeebhoy does indeed reflect the core values of the Parsis, as perceived by themselves (see Part 3), by academics such as Kulke and Hinnells (see Chapter 1) and by eminent Indians, for example Mahatma Gandhi himself (see Chapter 6).

\footnotetext{
${ }^{40}$ The Zoroastrian Association of Metropolitan Washington, Jashan, "Getting to Know Parsi Zoroastrians," Navy Kapadia, Jaydipsinh Dodiya, R. K. Dhawan eds., Parsi Fiction, Vol., 1 (New Delhi: Prestige Books, 2001), 26.

${ }^{41}$ Nargolwala, 54

${ }^{42}$ Pesi Muncherji, “The Zoroastrian Association of Metropolitan Washington, Jashan,” Navy Kapadia, Jaydipsinh Dodiya, R. K. Dhawan eds., Parsi Fiction, Vol., 1 (New Delhi: Prestige Books, 2001), 40.

${ }^{43}$ The Zoroastrian Association of Metropolitan Washington, Jashan, 26-27.

${ }^{44}$ H. D. M. Darukhanawala, Parsi Lustre on Indian Soil (Bombay: G. Claridge, 1939), 37-38, as quoted in Luhrmann, 94-95.
} 
As we shall see, some of these worldly attributes have proved to be double-edged swords for the Parsi community, causing rifts amongst them to the point where some modern-day Parsis, in New Zealand for example, point toward religion as the principal cause for the current decline in population. Few, however, would argue with Pesi Muncherji, who has written: "few in our small community realize what a dominant and big part religion plays in the lives of the few of us as compared with the millions of others in this world". 45

As will become apparent in Part 3, the Zoroastrian religion, as practiced by Parsis, and its adaptation to meet the needs of diaspora communities, such as in New Zealand, could well survive and even thrive world-wide but this may well also create major problems in terms of acceptability to traditionalists, particularly amongst the Parsi community in India but also within the New Zealand community itself.

\section{Purity Issues, Intermarriage and Conversions}

Although Parsis reject any suggestion that they are fire worshippers, much has been written about the importance of fire in the Zoroastrian religion. ${ }^{46}$ For example:

The fire is a symbol of the Zoroastrian faith just as the cross is a symbol of Christianity. In a Zoroastrian temple, the only symbol before which prayers are said is the fire which is tended by a priest five times a day.... It is a symbol of purity, for fire purifies everything. It also stands for the "inner fire" or divine spark in a human being". 47

Whilst fire "at home is a constant reminder that we should always keep our "inner fire" alive", a consecrated fire in a temple, tended by a Zoroastrian priest is not as simple as the presence of a consecrated cross and has always created major logistical problems for the community. ${ }^{48}$ The emphasis on purity as a corollary to the importance of fire has two aspects to it, one physical and the other ethno-religious. The physical side is manifest in terms of individual behaviour - characteristics such as cleanliness in the home, clean clothes and good facilities for washing and bathing. This in turn has directly fuelled the

\footnotetext{
${ }^{45}$ Muncherji, 42.

${ }^{46}$ Ibid., 40; The Zoroastrian Association of Metropolitan Washington, Jashan, 29-31.

${ }^{47}$ The Zoroastrian Association of Metropolitan Washington, Jashan, 29-30.

${ }^{48}$ Ibid., 30.
} 
constant drive towards high standards of living and the adoption of Western style behaviour. It also, over the centuries, has supported the Parsi insistence on purity of race, in religious terms. The ethno-religious aspect, with its requirement to maintain purity of race, has become the single most important and contentious aspect of modern Zoroastrianism. The controversy rages between various groups, each one holding radically differing opinions. There are the orthodox or conservative Parsis, who insist that, to be a Parsi, both mother and father must have been born Parsi. ${ }^{49}$ There are the moderates, who accept patrilineage, i.e. that, provided it is the father who is a Parsi, the children of intermarriage can be Parsi but if it is only the mother who is Parsi, they cannot. $^{50}$ Thirdly are those who, still more liberal, believe that, provided just one parent is Parsi, the children can also be Parsis. ${ }^{51}$ These more liberal elements believe that relaxation of the purity rules is critical in order to stem the population decline. The conservatives, on the other hand, believe quite the reverse that any relaxation of the purity rules will lead to dilution and eventually to extinction. Linked to and very much a part of the purity debate is the Parsi tradition that to become a Parsi other than by birth as well as conversion to its religion, Zoroastrianism, is absolutely forbidden under any circumstances. ${ }^{52}$ Much has been written about the conversion debate with reasons against conversion ranging from the absolute necessity to preserve the racial and religious purity of descent, or a continuing fulfilment of the promise made by the first Parsi settlers not to proselytise, to the much more mundane reason of the threat of being overwhelmed by lower caste Hindus with consequential loss of assets through dilution of charitable funds. ${ }^{53}$

Interestingly, both Sharafi and Palsetia state that there is no such absolute rejection of conversion amongst Iranian Zoroastrians, from whence the Parsi community derives. Furthermore, as Farrukh Dhondy suggests in Bombay Duck: "There is evidence to show that the first [Parsi] settlers had no women with them and must have intermarried with the natives, the Hindus, so the first claim of the Parsis to be racially pure is

\footnotetext{
${ }^{49}$ Palsetia, 320-330.

${ }^{50}$ Ibid.

51 Ibid.

${ }^{52}$ Ibid.

${ }^{53}$ Sharafi, 165, 167. Palsetia, 87.
} 
suspect". ${ }^{54}$ Palsetia suggests that conversion from Hinduism to Zoroastrianism went on up until the seventeenth century but cautions that the historical evidence regarding such conversions is hard to assess. ${ }^{55}$ Certainly this whole subject has become a major point of communal divisiveness. Along with such scholars as Homji and Palsetia, there are several New Zealand Parsis who believe that ethno-religious intolerance is one of, if not the main, cause of the current Parsi population decline in India. ${ }^{56}$ This subject will be discussed in detail in Part 3.

There is one other critical aspect of religious purity which has traditionally been of major significance and this is the issue of defilement by the dead. According to Zoroastrian belief, the dead body is unclean and must be dealt with expeditiously and in accordance with Zoroastrian rites. Kulke explains the requirements very clearly, when he refers to the importance of Zoroastrian purification ceremonies:

The Zoroastrians ask time and time again to take great care in keeping the body and the natural elements earth, fire and water pure from defilement especially through dead matter. This explains the function of the Towers of Silence (Dakhmas), upon which the deceased Zoroastrians are thrown because otherwise earth, fire or water - according to the method of burial - would be defiled by them. ${ }^{57}$

Only the special class of corpse bearers might handle corpses (contact with a corpse by anyone else involves complex, often lengthy purification ceremonies). ${ }^{58}$ These corpse bearers, along with priests, were the only hereditary occupational classes amongst Parsis. Referred to as Nasâsalârs, they were similar to Hindu Harijans, working in the dokhmas and being kept apart from the rest of the Parsi community. ${ }^{59}$ In recent years the availability of the traditional method of disposal, or rather its absence, has become another major issue, particularly in diaspora countries such as New Zealand, where there are neither corpse bearers nor dokhmas, necessitating a complete rethinking of funerary and purity rites. Even in Mumbai, where dokhmas are still available, a lack of vultures has created a major corpse disposal problem for the Parsi community there, with the

\footnotetext{
${ }_{55}^{54}$ Farrukh Dhondy, Bombay Duck, (Calcutta: Rupa, 1991), 190-191; Palsetia, 86-87; Sharafi, 163.

${ }^{55}$ Palsetia, 86.

${ }^{56}$ Homji, 89-91; Palsetia, 275-276 \& 326-337.

${ }^{57}$ Kulke, 19.

58 Ibid., 20.

${ }^{59}$ Ibid., 49 note. 4.
} 
usual dichotomy between orthodox and reformists on the best way forward. ${ }^{60}$ Not only are funerary rites an essential part of the traditional Parsi purity rules they are also a defining point of difference between traditional Parsi practices in India and pragmatic alternatives, of necessity adopted by diaspora communities.

\section{The Importance of Charity}

Zoroastrianism is not alone amongst religions in its emphasis on charity and charitable offerings. But what makes Parsi charity unusual has been the construction of very large, powerful charitable trusts. Charitable gifting to these trusts and the use made of the trusts by individuals has in the past had a major influence on Parsi identity, both as individuals and collectively as a community. It still does to this day.

To be a good Parsi involves, inter alia, giving away a portion of one's wealth to benefit others, not just within the Parsi community but to anyone in need. ${ }^{61}$ "Charity is not viewed as a means to earn merits in heaven; rather, it is viewed as a divine quality which, when imbibed by a human being, causes that person to 'instinctively' lend a helping hand to anyone in need". ${ }^{62}$ This emphasis on charity had a great influence on the development of the Parsi communities in Gujarat and Bombay, particularly during the nineteen and twentieth centuries, providing the financial resources to establish their infrastructure, and on a wider plain, the infrastructure of Bombay. This included not only the agiaries, fire temples, and dokhmas, but hospitals, libraries, schools and technical colleges, water supplies and roadways, housing colonies, rest homes for the elderly, investment capital for the young, endowment policies for the disadvantaged and a myriad of charitable trusts. ${ }^{63}$

Charity was never confined to helping the Parsi community, "the nature of Parsi charity was fundamentally born of the Zoroastrian life-affirming philosophy to contribute

\footnotetext{
${ }^{60}$ Hinnells, 116-17. Sherally Munshi, "Death Wish," The Australian Financial Review no. Friday 14 August (2009): 1 \& 9-11.

${ }^{61}$ Nancy and Ram Singh, "The Incredible Community," Nancy and Ram Singh eds., The Sugar in the Milk: The Parsis in India (Delhi: I.S.P.C.K., 1986), 15-16; Kulke, 72; Hinnells, 65-66.

${ }^{62}$ Singh, 16.

${ }^{63}$ Palsetia, 39-45 and 62; Luhmann, 33; Kulke, 73.
} 
to the welfare of the world". ${ }^{64}$ Stories abound regarding donations to relieve suffering, not only throughout India but as far afield as Europe. ${ }^{65}$ Nor did it abate after Indian independence. Records show that the Tatas and Wadias donated over six million rupees to the Gandhi Memorial Fund and that the Tatas and Godrejs gave four million rupees and five hundred thousand rupees respectively to the Indian Defence Fund at the time of the Indo-Chinese war in $1962 .{ }^{66}$

During the nineteenth century, charity became strongly linked to power and politics, not only within the Parsi community but also as a means of gaining favour with the British rulers in India. ${ }^{67}$ Within the community itself, this linkage was to cause the community leadership to pass from the priests to the Shetias, as they were called - the leading merchant houses such as the Wadias, Readymoneys, Jeejeebhoys. Petits and Tatas. Most of the heads of these houses were also to acquire British knighthoods or even baronetcies in recognition of their charitable deeds. ${ }^{68}$

The Bombay Parsi Panchayat, after losing its political control over the community in the late nineteenth century, became the major charitable trust and the principal administrator of Parsi charity; it remains so up to the present time. ${ }^{69}$ As Palsetia says in his Epilogue: "Parsi charity to Parsi and non-Parsi objects continues to be a hallmark of Parsi identity in Bombay and India.... In Bombay, close to a thousand Parsi charities have been listed in the Directory of Public Trusts under the Public Trusts Act since $1950 "{ }^{70}$

But this emphasis on charity has proved to be a mixed blessing. ${ }^{71}$ On the one hand, it has helped both individuals and organisations to establish themselves, survive and grow. But on the other hand it has also created an environment within which dependency has grown alarmingly. "The level of Parsi dependence on charity continues to grow, and cautionary tales and criticism continue to be heard regarding its

\footnotetext{
${ }^{64}$ Palsetia, 44.

${ }^{65}$ Ibid., 43-44.

${ }^{66}$ Hinnells, 62.

${ }^{67}$ Ibid., 45; Wadia, 130; McLeod, 137.

${ }^{68}$ Palsetia, 63; Kulke, 74-75.

${ }^{69}$ Palsetia, 63; Boyce, 193; Kulke, 69; Hinnells, 70.

${ }^{70}$ Palsetia, 334.

${ }^{71}$ Luhrmann, 149-150; Palsetia 334-335.

${ }^{72}$ Kulke, 76-77; Luhrmann, 150-151.
} 
liberal availability, its misuse, and enervation of Parsi initiative" ${ }^{73}$ There is also an increasing number of adverse comments regarding the management and lack of coordination of Parsi trusts. ${ }^{74}$ Palsetia goes so far as to suggest that all these charities need streamlining and refocusing to meet the modern needs of an aging population, under threat from external economic forces. ${ }^{75}$

Parsi charitable trusts, for better or worse, remain an important aspect of Parsi culture in India up to the present time. As will be shown in Part 3, they also still have an ability, albeit indirectly, to influence aspects of Parsi life in countries such as New Zealand.

\section{The Priesthood}

One other important area where religion has had a major impact on the Parsi community has been the traditional role played by the Zoroastrian priesthood. The position of the priest through the centuries has been an ambivalent one. ${ }^{76}$ If one goes back to the earliest days, immediately after the arrival of the Parsis in India, the priests had a dominant leadership position within the community. Priests were imported from Persia to maintain religious integrity and to provide a link back to their home country. ${ }^{77}$ These priests were not only community leaders and mediators but also the conduit through which contact was maintained between Persia and India. ${ }^{78}$ Priestly families were looked up to as a separate aristocratic group with hereditary rights to the priesthood for up to five generations. ${ }^{79}$ But in later centuries, although priestly families were still set apart, the role of the priest ceased to be all-powerful. ${ }^{80}$ Firstly there was a major split between the priests at Sanjan and Nausari at the beginning of the eighteenth century over primacy of jurisdiction. Then in 1785 the Governor of Bombay, at the community's request, appointed a Commission to adjudicate over whether or not priest and laity could

\footnotetext{
${ }^{73}$ Palsetia, 334.

${ }^{74}$ Kulke, 76-77; Luhrmann, 151.

${ }^{75}$ Palsetia, 334-335.

${ }^{76}$ Kulke, 20.

${ }^{77}$ Boyce, 172.

${ }^{78}$ Ibid., 166-167; Kulke, 22-23 \& 59; White, 36.

${ }^{79}$ Boyce, 167; Kulke, 31 \& 49; Palsetia 21-23.

${ }^{80}$ Kulke, 61; White 37; Palsetia, 23.
} 
intermarry. The Commission confirmed that they could. ${ }^{81}$ Both these events weakened the position of the priesthood in the eyes of the laity. Furthermore, with the increasing education, wealth and power of the laity, priests were more and more regarded with disdain by the Parsi community at large, because they were often ill-educated and poorly paid. ${ }^{82}$

In the nineteenth century, as the Parsi communities began to flourish, mainly in Bombay but also in Gujarat, education became all-important, particularly amongst the wealthy merchants who could afford to pay for it. This was to result in the balance of power, previously held in the Anjumans and Panchayats by the priesthood, passing to the lay leaders, particularly the leading merchant families such as Jeejeebhoy, Tata, Modi and Wadia. ${ }^{83}$ Most of these were descended from priestly families but were not actual priests.

As priests slipped down the ladder both economically and socially, so their relevance decreased and their position became largely ceremonial, although some attempts were made to revive their position through opening special schools to provide them with a better education. ${ }^{84}$ Declining relevance, together with the resultant lack of central religious guidance, was to have a major impact on the community. Matters such as adherence to or modifications of the purity rules increasingly divided both laity and the priesthood. For example, some priests were, and still are, prepared to be more adaptable than others on such matters as intermarriage, conversion and disposal of the dead. ${ }^{85}$ A bitterly-worded letter written in Parsiana gives an interesting modern-day comment on the priesthood: "Our priests have had their day pulling a fast one on a reverent laity, making a virtue of the incomprehensibility of rituals, the monopoly to which was their trump card". 86

One development arising from the changing circumstances of the priesthood has been the increase in part-time priests. ${ }^{87}$ Unable to survive on the meagre rewards offered

\footnotetext{
${ }^{81}$ Kulke, 60.

${ }^{82}$ Ibid., 77-78.

${ }^{83}$ Ibid., 61, 64 \& 69-71; Paul Axelrod, "Myth and Identity in the Indian Zoroastrian Community," Mithraic Studies III (1980): 156.

${ }^{84}$ Kulke, 95 \& 265.

${ }^{85}$ Palsetia, 32, 44 \& 228-229; Hinnells, 510.

${ }^{86}$ Phiroze B. Javeri, "Priestly Progress", Parsiana, September 7, 2009, 4.

${ }^{87}$ Hinnells, $471 \& 519$.
} 
them from religious duties and supported by the well-established principle that members of priestly families could take up secular activities, it has become normal, at least in the diaspora countries, for a priest to have a separate full-time lay job. ${ }^{88}$ When talking with a Committee member of ZANZ, I asked him how it was possible to carry out religious ceremonies in New Zealand such as the navjote or initiation ceremony, without priests. I was surprised by his response that there were at least five Zoroastrian priests living in New Zealand, all holding down lay positions but also available for religious duties.

\section{Summary}

For Parsis, their Zoroastrian religion is both a religion and a racial marker of social identity. Not only has their religion provided them with their distinctive identity but it is also still the driving force which can both unite and divide them. Charity remains a significant Parsi religious characteristic, an essential part of being and being seen to be a good Parsi. Major issues concerning intermarriage and conversion, specific to Parsis rather than all Zoroastrians, have their origins in the Parsi purity rules and remain the principal cause for debilitating schisms. This lack of cohesion can, in part at least, be traced back to the lack of any central religious authority and the weakness of the priesthood, although Kulke maintains there is a positive side to this weakness, when he says: "Thanks to their limited authority, the priests could not become a retarding factor in the process of social change". ${ }^{89}$ Some would say the same logic applies to their religion, while others such as Homi Homji would strongly disagree: "Our anomaly is that economically we are a free enterprise, capitalistic, liberal society but socially we are a rigid, conservative, no-changing religious group". ${ }^{90}$ Part 3 will address this anomaly and seek answers to it from a New Zealand perspective.

\footnotetext{
${ }^{88}$ Kulke, 49.

${ }^{89}$ Kulke, 260-261.

${ }^{90}$ Homji, xi.
} 


\section{Chapter 6 Social and Economic Factors and the Parsi Community}

In Chapters 4 and 5, I described the importance of individuality and religion in the formation of Parsi identity. In this chapter, I will indicate how that identity manifested itself, socially and economically, within the Parsi community in India. It is these socio-economic factors and behavioural characteristics that have, in turn, moulded the Parsi community and set it apart from other communities. They may also do so in the future amongst the diaspora communities. A great admirer of Parsi attitudes and behaviour, Mahatma Gandhi, is quoted by Palsetia as saying:

It is one of the supreme wonders of God that, though the Parsee community does not number more than a hundred thousand in the whole world, it has made a name for itself everywhere by virtue of its many illustrious qualities. It can be said that it is this community, which holds power in India. Bombay is the real capital of India [and] it owes its prosperity mainly to the Parsees. ${ }^{91}$

Much has been written in previous chapters regarding outstanding individual members of the Indian Parsi community, but it is also appropriate to discuss the special attributes of the Parsi community as a whole, particularly those which took the community to the pinnacle of its power prior to Independence, those which have tended to have a negative impact on community cohesion and those which have resulted in significant numbers migrating post-Independence to countries such as New Zealand.

\section{Independence, Adaptability and Insecurity}

Amongst the attributes with which the Parsi community in India is often associated by scholars, three in particular stand out: their independence of spirit, which can and has lead to internal dissent, their ability to adapt to differing circumstances and their historical sense of insecurity. "We the Parsis are such individualists that where three of us meet, there are four irreconcilable views, none of which are [sic] based on logic, learning or rationality". ${ }^{92}$ This quote from the preface to Homi B. Minocher Homji's introspective study of the Parsi community post-Independence encapsulates the

\footnotetext{
${ }^{91}$ Palsetia, vii, as quoted from Indian Opinion, 20.2.1909, in The Collected Works of Mahatma Gandhi, vol. 10, September 1908-November 1909 (Ahmedabad, 1966), 193-194.

${ }^{92}$ Homji, ix.
} 
first of those attributes. Palsetia reflects on their ability to adapt in the summary of his Introduction, when he says: "A historical pattern of response emerges that favours adaptability to the social environment, while refashioning influences within the social environment in support of the preservation, strengthening, and at times composition of a sense of group identity". ${ }^{93}$ B.K. Boman-Behram makes a very similar comment in his paper, "Social Relationships between the Parsis and Other Communities," when he says: "This brings us to an interesting characteristic of the Parsi community. The community accepts changes whenever they are suitable or necessary under the compulsion of circumstances, but maintains continuity so far as fundamentals are concerned". ${ }^{4}$ Their sense of insecurity can largely be attributed to the community never fully integrating, and therefore never becoming fully connected, with India. These feelings of insecurity were to become elevated as Indian independence and the departure of the British Raj approached and led directly to what has been described as the community's second and even their third migration. ${ }^{95}$ In spite of their many centuries of living in India, they have always and still regard themselves essentially as migrant refugees from Persia.

\section{Higher education}

Amongst the continuity of fundamentals referred to above has been the Parsi attitude towards education. Right from the earliest days under the British Raj, the Parsi community recognised the importance of education in their drive towards communal success as agents for and then in partnerships with the British mercantile community in Bombay. Susan Maneck, discussing at some length the earliest organised Western-style education for the various non-British communities in Bombay in the early 1800s, stated inter alia: "The Parsis were the only merchant community within Bombay that availed itself of the opportunity to acquire English medium education to any significant extent". ${ }^{96}$ She mentions that, during the1830s, some elite Parsi families began sending their sons to

\footnotetext{
${ }^{93}$ Palsetia, 33.

${ }^{94}$ B. K. Boman-Behram, "Social Relationships Between the Parsis and Other Communities," Nancy and Ram Singh eds., The Sugar in the Milk: The Parsis in India (Delhi: I.S.P.C.K., 1986), 56.

${ }_{95}$ Kulke, 12; Hinnells, 703-704; Hinnells, Hinnells and Williams eds., 265.

${ }^{96}$ Maneck, 184.
} 
England for their education. ${ }^{97}$ Apprenticing sons out to English firms provided another means of exposing merchant families to British culture. ${ }^{98}$ Apparently the Parsis were the only community in Bombay to adopt this strategy. ${ }^{99}$ The Elphinstone Institute, now known as Elphinstone College, one of the oldest colleges at the University of Mumbai, was founded at this time and became a centre for Parsi patronage and the education of Parsi youth. ${ }^{100}$ "In 1840 this [Elphinstone College] was combined with a school to form the Elphinstone Institute, and Parsis supplied most of the pupils there throughout the nineteenth century; and thus there was formed a Western-educated Parsi middle-class, numbering doctors and lawyers, teachers, journalists and the like in its ranks". ${ }^{101}$ Luhrmann corroborates this emphasis on education and learning the English language, when she states:

Most dramatically, Parsis spoke English. In the mid-nineteenth century Parsis built more schools and attended school more regularly than other communities, proportional to their numbers.... By 188174 percent of the community was literate.... By 1901 more than a quarter of the community spoke English, as compared to less than one percent of the Jains and half a percent of the Hindus; 63 percent of Parsi women were literate and nearly all men. ${ }^{102}$

Along with these high literacy levels, Parsis dominated white collar positions under the British, wherever professions were being made accessible to the local population. ${ }^{103}$

Thus began and continues to the present day the disproportionately high percentage of professional people within the Parsi community - disproportionately high by comparison with all other social and ethnic groups in India and probably anywhere in the world. Education was and remains one of the main keys to their success. A survey published in 1982 by Professor (Mrs) Malimi Karkal of the International Institute for Population Sciences in Bombay indicated that, whereas, between the ages of 25-29, the general population contained $5.33 \%$ males in professional/technical positions and $3.93 \%$ in Admin./Exec./managerial positions, the equivalent figures for Parsis were $17.80 \%$ and $22.44 \%$ respectively; for females the same categories were $20.90 \%$ and $1.00 \%$ for the

\footnotetext{
97 Maneck, 183

98 Ibid.

99 Ibid.

${ }^{100}$ Ibid., 221.

${ }^{101}$ Boyce, 196.

${ }^{102}$ Luhrmann, 113.

${ }^{103}$ Kulke, 50.
} 
general population against $21.14 \%$ and $20.58 \%$ for Parsis. ${ }^{104}$ What is particularly interesting about these figures, besides the obvious disparity between Parsi males and males in the general population, is the high numbers for Parsi females when compared with their male counterparts.

\section{Equality of the Sexes}

Closely linked to the importance of education and one of the very significant differences between the Parsi community and other communities in India has been the very dissimilar approaches taken from at least the early nineteenth century to female emancipation. In this regard, the Parsi community has been remarkably liberal in its outlook, indeed more liberal than most other communities not just in India but also world-wide. One needs to look no further than the Karkal survey of 1982 referred above. ${ }^{105}$ In that survey, Parsi women between the ages of 25-29 exceed their male counterparts by significant margins in three out of the four top categories Professional/Technical, $21.14 \%$ against $17.80 \%$; Clerical, $21.61 \%$ against $18.20 \%$ and Sales, $28.81 \%$ against $19.01 \% .^{106}$ Only in the Admin./Exec./Managerial category are the roles reversed at $20.58 \%$ against $22.44 \%$ - still no mean achievement by the females and way ahead of what one would expect in most societies not just in the 1980s but up to the present time. ${ }^{107}$ In the same survey, Karkal found that, whilst Parsi postgraduate males below the age of 40 years outnumbered females $8.93 \%$ to $7.61 \%$, the numbers were reversed for graduates with females outnumbering males $35.08 \%$ to $32.27 \%$. $^{108}$

The other side to this female emancipation, has, as noted in the pamphlet Suntook n.d., been the threat to family stability and growth:

Paradoxically as it may sound, it may be stated again that, the very higher standard of education that we are seeking to have for our youngsters, seems to have gone by itself to mitigate against our numerical strength.

\footnotetext{
${ }^{104}$ Hinnells, 51 .

105 Ibid.

${ }^{106}$ Ibid.

${ }^{107}$ Ibid.

${ }^{108}$ Ibid., 50.
} 
This happens to be particularly so with respect to our girls who having once obtained higher education are often found to outstrip our boys in many fields by securing posts oft times more lucrative than the boys... ${ }^{109}$

Luhrmann goes on to suggest that Parsi women are generally perceived by Parsi men as both very powerful and often the strong partners in the household. ${ }^{110}$ Whilst this may well be true within the household, it has not translated into the public arena. There have been few examples, other than the famous twentieth century political activist Madam Cama, otherwise known as Bhikaiji Rustom Cama, of women taking part in any dominant public roles. ${ }^{111}$ Madam Cama, who came from a well-to-do Parsi family, sympathised with radical nationalists and was a passionate advocate for Indian independence. ${ }^{112}$ She is best remembered for unfurling the future Indian tricolour flag at the International Socialist Conference in Stuttgart in $1907 .{ }^{113}$ What is certainly true is that, from the middle of the nineteenth century, Parsi women were encouraged by their community to obtain an education, to learn to speak English and to lead un-secluded lives. ${ }^{114}$ This was to pave the way for the current situation in which many young Parsi women delay marriage because of their careers, in the same way as their peers in Western societies. ${ }^{115}$ Personal independence and the ability to support themselves is synonymous with late marriage and small families. ${ }^{116}$

There is, of course, one significant omission to this traditional stance on equality for women and that is the question of inequality in the debate on intermarriage: whether or not the Parsi mother who marries out of her community may still be regarded as a member of the Parsi community and whether or not her children may be regarded as Parsis. John Hinnells tries to justify this inconsistency, when he discusses gender issues:

Another distinctive feature of the Zoroastrian diaspora is the role of women. Zoroastrians have commonly emphasised, with good cause, that men and women are equal in Zoroastrian belief and practice: ... The implications of the purity laws complicate the picture for women, but the traditional view is that because

\footnotetext{
${ }^{109}$ Suntook n.d., published pamphlet as quoted in Luhrmann without further publication information, 134.

${ }^{110}$ Luhrmann, 174.

${ }^{111}$ Kulke, 210-211.

${ }^{112}$ Palsetia, 305-306, n. 98.

${ }^{113}$ Ibid,.

${ }^{114}$ Ibid., 104-105; Luhrmann, 112-113; McLeod, 138

${ }^{115}$ Hinnells, 51-52.

${ }^{116}$ Luhrmann, 170-171.
} 
women have the key role in the birth of another member of Ahura Mazda's army their role is especially significant, and the purity laws are a consequence of this special status. $^{117}$

Whilst this may well be true of the past, if Ahura Mazda's army is not to shrink still further in the future, the recruitment rules may well need changing. This will form a very important part of later discussions on the future of the Parsi community from a New Zealand perspective (Part 3).

\section{Wealth Accrual and Standards of Living}

Another fundamental continuity and an important feature of Parsi identity is the respect accorded by the community to the accrual of wealthy. Wealth accrual for the very wealthy has traditionally been a family dynastic affair, with one generation building on the achievements of the previous generation. At the same time, the importance of a good standard of living through personal wealth accrual was, and still is, an important, general Parsi characteristic.

Parsi pre-eminence had, since the arrival of the British in Gujarat in the seventeenth century, been tied to the fortunes of the British mercantile enterprises in Western India, declining substantially with the departure of the British at the time of Independence but still surviving and remaining a force in India to this day. The giving of charity had traditionally been used to gain both power and additional wealth. The reward for significant charitable donations was an increase in political or economic influence, leading to enhanced opportunities for further personal or corporate aggrandisement.

As stated earlier in Chapter 2, prior to the British drive for trading dominance in Western India in the late seventeenth and early eighteenth centuries, the Parsi community, principally located in Gujarat, consisted of small time merchants, farmers, weavers and toddy makers. ${ }^{118}$ The Rustum Manock dynasty, which lasted for three generations before it imploded in the middle of the eighteenth century, provided the model for individual and dynastic success, through having a close relationship with the

\footnotetext{
${ }^{117}$ Hinnells, 720 .

${ }^{118}$ White, xiii.
} 
British. ${ }^{119}$ More recent examples of Parsi dynastic successes under the British umbrella have been the Wadia ship-building empire, founded in Bombay by Lowji Wadia in the 1730 s, and the Jeejeebhoy dynasty founded by Jamsetjee Jeejeebhoy in $1818 .{ }^{120}$ Jamsetjee Jeejeebhoy started with nothing, rising to become the major exporter of such items as cotton and opium. He was probably the wealthiest Indian merchant of his time and the first Indian recipient of a knighthood (1842) and then a baronetcy (1857), for his contributions to charity and local Bombay politics; his company Jeejeebhoy and Co was set up in 1818. ${ }^{121}$ The Jeejeebhoy dynasty's power, wealth and influence were to continue well into the twentieth century, mainly as a result of its numerous charitable trusts; the baronetcy continues to this day. ${ }^{122}$ The Jeejeebhoy dynasty is remembered principally for its leadership role within the Parsi community, its political interaction with mainstream Indian politics, both before and post-Independence, and in particular for its charitable activities. ${ }^{123}$

Two of the most recent Parsi dynastic successes are the current industrial giants the Tata Group and the Godrej Group. Tata Group is best known for its steel and automotive divisions, but has expanded into many other interests such as aerospace and information technology. ${ }^{124}$ Godrej is renowned for its safety equipment and office furniture, in particular safes, locks and filing cabinets; it has also diversified widely. ${ }^{125}$ Both were formed in the nineteenth century, Tata in 1868 by Jamsetji Nusserwanji Tata and Godrej in 1897 by Pirojsha and Ardeshir Godrej. ${ }^{126}$ Both have survived and then thrived since Independence, both are still run by members of the founding families. Ratan Tata is Chairman of the Tata Group and Adi Godrej is Chairman of the Godrej Group. ${ }^{127}$ Both are now not only industrial giants within India but also major global

\footnotetext{
${ }^{119}$ White, xii-xiv.

${ }^{120}$ Palsetia, Hinnells and Williams eds., 84.

${ }^{121}$ Ibid., 81-99.

${ }^{122}$ Hinnells, Hinnells and Williams eds., 255.

${ }^{123}$ Kulke, 69-77.

${ }^{124}$ Tata Group, Products, accessed June 08, 2011, http://www.tata.com/products/index.aspx?sectid=U2YC1EMmQuk= .

${ }^{125}$ Godrej Group, Products, accessed June 08, 2011, http://www.godrej.com/godrej/godrej/ourproducts.aspx?id=1\&menuid=1167 .

${ }^{126}$ Tata Group, Profile, accessed January 28, 2010, http://www.tata.com/; Godrej Group, Profile, accessed January 28, 2010, http://new.godrej.com/godrej/Godrej/index.aspx?id=1.

127 Ibid.
} 
enterprises. ${ }^{128}$ Both stress the importance of their philanthropic activities on their home websites. $^{129}$

Although the Parsi charitable trusts have declined in leverage with the decline in fortunes of the Parsi community in Mumbai since Independence, they are still very much alive with the total numbers of trusts continuing to increase. ${ }^{130}$ Charitable thoughts and deeds are still inherent in what it means to be a worthy Parsi.

Wealth accrual, however, has not been confined to the large Parsi corporations. As a community, the Parsis have traditionally enjoyed a higher standard of living than other communities in Bombay. Although the gap has narrowed in recent decades, they still enjoy an advantage. ${ }^{131}$ Kulke cites an increasing number of Parsis in public administration, occupational restructuring and partial socio-economic deterioration accompanied by increasing unemployment as major contributing factors for the gap starting to narrow during the first half of the twentieth century. ${ }^{132}$ This trend was to continue and escalate after Independence but not close entirely. According to Luhrmann, quoting from Marlini Karkal's 1982 survey, all the statistics show the Parsi community in Bombay still well ahead of the average for the "Greater Bombay population" in terms of possessions, housing, education, professions and monthly incomes. ${ }^{133}$ Wealth accrual at every level, both corporate and personal, is an important element of Parsi identity, something to be both striven for and extolled.

\section{External Relationships and Politics}

Of equal importance to the emphasis on wealth accrual in the development of Parsi identity has been their attitude towards external relationships and politics. It is necessary to go right back to the genesis of the Parsi community in Sanjan in the eighth century CE and the agreement between the new arrivals from Persia and their Silhara

\footnotetext{
${ }^{128}$ Tata Group, Profile, accessed January 28, 2010, http://www.tata.com/; Godrej Group, Profile, accessed January 28, 2010, http://new.godrej.com/godrej/Godrej/index.aspx?id=1; Kulke, 127.

${ }_{129}$ Tata Group, Profile, accessed January 28, 2010 http://www.tata.com/; Godrej Group, Profile, accessed January 28, 2010, http://new.godrej.com/godrej/Godrej/index.aspx?id=1.

${ }^{130}$ Hinnells, 62, 66, 70, 86-87.

${ }^{131}$ Kulke, 57-58.

132 Ibid., 58.

${ }^{133}$ Luhrmann, 39.
} 
benefactor, Jadi Rana, for the key to their enduring attitude to external relationships and politics. ${ }^{134}$. One of the five conditions imposed on the new community was that "the men should lay down their arms" and, according to Kulke et al., this has resulted in an ethic of "loyalty of the Parsis still to be observed today towards the current ruler or elected government". ${ }^{135}$ Whilst any direct relationship between the original story regarding their arrival in Sanjan and Parsi civic loyalty is at best tenuous, there is no denying their traditional respect for authority. Down the ages they have kept a low profile towards their numerically stronger hosts and, as a community have mostly worked in harmony with whoever has been in charge politically, initially with the East India Company, then with the British authorities and most recently, since Independence, with the Central Indian Government in New Delhi and the State Government of Maharashtra, where the majority of the Parsi community is located, in Mumbai. ${ }^{136}$ Naturally there have been some exceptions, such as those who actively supported the Indian independence movement against the British, as referred to below.

Grafted onto the traditional will to maintain harmonious relations with whoever is in charge have been the somewhat contradictory but inherently Parsi traits of strong individuality and internal disagreements. These traits became more dominant as the twentieth century progressed from Swaraj, the Gandhi inspired freedom movement, to anticipation of Independence and from pre-Independence to post-Independence. In the early days of the Indian National Congress (INC) led independence movement, several Parsi leaders played important roles within the INC. Examples include such respected names as Dadabhai Naoroji, known as the Grand Old Man of India, Sir Pherozeshah M. Mehta, Sir Dinshaw Edulji Wacha and Firoze Gandhi. ${ }^{137}$ At the same time, other important Parsi leaders, who were eager for the British to remain as overlords and feared the future under a possibly more unfavourable Hindu led Government, strove to support the British. This movement was led by K.N. Kabraji and his Parsi newspaper, Rast

\footnotetext{
${ }^{134}$ Boyce, 199; Kulke, 26.

${ }^{135}$ Kulke, 28.

${ }^{136}$ Kulke, 78 \& 147-158; Hinnells 54-61.

${ }^{137}$ Hinnells, 55; Kulke, 173-182; Luhrmann 92.
} 
Goftar, and supported in its opposition to Congress by such as Sir Jamsetjee Jeejeebhoy and Dossabhoy Framjee Karaka, both eminent Parsi leaders. ${ }^{138}$

As the date for severance from the British Raj approached (15 August 1947), so the dispute between those who supported the independence movement and those who opposed it became more polarised. Those who opposed feared not only a loss of status under the new regime, but some even feared retribution for having been so dominant and successful under the British. ${ }^{139}$ In the final analysis, the Parsi community in Bombay was not seriously threatened during the bloody sectarian riots and killings immediately postIndependence nor during the more recent communal riots of the 1990s. ${ }^{140}$ Indeed, the Parsi community has been able to provide a haven of peace within the carnage. ${ }^{141}$ But, those who feared loss of status and positions of influence post-Independence were to have their fears realised as the other communities gained maturity and traditional Parsi pre-eminence in local government and mercantile leadership diminished. ${ }^{142}$

This period of time was, therefore, a watershed for the Parsi community in Bombay, dividing the community irrevocably into three parts. There were those such as Firoze Gandhi, Sir Homi Mody and Nani Palkhivala, also industrial giants such as the Tatas, Wadias and Godrejs, who perceived themselves as part of the wider Indian community and in many cases became important leaders within the new Indian Republic. ${ }^{143}$ There were those who perceived themselves as more aligned to everything British, with no future in an independent India. Many of these migrated. ${ }^{144}$ Thirdly, and for this thesis most importantly, there were those who initially decided to stay in India, but for a variety of reasons, as time moved on, became disenchanted with their position within a social and economic downward spiral in Bombay. They have shown the individual courage and determination, so much admired in their forebears, to break away from their local communities and to try their luck overseas in developing societies such as New Zealand. ${ }^{145}$ It is this group of people who form the main focal point for Part 3.

\footnotetext{
${ }^{138}$ Kulke, 182-183 \& 189.

${ }^{139}$ Ibid., 263-268; Hinnells, 136

${ }^{140}$ Kulke, 263-268.

${ }^{141}$ Ibid., 247.

${ }^{142}$ Hinnells, 136.

143 Ibid., 55-61.

${ }^{144}$ Luhrmann, 53-62; Hinnells, 136.

${ }^{145}$ Hinnells, 600.
} 


\section{Internal Controls and the Parsi Laws}

In juxtaposition with the differing individual approaches taken to external affairs has been the comparative weakness of any centralised internal controls. As noted previously, initially through the weakness of the priesthood, followed by the collapse of any secular attempt to replace the religious authority with a system of local governance the Panchayats - the main authority within the Parsi community in India has, in more recent times, rested loosely with the Parsi Central Association formed in 1919 by eminent mercantile leaders, or Shetias, such as Sir Jamsetjee Jeejeebhoy, Sir D. E. Wacha and Sir Cowasjee Jehangir. In 1940, it was renamed the Parsi Central Association and Political League. ${ }^{146}$ This group was mainly drawn from priestly families who had also succeeded in acquiring wealth and therefore prestige and power, not only within their own community but also in the wider spheres of municipal or even national affairs. ${ }^{147}$ During the nineteenth and twentieth centuries, a lack of any recognised, central Parsi jurisdiction resulted in matters of internal importance such as religious disputes and inheritance being settled not by their own Parsi authorities but in the British run law courts. ${ }^{148}$ Good examples of this include the 1908 Parsi Panchayat Case in which a British High Court judge, admittedly sitting with a Parsi judge, made a religious ruling regarding conversion and the acceptance of children of mixed marriages (Chapter 2), which to this day is still hotly supported or disputed according to individual choice. Similarly and of equal importance is the Rangoon Navjote case. ${ }^{149}$ This case concerned Bella, the child of a Parsi woman who had been married to a Christian. At issue was whether or not Bella could be accepted as a Parsi. ${ }^{150}$ The case was heard in 1915 in the Court of Lower Burma, which found in favour of the girl. Subsequently the case was appealed to the Judicial Committee of the Privy Council in 1925, which reversed the decision. ${ }^{151}$ This case also remains a point of major dispute and division within the Parsi community. ${ }^{152} \mathrm{~A}$ third example was the court case to decide which should take precedence - the traditional

\footnotetext{
${ }^{146}$ Kulke, 153-156 \& 213-216.

${ }^{147}$ Ibid., 49 \& 78.

${ }^{148}$ Kulke, 60.

${ }^{149}$ Palsetia, 266-275.

${ }^{150}$ Ibid.

${ }^{151}$ Ibid.

${ }^{152}$ Ibid., 266 \& 273-4.
} 
Parsi practice of equal inheritance amongst the offspring or the British laws of primogeniture. ${ }^{153}$ This in fact led to a major move within the Parsi community to draw up their own laws, including laws of inheritance, in the Parsi Laws of $1865 .{ }^{154}$ Prior to this, as stated by Palsetia: "A dual system of substantive law prevailed over the Parsi community of Western India: with the Parsis of Bombay subject to English law, and the Parsis of the provincial areas subject to the laws of usages and customs applicable to the Parsi community". ${ }^{155}$

Lack of internal controls, leading often to disputed legal argument and court rulings on strictly internal Parsi matters, sit strangely within a community which had proudly proclaimed over the centuries that, provided it was allowed control of all its internal, spiritual and corporeal matters, it would be 'a good citizen' regardless of the regime under which it lived. It is hardly surprising that an absence of clear leadership and a legacy of internal dissent had ill-equipped the Parsi community in India to cope with the severe threats, both internal and external, which followed Independence and the emergence of a rearrangement of power structures, often disadvantageous to the local Parsi community. In turn this was to provide impetus for disadvantaged and or ambitious elements within the Indian Parsi community to turn to greener pastures such as New Zealand to secure and enhance their futures.

\section{Summary}

Parsi commitment to higher education, gender equality, wealth accretion through the creation of dynastic excellence, commitment to communal activities, both internal and external, have all contributed to the justifiably high regard in which individuals have been held both within their own community and amongst the wider community at state and national levels. By their actions, they have faithfully fulfilled their legendary pledge on arrival in Sanjan all those centuries earlier to be both the sugar and the gold ring in the

\footnotetext{
${ }^{153}$ Palsetia, 199-202; Manek, 222-224.

${ }^{154}$ Palsetia, 197; Manek, 222-224.

${ }^{155}$ Palsetia, 200.
} 
milk of the local population. ${ }^{156}$ In the process of striving to achieve these levels of excellence, they have developed some quite specific and definitive characteristics. These have included their determination to succeed as individuals and their inclination to take up an entrenched and uncompromising viewpoint from which they were not easily dislodged. At the same time, they have exhibited an amazing ability to adapt to changing circumstances. They believed that their unique religion and way of life was superior to those of other communities in India, whilst portraying an historic sense of insecurity, because of those very differences. These special but contradictory characteristics led them to the pinnacle of success in India, but also led them to disillusionment as their environment became more difficult in post-independence India following the departure of their British patrons. Disillusionment combined with fewer opportunities for individual success was to escalate migration to countries such as New Zealand in search of greener pastures.

\footnotetext{
${ }^{156}$ Novy Kapadia, "The Parsis: An Introduction”, Novy Kapadia, Jaydidsinh Dodiya, R. K. Dhawan eds., Parsi Fiction vol.1, (New Delhi: Prestige Books, 2001), 14-15; Mehta, 31; Nanji and Dhalla, 35 \& 55 note 1.
} 


\section{Part 3 Individuality and the Future for Parsis in New Zealand and World-wide; a New Zealand perspective}

In Parts 1 and 2, I introduced my hypotheses, gave brief histories of Parsis in India and in New Zealand and examined the significance of individuality within the Parsi community, along with the importance of their religion and other socio-economic factors, which, over time, have moulded Parsi identity. This background provides a framework of knowledge within which to present the current situation in New Zealand and to compare it with the position of the Parsis in India

In my Introduction (Chapter 1), I stated my hypothesis to be that the drive for individual achievement and success has negatively affected the cohesion and therefore the internal stability of the Parsi community, both historically and at the present time. I also stated that the search for individual success had led to accelerated migration, but that this migratory drive might lead to a global renascence of the Parsi community and to its longer term health and survival in India.

As far as I know, up to the present there has been no academic work published regarding the Parsi community in New Zealand, although John Hinnells has covered most other diaspora countries in his book The Zoroastrian Diaspora: Religion and Migration, published in 2005. As stated in my Introduction, he had not, up to that time, had an opportunity to include New Zealand in his studies. My intention in Part 3 is to fill this gap, utilising extracts from the very extensive bank of oral data collected from indepth interviews with a cross-section of the Parsi community domiciled both in Auckland and Wellington. I conducted interviews over a three-month period between May and July 2010. Whilst questions asked were wide-ranging (see Appendix A), only responses directly related to my two main hypotheses are included here. To this end, I shall concentrate on responding, strictly from a New Zealand perspective, to the two main themes in my argument: the impact of individuality on community cohesion and the prospects for the future health and survival of the Parsi community worldwide as a result of accelerated migration. As will become clear, the evidence collected substantially corroborates the first of my two hypotheses whilst raising serious doubts about the validity of the second one. 


\section{Chapter 7 Individuality}

In this chapter, I seek to show how Parsi proclivity for strong independence of thought and action, so apparent historically, is still the main driving force behind how modern Parsis, now domiciled in New Zealand, order their lives.

\section{Individuality and Migration}

Individual or nuclear family choice was the keyword in the responses to questions regarding reasons for migrating to New Zealand. Individuals, sometimes but not always accompanied by their immediate family, had often left established and secure positions elsewhere and come to New Zealand with no immediate commensurate positions in view, but on the basis of perceived future prospects. These included wider opportunities for themselves and their families, a better physical environment to live in or for financial advancement.

When I came to New Zealand I couldn't get a job. My husband couldn't either. He worked for MacDonald's - in the kitchen for 9 months. Then [he] got a job as a production operator for a year or so then slowly started getting into his field. I also worked at MacDonald's for 5 months. ${ }^{1}$

These are the words of a young wife, who already had a BA and a good administrative job in Mumbai before migrating to New Zealand nine years ago. Her husband, who also had a steady job in Mumbai, preceded her by six months. She now has a fulltime professional position in New Zealand. Her husband is working in his original area of expertise whilst studying to become fully qualified. This is an excellent example of a small nuclear family carefully planning and then executing that plan to move to a new country, not because of deprivation in their country of origin but in anticipation of a better lifestyle. They had no jobs to come to and had to take whatever unskilled work was available.

I came in July 2000, my wife [and daughter] came in February 2001. I came on my own because I wanted to see how New Zealand would be first. I didn't have a job lined up when I arrived. I was unemployed for the first two months. Then I got a job as an assistant accountant at a restaurant. I worked there for a year or so.

\footnotetext{
${ }^{1}$ Transcribed responses from interviewees are quoted in italics.
} 
This interviewee had gained a Masters in Commerce and a Diploma in Financial Management from Mumbai University before moving to New Zealand. He later obtained more appropriate employment within his chosen profession and enhanced his qualifications through further studies. He and his wife are currently both employed in senior fulltime professional positions. It is almost a carbon copy of the previous example and demonstrates that moving from a secure position in the country of origin to one without immediate prospects is not an isolated incident within the New Zealand Parsi community. In this interview, the interviewees went on to say:

We wanted a better life and to be away from relatives. Also, in India we were staying in my wife's company's accommodation; we didn't have our own house. We saw an advertisement for migration to Australia and New Zealand. It looked enticing. [We] decided to try.

Of particular interest here is the reference to accommodation. For young families in Mumbai, it would be almost impossible, except amongst the wealthy, to own your own house. Of even more interest is the reference to relatives. There is no hint here of wanting to live in close proximity to the extended family but, quite the reverse, a desire to be independent.

My wife and I chose New Zealand because of its cleanliness, hygiene, noninterference, live and let-live policy. One of the reasons we left India was because we have daughters and we wanted them to be able to do whatever they want. We said to them we need to live in a country where individuals are respected for what they are - not for their gender.

Whilst there were no instances of interviewees saying that their migration was prompted by feelings of being persecuted prior to moving, many of those coming from the subcontinent included such reasons as commercial or educational discrimination, overcrowding, an antipathy to corruption, a wish for a less polluted environment, or a desire for separation from traditional family ties as either the main or contributory reasons for migration

Quite a few families had cousins or friends who had also migrated to New Zealand but, interestingly, several people commented that other close family members, who were already well-established in India, would not wish to migrate. 
"[I] do not think [my] family will come to NZ - [they] are established where they are"; "Two kinds of people still there [in India] - well-settled, good standard of living and older people, don't want to move"; "My wife has a lot of family in India. They are happy there".

This raises a very interesting point in regard to the general attitude of Parsis towards family allegiance. Whilst family is important to them and they keep in touch with each other, this does not deter them from making decisions independently. Those who have chosen to migrate in search of better opportunities for themselves and their children have made their choice as individuals or as a nuclear family group, whilst other members of the same family have, for their own reasons, made an individual choice not to migrate. There seems little case history of one member of a Parsi family migrating and then the rest of that family following on behind. Quite a number of people interviewed had close relations, not only still living in India but spread out around the world in places like the USA, Australia and Canada.

There is no doubt that the decision whether to migrate or not was based on the individual's perception of what was best for themselves and their families. In no circumstances had families migrated here as an integral part of a wider communal movement, nor do Parsi migrants make any effort to congregate and live in close ethnically oriented groups, preferring to live in and integrate with a culturally diverse community.

Although close touch is maintained with family and friends, both in India and elsewhere, with quite frequent trips being made to coincide with important occasions such as the marriage or navjote of a relative, only a very few interviewees, when asked about their future intentions, expressed any interest in ever returning to India permanently. By far the majority stated that they were in New Zealand to stay. Several interviewees, in particular amongst the younger ones, went so far as to say that they now considered themselves Kiwis. Again, this was overwhelming evidence of individual lifestyle being preferred to the prospect of returning to their original heritage and the communal infrastructure that such a move could afford them. 


\section{Individuality and Religion}

The initial response to the question 'Do you follow the Zoroastrian Religion?' would appear to have been so obvious as not to warrant having been asked in the first place and must have appeared extremely naïve to all the interviewees. Being a follower of Zoroastrianism is so naturally an essential part of what it is to be a Parsi that the question begs no answer other than: yes of course. But the second part of the question, 'and if so how?' by no means provided such a simple, single, answer. Indeed the answers gave as clear an example as one could wish of the significance of individuality within Parsi identity and proof that their individuality is alive and well amongst the New Zealand community.

Their Zoroastrian belief is at the very heart of what it is to be a Parsi. They are totally united in the concept of 'good thoughts, good words, good deeds' which lies at the very centre of that belief. During my interviews that expression was used time and time again to explain the essence of being a good Parsi. But, as one interviewee, who has lived in New Zealand for over twenty years, said:

This is a simple but very strong concept but could also be a problem for the religion. Moses gave specific commandments that people could identify with. But our religion is very complex - the concept of 'good thoughts, good words, good deeds' is in every action you do. Being a true Zoroastrian is very difficult.

And herein lies the dilemma. What seems to be a very simple, uncomplicated formula, because of its very openness is subject to individual interpretation. With no absolute commandments to be obeyed, the individual is left relatively free to make his or her own mind up on important doctrinal matters provided that they fall within the personal interpretation of 'good thoughts, good words, good deeds'.

Individuality of religious expression, within the unanimity of belief in ' $g o o d$ thoughts, good words, good deeds', came in many different forms. One interviewee, whose views did not accord with those of her husband or mother-in-law, felt no need of ritual or what she referred to as the trappings of her religion, such as a fire temple, because she believed that the principles of her religious faith came from within and were ingrained in her. On the other hand, quite a number of homes were fitted out with small 
private prayer rooms, complete with a permanently burning lamp to represent fire, together with a selection of Zoroastrian icons. Most of these facilities were very visible to the casual visitor, but access to them varied from being restricted to members of the Zoroastrian faith only, to a juddin, or non-Zoroastrian such as myself being invited to enter. Interestingly, in one such prayer room the images were not confined to Zoroastrian icons but included Christian and Buddhist ones as well. In a similar vein, one interviewee expressed a very personal belief in Zoroastrianism and Christianity having an historical link. I believe both these interviewees were demonstrating their individual interest in an expanded religious experience.

The continuous wearing of sudra/kusti (the sacred Zoroastrian undershirt and cord) was the general practice amongst most interviewees and their children although there were a few examples of it only being worn on religious or special occasions or when visiting India. Similarly, the daily recitation of prayers was universal, but the extent of praying varied enormously from more than an hour a day to a quick prayer "just before leaving the house". A comment from a teenager was very enlightening, when he said that he found praying very calming e.g. before an exam. Another example of individual choice being expressed was the instance of a husband stating that he is a devout Zoroastrian and his wife following that statement by saying she does not know as much about their religion as he does and does not pray as much. All these comments reinforce the view that individual choice takes preference over doctrinal requirements.

An insightful comment in regard to the relationship between their religion and their personal belief came from discussions with a liberally oriented family in which the wife stated that she became upset when "religion becomes the divider of people. It is something you hold individually and do not use [it] to judge other people by". At the same time, no one interviewed expressed anything other than a deeply felt religious conviction.

"Parsis don't feel the need to brandish their religion as a sign of who they are"; "What you do in your private life is fine as long as you don't impose it on others. I was brought up [in India] to respect other people and to be able to integrate into another society"; "our culture is rich, worthy of being told and passed on". 
Several people referred to the private nature of their religious beliefs. At the same time, there was a clear thread running through the responses of feeling special and being proud of whom they are. Several interviewees indicated that, whilst they did not advertise their beliefs and customs, they were more than happy to explain them to people that showed an interest. This openness to spend time explaining to others their ethnicity and religious beliefs is a clear indication not only of their ethnic pride but also of their passionate adherence to their religion. Most Parsi homes display some symbol of Zoroastrianism such as the Fravashi (or Faravahar). Many also wear a similar symbol as a necklace.

Individual opinions varied sharply in regard to the desirability of having a consecrated fire temple in New Zealand for purposes of worship.

"If there is a fire temple, it should be authentic. Everything is now possible, I would like it if there was a proper one"; "It would be wonderful. If we don't do things like that, we will be letting down the next generation. I would like it to be a real [i.e. consecrated] fire temple. I can see no reason why not; if I had the money I'd do it"; "It will never happen, the fire can never cross the water".

The problem with transporting these consecrated fire temples overseas outside Iran and India arises from the very strict protocols associated with transporting the fire itself, which must originate from an existing consecrated fire. According to one interviewee, if the consecrated fire was to be air-freighted, not only would all the handlers have to be Parsis, but so would the pilots and air crews. But these difficulties did not deter other interviewees from expressing optimism that such an event might occur in the future. An article in Parsiana discusses the possibility of transporting redundant fire temples, such as one at Bhuj in Gujarat, to North America. ${ }^{2}$

During discussions regarding what facilities should be provided by any future Parsi community centre, it again became apparent that opinions were sharply divided. The conservative position was quite clearly expressed by an interviewee who stated that places of worship should be separate from community centres as places of worship are not a place for social events. This view is in stark contrast to the aims of the Zoroastrian Community Trust of New Zealand, an offshoot of ZANZ and therefore supported by the more liberal elements of the Parsi community in Auckland, the aims of which are centred on raising funds "to have a permanent venue for their functions and get-togethers and

\footnotetext{
2 “A fire in North America," Parsiana, May 21, 2009, 18.
} 
provide a place for communal worship". 3 Yet a third opinion on this question was the interviewee who simply said that she did not think they should have a consecrated fire temple, because access to it would be denied to the families of Parsis who had married out of the community and she has strong feelings against such exclusionist rules. She believed that such rules did not apply in other diaspora communities such as Canada and London where anyone can go into fire temples; you don't have to be Zoroastrian. This opinion reflected my own experience that I was welcome to enter some private prayer rooms but not others.

The question regarding religious guidance in New Zealand afforded an insight into how the religion is very reliant on individual teaching rather than on prescribed doctrine with almost universal reliance on the family, a parent or grandparent for guidance on and maintenance of religious traditions - the learning of prayers and their meaning, the ceremonies pertaining to certain religious festivities and which traditional dishes are to be served on those occasions. Interviews with younger members of the community were particularly revealing in this regard.

"I look to both my parents"; "My grandma"; "Just my parents"; "If it was a topic related to custom, I would speak to my mother".

Of particular note here are the references to the mother or grandmother as the main source of information. In two families, both of mixed religions, the non-Parsi mothers had a strong involvement in bringing up their children as Parsis, although they themselves are denied the opportunity of becoming Zoroastrian or Parsi through the ethnic purity rules which forbid conversion to Zoroastrianism and acceptance as a Parsi (see Individuality and Ethnic Purity below).

Amongst more mature interviewees, the most general response was that they relied on themselves. In some instances, reliance was on an older family member and a couple of wives said they relied on their husbands, who were more knowledgeable. The reverse did not seem to arise, which was perhaps strange, given that, in discussions, as mentioned above, it was mainly the females of the family who gave instruction to the children.

${ }^{3}$ Zoroastrian Community Trust, Trust Deed, accessed September 24, 2010, www.zct.co.nz/deed. 
"If it was a heavier topic like the meaning of something she [my mother] would not know, I would probably hit the internet first, or look up some books"; "I might go to a Parsi priest but I would ask someone in India first before someone in New Zealand".

Several interviewees added that, if they were seeking the answers to more weighty religious questions, they would probably refer to books or the internet first. Just a few respondents mentioned the possibility of seeking guidance from a priest, but this did not seem to be very significant. The conclusion to be drawn from this is that the role of the Parsi priest in New Zealand is principally ceremonial rather than pastoral. This supports the comments on the priesthood contained in Chapter 5 regarding the role of the Zoroastrian priest being comparatively minor and largely ceremonial. A pastoral activity being conducted by one priestly family was the regular holding of prayer meetings in Auckland for both children and adults. Strangely enough, a similar role is carried out regularly for another group in Auckland by a member of the Parsi community who is not a priest. As in India and elsewhere, there are Parsi priests in New Zealand who come from both conservative and liberal persuasions. I believe this lack of direct pastoral involvement and its consequent weakening of the clerical authority has contributed significantly to the religious individuality of both laity and priests. But, of all the comments regarding the relationship between individuality and religion, the most telling were the references to inner-self.

"It comes from inside"; "At the end of the day, it is all about 'good thoughts, good words and good deeds'. The real guidance comes from within, and it is called conscience".

This feeling of inner religious strength pervaded all the interviews demonstrating the overriding importance of religion in the everyday lives of Parsis.

\section{Individuality and Ethnic Purity}

Individual opinion regarding the ethnic purity rules, in particular the differing perceptions of conservative and liberal adherents, is widespread throughout the New Zealand Parsi community. These differences run right through the community and 
indeed within families, impacting on both the older and younger generations. They also reflect similar divisions amongst Parsi communities in India and worldwide.

The question asking whether the interviewees described themselves as a conservative Parsi, a liberal Parsi or something else brought out the most important and most controversial issue facing the Parsi community both globally and in New Zealand. ${ }^{4}$ Responses were noteworthy not only for their variety but also for the sheer intensity of individual feelings with which they were expressed. They quite clearly demonstrated the significance of individual opinion on what is a fundamental aspect of being a Parsi and a follower of Zoroastrianism. Diversity of opinion on the question of ethnic purity has done more than anything else to jeopardise the future of the Parsi community worldwide and nowhere more so than in New Zealand. Indeed, one might be tempted to believe that diversity of opinion regarding ethnic purity issues is the principal cause of a weakened Parsi community. On the contrary, important though the issue is, I firmly believe that it is merely a symptom and not the main cause. It has been brought into heightened focus by the diversity and passion of individual opinion which is a hallmark of Parsi identity when debating internal community matters; the determination to maintain a position at all costs and not to compromise.

Those who described themselves as conservatives were quite clear that there was only one type of Parsi. In answer to the question 'Would you describe yourself as a conservative Parsi, a liberal Parsi or something else?' one highly respected interviewee, who had lived in New Zealand for many years, replied:

Neither, I consider myself a Zarathushtee or a Parsee. We have our laid down customs and practices in a book called Vandidad or Dinkad, one is supposed to believe in the principles laid down and follow them. There is no such thing as a liberal Parsee.

This comment was very much supported by another interviewee who objected to being name-tagged at all, saying that she did not like such labels and adding: "There's the way it [being a Parsi/Zoroastrian] should be practiced and that's what I am”. Both these

\footnotetext{
${ }^{4}$ The original question used the word 'orthodox', as is used in most academic works, rather than the word 'conservative', but this was roundly criticised as inappropriate by a number of participants, some of whom preferred the word 'traditional' but most preferred the word 'conservative' and, in deference to them, was subsequently adopted. Those who objected to the word 'orthodox' did so because they perceived it as being synonymous with being fundamentalist, which they rejected.
} 
interviewees were quite clear that their views were the correct ones and were not open to any debate.

At the other end of the spectrum were those who believed that the only way forward for the community was to accept conversions into Zoroastrianism, if their faith was to survive.

"If you learn the prayers and can find a priest to convert you to become a Zoroastrian then fine. Please come on board, we need more Zoroastrians in this world": "all the talk about ethnic purity is bullshit, absolute bullshit. Parsiism will die in another one hundred years through communal bickering and I want to dissociate myself from it [the bickering]. Zoroastrianism will survive; it may be an old religion but the values are still relevant today. It won't grow if you don't allow conversion. It is such a beautiful religion - respect for nature, for others, giving moral guidelines, why shouldn't we be allowed to spread it?".

These two opinions plainly expressed the opposing view that change in the ethnicity rules must occur, if Zoroastrianism is to survive in the modern world. Of particular significance is the second comment, differentiating between the likely demise of Parsiism and the hope that Zoroastrianism will survive. This comment was made by another very respected and successful Parsi, who has also lived in New Zealand for many years. Whilst doctrinally unacceptable, apparently there are 'back door' conversions taking place, particularly in certain diaspora countries, such as Canada and USA, but there was no such suggestion of this having occurred in New Zealand. The whole issue of ethnic purity has taken on such a fundamental importance because Parsis are so passionate about their heritage and their religion, together with their individual perceptions of what is right and what is wrong.

The majority of those interviewed ranked themselves in the middle, neither conservative nor ultra-liberal. Most of this group favoured acceptance of intermarriage and that the offspring of such unions should be regarded as Parsi, regardless of which parent was Parsi. Some of this group retained the more conventional view that the offspring could only be Parsi where the father was Parsi and not if it was the mother who was the Parsi. A young member of a wholly Parsi but liberal family, when asked this question, stated that she accepted that, if she married "an ordinary Kiwi bloke", her children would not be Parsis. Most of this moderately liberal group rejected conversions 
leading to acceptance as Parsis on principle with some saying that it could well happen in the next generation but was a step too far for them to take.

It was during discussions on this question that I was first made aware that, if a Parsi 'married out' of the community, in the eyes of the conservative element, not only were the spouse and children not able to be Parsi, but the person marrying out was no longer to be regarded as being Parsi either.

Mixed marriage is not allowed; should one marry outside the community, that person does not remain a part of the community; as such the question of children does not arise.

In other words, the act of intermarriage in itself caused the perpetrators to excommunicate themselves. Interestingly, as recently as 28 May 2010, at an interview held in Canada with Dastur Khurshed, the Vada Dasturji of Udvada (the high priest of the Iranshah Atashbehram in Udvada, the holiest Parsi temple in India), the seriousness and insolubility of this major problem was a major topic of discussion. In answer to a question posed by his Parsi interviewer, Teenaz Javat "Why is there so much of bad blood flowing within our community vis-à-vis the debate over inter-community marriages? Do you ever get the sense of how divided a community we have become?" Dastur Khurshed stated, inter alia:

Our religion is based on gender equality and if a Parsi/Irani girl or boy chooses to marry outside of our faith and does so by way of a civil ceremony he/she has, according to me, every right to continue to attend the Agiary or Atashbehram of their choosing... Let me be clear, this is not my ruling - it is what Dasturji Dabu, a great scholar, had suggested back in 1968 and I wholeheartedly endorse it. However, in some cases where the immediate family pressurises the intermarried $\mathrm{girl} / \mathrm{boy}$ not to visit our place of worship then there is nothing one can do about it. $^{5}$

This is just one more example of how an individual opinion, even one expressed at such a high level, is unlikely to be regarded as definitive amongst those individuals within the community who have a different view.

\footnotetext{
${ }^{5}$ Teenaz Javat, "An Interview with Dastur Khurshed of Udvada: No more an option to stay quiet," FEZANA Journal, December 2010.
} 
A very interesting concept was raised separately by several interviewees, albeit from somewhat different angles, and that was to separate out being a Parsi, as being an ethnicity, from being a member of the Zoroastrian faith.

"I am dedicated to my Zoroastrian religion. It is very important to me; Parsiism is [only] an ethnicity and I am disillusioned by this aspect; people get confused. I am a Zoroastrian Kiwi"; "I can stop you being recognised as a Parsi; you can never be a Parsi. But I cannot stop you being a Zoroastrian because that is something which comes from within you"; "If you are born into a Parsi family you are Parsi whether you like it or not. You have a choice whether you want to practice being a Zoroastrian”.

Whilst clearly a way forward as perceived by more enlightened, liberal Parsis, this idea would be an anathema to the conservative group, who consider Parsi identity and Zoroastrianism to be indivisible. The reasoning behind absolute insistence on religious and ethnic purity ranges from a belief that we are all born into a particular religion as the will of God and cannot therefore change, to a belief in purity as an essential survival strategy. Conservatives state that: "Conversion is wrong. There is a reason why one is born into a particular religion. Conversion is going against nature and it never works".

As I have already explained, diversity of opinion regarding the sanctity of the ethnic purity rules is the single most intractable problem facing the Parsi community, not only in India but in New Zealand and world-wide. As it was described by one interviewee who, whilst of a fairly liberal disposition and in favour of some modification in the ethnic purity rules, called himself orthodox and was certainly not in favour of nonParsis, such as the wives or husbands of intermarried Parsis, being recognised as Parsis: "Amongst the New Zealand community the ratio is about 10\% conservatives, $50 \%$ liberal and $40 \%$ sitting on the fence undecided"! Whilst these percentages are purely speculative, they probably conform fairly closely to my own observations. The big difference is that the minority group of conservatives are quite single-minded in their perceptions of what is right and what is wrong. The larger group of liberals are divided into subgroups as to how far liberalisation should go. There is an obvious similarity here between the traditional divide between Roman Catholicism and Protestantism, with Catholics holding fast to their traditional dogma and Protestants only united in their opposition to Catholics, whilst disagreeing amongst themselves on most other matters. 
As with Christianity, there is really no chance of any reconciliation now or in the future between the two extremes. Whilst some people might argue that, rather than being a problem, diversity of opinion is healthy for any religious group, as is tolerance of such diversity, in this instance, with a few exceptions, there was very limited tolerance shown by most individuals to any opposing opinions.

"They [the New Zealand Parsi community] need to get over some of their ideas, obstacles - such as the argument between the more conservative and liberal Parsis. They need to agree to disagree and then work together".

This comment was made by one young interviewee. In general, members of the younger generation were more pragmatic than their elders.

As an independent observer, I can comprehend the rationale of both sides. The conservatives, quite reasonably, look back at their history in India and say that the only reason that they survived for all those centuries as a miniscule minority group surrounded by much larger ethnicities was because they adhered strictly to the ethnic purity rules. They say that, where marrying out has occurred, their religion has not survived. As a conservative interviewee said to me:

When one of the princes of the fallen Sassanian Dynasty sought refuge in China with a contingent of Persians, he was accorded all the status he deserved, other than Chinese military help, to fight the invading Arabs. However the young leader and his followers married locally and simply melted away in the embrace of Chinese hospitality. No fingers to be pointed here, other than the absence of 'Conservatism'.

The point being made here, of course, is that even in such an august example, when Zoroastrianism was still a powerful Persian tradition, Zoroastrianism could not survive ethnic dilution. They also rightly point out that demographic numbers have never exceeded 125,000 (current global estimate 120,000). ${ }^{6}$ For them, the only way forward is to continue to behave exactly as in the past. They acknowledge that more needs to be done to encourage young Parsis to come together and to increase family sizes. They say that much is being done, at least in India but also world wide, to achieve this. The weakness in their argument, however, is the incontrovertible evidence that numbers in India have been falling steadily for the last 60 years (see Chapter 1) and that, whereas in

\footnotetext{
${ }^{6}$ Hinnells, Hinnells and Williams eds., 273.
} 
the past, the majority of Parsis lived in close proximity to each other in Bombay, more and more families and singles are choosing to migrate in search of individual opportunities. This in turn is further eroding the chances for young people to marry within the Parsi community in accordance with the ethnic purity rules. Not only is their individual drive leading to greater migration, it is also resulting in a loosening of the traditional ties of heritage as individuals decide, on their own initiative, how best to adjust to their changing cultural and social circumstances. This important aspect of modern Parsi cultural development will be further discussed in Chapter 8.

Those in the middle group, whilst rejected conversion as being inappropriate to their beliefs, felt that some form of intermarriage was both inevitable and acceptable. Whilst by no means unanimous in how far to allow liberalisation of the ethnic purity rules to go, they were generally agreed that the community must look forward not backward to find solutions to their demographic problems. They also, quite reasonably, said that given the certainty of the current diaspora carrying on into the future, at the very least the ethnic purity rules must be relaxed to allow the children of one Parsi parent in a mixed marriage, be it the mother or the father, to be recognised as both Parsis and Zoroastrians, provided they are brought up as such. The more conservative argument that, although the children of a Parsi father may be acceptable, as has been legally adjudicated on in the past (see the BPP Case discussed in Chapters 2 and 6), the children of a Parsi mother should not, seems somewhat illogical. It is more than likely that the children's religious and cultural upbringing will be in the hands of the mother rather than the father. This applies in particular within Parsi families, where, as established in my interviews, the wife usually plays a strong if not dominant role within the family (see Individuality as both Strength and Weakness below).

The rationale for the group that advocates relaxing the law to permit children of all mixed marriages to be brought up and accepted as Parsis and Zoroastrianism is that it will increase the total size of the population and introduce much-needed fresh blood to the gene pool, whilst still maintaining the exclusivity of being born a Zoroastrian Parsi. This situation compares somewhat to the Jewish provision that to be a Jew, only one 
parent, the mother, needs to be Jewish. ${ }^{7}$ The weakness in their argument is that intermarriage and acceptance of the offspring as Zoroastrian Parsis, whilst it may provide an opportunity for Zoroastrianism to survive in the future, can only dilute the purity of Parsi ethnicity. The views of this middle group can best be described as varied, individualistic and at times confused and confusing.

"I personally don't have strict views. Although I would prefer my daughter to marry a Parsi, I have never been conservative. If my daughter wanted to marry a non-Parsi, I don't know how I would stop it. I don't have a strong opinion on whether she should then be allowed to continue as a Parsi. There is no clear opinion from religious priests that I have heard; there is confusion; how then can I form an opinion being just an ordinary member of the community? "Ethnic purity is critical to the survival of the Parsi community. [We] will accept nonParsi spouses but it will weaken the community"; "why the children of men should be allowed [to be brought up as Zoroastrian Parsis] in mixed marriages but not those of women? I think they should, but not all Parsis agree with this".

This confusion was well encapsulated by the above responses, the first of which came from a very recent migrant who had not been in New Zealand long enough to be influenced one way or the other by local opinion. One very committed and religious Parsi, on the same subject, stated that, although he would talk to his daughter about cultural differences, he thought she should be allowed to marry outside the community, if males can. This family, whilst firmly rejecting conversion for the present, thought, as did others interviewed, that it might happen in the next generation, adding the caveat that such converts might call themselves Zoroastrians but would never be accepted as such by the Parsi community

One of the most interesting comments on ethnic purity came from an interviewee in the more moderate, middle group who, in direct contrast to the views of the conservative group, also chose to separate the ethnicity of being a Parsi from being a member of the Zoroastrian faith.

We have ethnic purity called Parsi [although] this has been mixed with other blood. Historically the Iranians weren't any single race.... Marriage is between you and the person you are marrying. Religion is between you and God.... If the parents want the child to be a Zoroastrian, good on them. People merge the two together. Zoroastrianism is a religion; Parsiism is an ethnicity. What do the rules

\footnotetext{
${ }^{7}$ EconomicExpert, Matrilieality: Judaism Descent, accessed January 29, 2011, http://www.economicexpert.com/a/Matrilineality.html.
} 
of ethnicity say? You can only be a Parsi if both parents are ethnically Parsi. If you are talking about conversion you are talking about Zoroastrianism not about being a Parsi. If my wife was Polynesian my children would not be Parsi. Zoroastrianism is a straight-forward thing. It's an initiation...

This comment not only differentiates the ethnicity of being a Parsi from being a follower of Zoroastrianism, it also highlights the important distinction between single and dual parent ethnicity. In most modern Western societies, ethnicity is not always strictly based on paternity or maternity, or even parentage. Because of their traditional ethnicity rules and historical survival strategies, such ethnic flexibility is an anathema to Parsis.

There is a third group, those liberal Parsis who go so far as to advocate conversions.

"There is nothing that says conversion cannot happen"; "From childhood we've been told 'no this does not happen'... but is there something that can give proof, evidence, a reason besides bloodlines for no conversions?"; "We should identify ourselves as Zoroastrians rather than Parsis and get away from all this ethnic nonsense, become New Zealand Zoroastrians and represent ourselves as a minority religious community”.

They have similar views to the moderate liberals discussed above except that they believe their religion and culture should be open to all who sincerely embrace the concepts of Zoroastrianism. One family expressed the belief that both the non-Parsi wife and the children of a mixed marriage should be allowed to become Zoroastrians provided they are prepared to do their navjote. At another interview, it was suggested that ethnic purity was more a political issue than a religious or spiritual matter. Those amongst this group believe that the strength of their culture and religious beliefs comes from within themselves and, at the same time, that they have much to offer to the modern world. For them, expansion through conversion is the only way that their unique Zoroastrian religion will survive. They seem to be less concerned with survival of Parsiism per se and more that the concept of 'good thoughts, good words, good deeds', in other words Zoroastrianism, should thrive and grow. Comments in Parsiana support these views, for example, "Zoroastrian religion enjoins conversion which is confirmed by not one but two 
court judgements apart from research scholars. Many Parsis are married outside the community. They want their children to follow and profess the Zoroastrian religion". 8

The Parsi community both in New Zealand and elsewhere is in a cleft stick. The conservative elements will not change their views under any circumstances. With shrinking numbers, the tipping point will soon be reached beyond which, in spite of all the current efforts, numbers may be too small for long-term survival. On the other hand, evidence would seem to support their contention that dilution of ethnic purity, through intermarriage and or conversions leading to acceptance of non-Parsis as Parsis could lead to the demise of Parsiism both as a culture and as an ethnicity. This process can only be accelerated through migration to countries such as New Zealand, where the children of migrant Parsis and some of the adults already see themselves as Kiwi Zoroastrians rather than as Parsis.

One could argue that, by splitting into two disparate groups, there are two chances for survival, but with such small numbers involved, the split can and already has adversely affected the cohesion and drive of the New Zealand community. What is also quite clear is that there is very little chance of the differing factions, who are constantly carrying on a war of words in the media and on the internet, ever backing down on their individual opinions regarding the importance or otherwise of ethnic purity. This is directly and adversely impacting on communal cohesion in India, here in New Zealand and wherever else there is a sizeable Parsi diaspora.

\section{Individuality as both Strength and Weakness}

During the course of my interviews with the NZ Parsi community, I was constantly being made aware of Parsi individuality, both as a strength and as a weakness. The fact that the decision to migrate or to stay in India never seems to be a collective communal or even an extended family one was early evidence of the strength of their individuality. Whilst there was the odd occasion where an individual selected New Zealand as the preferred destination because of a prior contact with a relation or friend, in

\footnotetext{
${ }^{8}$ Behram Aga, “Talibanization of the BPP”, Parsiana, September 7, 2009, 6.
} 
most instances those who have come to New Zealand have come on their own without any close connections.

Areas which highlight the strength of this propensity for individual rather than communal behaviour and collective action include their preference for living separately from their extended families, choosing not to live in close proximity to other members of the Parsi community here in New Zealand, even when they are living and working in the same city, their insistence on being self-sufficient and never relying on social welfare and, of course, the constant drive towards individual material success in their chosen field of expertise. One could argue that this drive is not confined to the Parsis, but I would suggest that its intensity and universality is distinctly unusual. I base this on my observations concerning their constant quest for higher qualifications, their long hours of work and their willingness to move anywhere and put up with considerable privation in the short term for anticipated but by no means certain longer term benefits.

I had an excellent job; we were ok as far as living standards went; I was a General Manager. I am still working for the same company in New Zealand but it [the job] is much smaller here. We were quite settled [before we migrated] but as we had the opportunity to move, so we thought we should try. I see the New Zealand experience as important to getting good jobs [in the future].

How many people would have the energy and courage to give up a good job, a comfortable life style and a secure albeit moderate salary, pack up and move to another country and culture, without any definitive long-term security, in search of a better longterm future for their children as well as for themselves, as many interviewees have done? Coupled with this and another example of this individual drive, although by no means exclusive to Parsi migrants, has been their preparedness to accept menial low paid jobs on arrival in New Zealand, whilst looking for jobs more suited to their qualifications and background.

"A Parsi is forthright and honest, no beating about the bush...very charitable, generous..."; "It's hard for a Parsi to be bad if [they are] living by the teachings. They will deal with other Parsis because they know it will be good, honest. They can be trusted".

These two statements highlight another strength: the individual importance which each and every Parsi ascribes to their religion. There is particular emphasis on its principal 
tenet of 'good thoughts, good words, good deeds' together with the attributes that flow directly from it such as hard work, drive, integrity, honesty, generosity and forthrightness.

"If you derive wealth through the right means go ahead and do it - there is no stigma attached to doing well. You should prosper and then give back to the community"; "Helping others is part of our religion - to help and give to others"; "You have to achieve... I admire this drive. It is part of the Parsi psyche”.

An important characteristic, frequently referred to, is the connection between the individual desire to achieve success and wealth with being generous and giving back to those less fortunate. Being achievement oriented was also seen as a positive in itself.

"Parsis are flexible, able to change"; "We are adaptable and flexible. We are quite harmonious with other [communities]". "We are easy going and peace loving"; "We have an ability to co-exist and seamlessly integrate into any situation"; "We are not confrontational... and show respect for other communities and other religions"; "We have a strong sense of community - of the general community, not the Parsi community”.

Perhaps not surprisingly amongst people who for centuries have had to live as a minority group amongst far more numerically dominant communities, both in India and now in New Zealand, adaptability and flexibility were held up as essential Parsi attributes. It has certainly stood them in good stead. For example, if Parsi migrants to New Zealand were to live as a community on arrival rather than branching out on their own as individuals, the need for flexibility and adaptability would be less important. Interestingly one interviewee did question flexibility saying, "I don't think we are flexible but we are adaptable”. She was, I surmise, referring to the inflexible attitudes taken on communal issues such as ethnic purity. It is interesting to reflect on the contradiction here between adaptability to external factors and inflexibility towards internal communal matters.

"We're not followers [but] individualistic.... We feel pride to stand on our own two feet., don't expect anything free, work for things"; "We don't like being told what to do - we are individualistic"; "[we are] very vocal in our views"; "we are strong headed"; "we fight amongst ourselves".

Strong-mindedness and individuality were both perceived as valued characteristics by interviewees. But, as indicated by several of the comments above, these strengths also carry vulnerability in the form of an inability to compromise on important community 
issues. One need only glance at a few copies of Parsiana for corroboration of the intensity of individual opinion which accompanies any important communal debate. For example: "I have gradually come to the conclusion that I shall not renew my sponsorship of Parsiana because of the continual news of conflict and bad behaviour within the community.... I think I would be much happier not reading them". ${ }^{9}$ There is also a very relevant article by Councillor Filly K. Maravala titled, "Traditionals protest against disgusting Editorial of Parsiana January 2004”. ${ }^{10}$

"We are easy-going and peace-loving"; "We have an ability to co-exist and seamlessly integrate into any situation"; "We are not confrontational... and show respect for other communities and other religions"; "Being Parsi you don't push your views on anyone else [outside the community]".

Strangely enough, Parsis also see themselves as easy-going and peace-loving, the distinction being made here, once again, between internal communal relationships and relationships with the external community where they co-exist with other communities.

One attribute which the Parsi community perceive as a positive, but which I believe is also a weakness, is in the area of self-identity and the traditional Parsi reluctance to be pushy or to advertise themselves. Such modesty may be very laudable but can also lead to anonymity in an open society such as New Zealand's and can therefore be perceived as a distinct disadvantage in their efforts to maintain their traditional Parsi culture. As one conservative person put it, nicely encapsulating the point:

Instead of saying 'I came from Bombay, India', and leaving an inaccurate inference that I am an Indian, I make it a point to instil clarity by conveying that I am a Parsi and, dependent on the situation, spend as much or as little time as may be needed to ensure that my identity has been adequately established.

This sentiment of an inability to establish a separate identity in New Zealand was echoed by another interviewee who said: "People [in New Zealand] don't understand what it is to be Parsi. In India, people knew”. Most people in New Zealand would have great difficulty in distinguishing one Indian community from another let alone having

\footnotetext{
${ }^{9}$ Editorial Viewpoint, Parsiana, June 21, 2009, 6.

${ }^{10}$ Councillor Filly K. Maravala , "Traditionals protest against disgusting Editorial of Parsiana January 2004", accessed October 20, 2011, http://tenets.zoroastrianism.com/toParsiana33.html.
} 
sufficient knowledge to appreciate the singularity of an ethnic group such as the Parsis who have lived in India for centuries but have never regarded themselves as being Indian.

An area which clearly exemplified individuality as a positive, but also as a threat, was demonstrated in the role of women in Parsi society.

"Historically, Persian women ... worked alongside their husbands and were viewed as the epicentre of the family. Grandmothers were accorded the same respect as grandfathers".

In Parsi families, it is normal for both the husband and the wife to pursue their own careers on a separate but equal footing, with each one striving for individual advancement and success. Almost every woman interviewed was either currently employed or seeking employment. Not infrequently the type of work in which they were engaged was equal or superior in status to that of their husbands. The importance of women in Parsi culture cannot be overemphasised. Their strength lies not only in terms of their education, careers, equal opportunities and material success but also, as wives and mothers, they are the mortar that holds the nuclear family together. Many interviewees mentioned that Parsi women have very strong characters and are at least the equal of their men folk. This is still very much the case with modern-day Parsi families in New Zealand. Against this strength, and as mentioned in Chapter 4, must be measured the adverse demographic impact, particularly in India, of late marriages, low fertility rates and high instances of career-induced spinsterhood. But in New Zealand, this vulnerability was not so apparent. For example, the family sizes of those interviewed ranged between one and three children with an overall average of exactly 2.0 per adult woman. This compares with the average number of births in New Zealand in the year to June 2010 of 2.2 per woman. ${ }^{11}$

Parsi individuality is manifest in their intense personal pride in their heritage, culture and religion, with individual interpretation of their religious duties and devotions particularly revealing. This pride makes Parsis self-confident even in a society such as we have in New Zealand, where such matters as status and origins are of little

\footnotetext{
${ }^{11}$ Statistics New Zealand, Births, accessed October 20, 2010, http://search.stats.govt.nz/search?p=Q\&lbc=statsnz\&uid=811577908\&ts=custom\&w=births\%20per\%20mi llion\&af=ct2:population_births.
} 
consequence. Parsi lack of defensiveness about their culture is combined with a very ready willingness to participate with others, not of their culture, on an equal footing, making it easy for them to integrate with members of other ethnicities on a one to one basis. This sort of inter-communal relationship is enhanced by the general Parsi ethic of becoming involved in public affairs such as school committees and fund-raising activities.

On the other hand, their individuality also manifests itself in traits which undoubtedly detract from their ability to progress as a united community, moving forwards collectively toward a more secure future: Their many and bitter religious disagreements have already split the New Zealand Parsi community, resulting directly in a loss of impetus towards securing a community centre, which would be invaluable for enhancing the chances of their long-term survival. The same divisiveness is likely to impinge on any future attempt to organise a more substantial place of worship, here in New Zealand. Their readiness to pursue their ambitions as individuals rather than as family or communal groups must inevitably weaken future communal structures, given that families and extended families are the building blocks of society. Interviews with members of the New Zealand Parsi community have more than substantiated my views based on historical research that, within their own communities, Parsis are strong-minded and vocal in their individual opinions, particularly on matters concerning their culture and their religion.

\section{Summary}

There is little doubt that, through their propensity to migrate, their religious practices and their variable attitudes towards traditional ethnic purity rules, there runs a strong current of individuality amongst the New Zealand Parsi community. This became clearly evident during the interviews with a cross-section of Parsis now living in New Zealand. Personal preferences and individual action take precedence over extended family or communal cohesion. This was demonstrated by individual patterns of behaviour, religious practices, and degrees of adherence to or desire for modification in the strict ethnic purity rules as a means of preserving their culture and religion. Such 
diversity of individual opinion presents a real threat to the global Parsi community in the face of changing dynamics caused by the current global diaspora and consequential dispersal into much smaller groups than has traditionally been the case in Gujarat and Bombay.

The strengths applicable to such strong elements of individuality are clearly manifest in the ease with which Parsis assimilate and interact with other ethnicities, their personal drive, their honesty and their commitment to material success without losing sight of the need to contribute to the community in which they live and to help those in greater need than themselves. But these strengths as individuals come at a cost in terms of disagreements and even divisiveness within the local Parsi community on important issues regarding best cultural and religious practices. 


\section{Chapter 8 Possible Future Directions}

Traditionally a very dynamic albeit demographically small community within Indian society, with increasing numbers of Parsis joining the diaspora, questions must arise concerning their ability to survive as an integral community both in India and elsewhere. This chapter will consider possible future trends not only for the Parsi community here in New Zealand but also in India, its traditional powerbase. It will consider how the diaspora is impacting on the Indian community and whether such impact is positive or negative for the longer-term survival of both the global Parsi community and Zoroastrianism.

\section{A Future Role for Parsis in New Zealand}

As already noted, traditionally Parsis have always contributed far more to the economic and social well-being of their country of adoption than their numerical strength would suggest. Although most of those interviewed were comparatively recent migrants, responses to a question regarding their own perceptions about any future role in New Zealand were both revealing and encouraging.

"New Zealand Parsis are young families, still struggling. The next generation will make its mark more than the present one. The wheels are in motion with the emphasis on education"; "This [high achievement of the community in India] will happen here; just give us time; it is beginning to happen already"; "We volunteer and contribute were we can... In India we were part of the wider community. It's wider than the Parsi community. You must step outside your [ethnic] community".

Some interviewees felt that the community was still too young and individuals too busy establishing themselves for much of a pattern to have yet emerged. This reaction is very understandable, given that many of those interviewed had school-age children and had only been in New Zealand for a few years. They would have arrived in New Zealand with limited, if any, material possessions such as household furniture or white-ware, much less a vehicle. Initial incomes would have been extremely modest particularly, as referred to earlier, for the many that had to take low-paid jobs until they could establish 
themselves. Having said that, there were also frequent comments regarding the major contributions of their forebears to Indian society and its economy and that these could well be replicated some time in the future in New Zealand. These positive expressions conformed very closely with my own perceptions. New Zealand Parsis are already very involved in the activities of their wider local communities. For example, when trying to make weekend appointments with interviewees, suitable times had to be found around a constant stream of local community activities, particularly related to school functions such as fund-raising. One interviewee reflected the traditional Parsi obligation to participate in local government by saying that if he had the resources he would have liked to stand for mayor.

Parsis have a great deal to offer New Zealand society. More than any other migrant group in New Zealand, they can lay claim to the experience of hundreds of years of being migrants so assimilation without loss of identity is second nature to them. They do not have to learn how to survive and prosper in a strange land, they already know. They are not coming to New Zealand because they are being persecuted in their homelands, but because, as individuals, they have decided that the opportunities for their future prosperity are brighter in New Zealand than in their country of origin (usually but not always India). They have chosen New Zealand to live in, rather than it being a refuge of last resort. Adherence to their Zoroastrian belief in 'good thoughts, good words, good deeds' combined with becoming the 'sugar in the milk' of their newly adopted home makes them worthy New Zealanders.

\section{New Zealand Parsi Perceptions of Demographic Trends in India}

Answers to a question regarding reasons for the decrease in numbers within the Parsi community in India in the recent past and what should be done to reverse these trends in the future were fairly uniform and reinforced all the traditional views referred to in Part 2. The major point of disagreement occurred, as could be expected, in attitudes to the effects of intermarriage on demographics.

"Numbers are shrinking because they [priests] have not allowed intermarriage. There needs to be more flexibility....The gene pool is too small. If they allow intermarriage, then the community will survive"; "They need to more openly 
accept people otherwise it will continue to decline"; "Unless they change the thing that only the male hierarchy is important, then things won't change. If the mother wants to do the [cultural and religious] teaching that would be fine".

Those in favour of intermarriage pointed strongly towards non-acceptance as a significant factor in declining numbers in recent years. These views, whilst generally reflecting the views of the moderates towards intermarriage also contain a further division between those who accept patrilineal but not matrilineal descent and those who advocate both. By allowing the children of mixed marriages where the woman marries out to be Parsi as well as when the man does, there is an obvious increase in the number of children born of mixed parentage who have an opportunity to be raised as Zoroastrian Parsis. Interestingly enough, these views were not shared by a Parsi domiciled in Malaysia who, writing in Parsiana, said: "We as Parsis and Zoroastrians look at interfaith marriage as a problem or a solution to our dwindling population, whereas it is none [sic]". ${ }^{12}$ He goes on, however to advocate acceptance of all children of mixed marriages as Zoroastrians, without commenting on their ethnicity. In another edition of Parsiana, a United Kingdom-based correspondent, Shahpur Captain, under the caption "Survival imperatives", recommends welcoming all non-Zoroastrian spouses to Parsi communal and religious functions and performing navjotes for all children of Zoroastrian mothers that have married out of the community. ${ }^{13}$

"They are just spreading out.... There are great Parsis left in India. The cream hasn't all left"; "They [the Indian authorities] do not collect the numbers accurately. I think that only registered children are counted. I know many people who haven't registered their child's birth".

Opposing the views of the moderates regarding demographic decline, a view was expressed by some conservatives that the Indian census figures being used are not always accurate. Whilst there is probably an element of denial in such a statement, there can be no gainsaying the difficulty of collating accurate census figures for such a small population in such a vast and administratively challenging country as India. Nor of course, as suggested by Hinnells (see Chapter 1) do the figures reflect the total global situation.

\footnotetext{
${ }^{12}$ Malaysia's Mazdayasnis, Parsiana, August 21, 2009, 43.

${ }^{13}$ Intermarriage in the UK, Parsiana, June 7, 2006, 21.
} 
Of interest on this subject were the comments regarding the progress being made in India to encourage earlier Parsi marriages and larger families:

"The BPP, the richest charity in India, give money to people for the second child and third child to encourage a higher birth rate"; "There are organised groups now for young people, and there are websites to find a [Parsi] partner".

These words were echoed by another conservative interviewee, who cited the BPP and charitable trusts as providing incentives for endogamous families in the form of facilities for young Parsis to meet each other socially. Financial and material assistance is also available to young couples to encourage them to have more children. A 2009 article in Parsiana advised that the BPP was paying out incentives of Rs. 1,000 and Rs. 3,000 per month for second and third children respectively, born after April 1, 2009, until the age of eighteen years. ${ }^{14}$ The BPP has traditionally been responsible for the bulk of charitable undertakings amongst the Parsi population, so it is hardly surprising, given its traditional, conservative leanings that it should now be providing resources specifically aimed at encouraging larger families. ${ }^{15}$

Of the other reasons given for declining numbers, education of women leading to a career, rather than matrimony, migration and delayed marriage with consequential low fertility, was singled out by most interviewees as a principal cause along with traditional pressure to marry endogenously:

"There are a lot of unmarried people in the community because of their careers or being picky about whom they marry. Having children outside marriage is unacceptable...intermarriage is frowned on in India... a lot of people run away [migrate] to marry because of that"; "There were huge pressures on women to marry a Parsi and they couldn't always find one. The attitude was that if you can't find a Parsi then don't marry"; "Late marriage, more focus on education, not having children early then having problems with fertility"; "We have adopted Western culture - to have less children".

There is a suggestion here, echoed by other interviewees, that Western influence has adversely affected Parsi demography. This is true in that the British were traditionally the role models to whom Parsis aspired and for which material success was an essential ingredient. But in a strange inversion of the traditional influence of Western culture on the East, what we are seeing happen within the global Parsi community and its struggle

\footnotetext{
14 "Pride and Prejudice," Parsiana, November 21, 2009, 19.

15 “Editorial Viewpoint: Who Lost?", Parsiana, November 7, 2009, 2.
} 
for survival could well be the harbinger for future struggles to survive in Western societies. Emphasis on global careers combined with greater attention to education and career opportunities for women in the West is undoubtedly leading to later marriages, problems with fertility and fewer children, particularly amongst the more affluent and higher educated classes. It is just that this phenomenon has occurred sooner amongst the Parsis because they embraced gender equality and higher education for women so much earlier than the West. But this thought is of little comfort to Parsis and their predicament.

Parsis believe in a good quality of life-you have the number of children you can afford to bring up well. My mother was angry with me when she heard I was pregnant with my third child as she didn't think I could afford it. My mother was very orthodox. She thought that one must be able to give children all opportunities; best schools etc. That's the main reason why numbers have decreased. Also Parsi girls are educated. They want spouses who are welleducated too. So they end up marrying late.

This simple statement by a cosmopolitan-minded senior citizen admirably sums up the complex reasons for demographic decline. It brings together a great number of the complex threads that are woven into the pattern of Parsi identity: the imperative to have a good quality of life, the importance of having adequate financial resources, the need for good education, the emphasis on female emancipation and matriarchal influence. A good quality life means living within your means whilst striving to better yourself which in turn is likely to lead to smaller but more prosperous families

\section{The Future for Parsi Identity and for Zoroastrianism in New Zealand and World- wide; the Threats and Opportunities}

What of the future? This is surely the most important question, not just for this thesis but, more importantly, for the global Parsi community itself to address.

"Most religions have disagreements and they [the Parsis] are no different. They learn to live together, each respecting the other's religion"; "We have adapted and survived for centuries, against the odds, why should we not go on adapting and surviving?".

As has become readily apparent in previous chapters, it is difficult to separate Parsi identity from Zoroastrianism, but in coming generations their paths may well diverge. 
Indeed there are signs that such a move is already taking place as, for example, in the website, "Conversion in Mazdayasna", which offers advice and help on how to convert to Zoroastrianism, along with initiation ceremonies. ${ }^{16}$ In general, responses by interviewees to questions about the future were fairly positive with most interviewees saying that Parsi identity would survive in New Zealand, in India and world-wide. This applied both to those of a conservative persuasion and to those who had more liberal beliefs. But there was a great variety in the caveats and also in where survival would be strongest. Of particular value were the views expressed by the younger generation who had been brought up and educated primarily in New Zealand and whose ages ranged between 16 and 25 years. They expressed a greater sense of realism than their elders. They also expressed the view that questioning everything to do with their culture and religion was entirely healthy. As the future will soon be in their hands, their views should perhaps be given more weight than those of their parents.

Of the young people interviewed, three were from a conservative background and three were not. All three of the conservative group believed that the community in New Zealand would thrive, although one interviewee felt there was some risk of dilution through intermarriage. At the same time, one interviewee amongst this group felt that all the questioning going on in New Zealand was good for the culture and that she believed the community is more conservative than liberal. All three were very positive about the enthusiastic efforts now being made in India to preserve and rejuvenate traditional Parsi values.

"From the scientific point of view you need genetic diversity but I don't believe in conversion or intermarriage.... If you start conversion, it [the culture] is going to be something different"; "I believe in the values of the religion-you need to be a pure blood in order to practise, but it's each person's choice to make. They may choose to marry outside. [But if they do] I don't believe they can then bring their children up in the religion. That's a privilege to be born a Zoroastrian".

These comments clearly demonstrate the bind that the younger generation of conservatives is in. They passionately want to preserve their traditional ethnic purity rules but also recognise both the scientific reality of an ever-declining gene pool and the social reality of increased intermarriage particularly within such a small Parsi community

\footnotetext{
${ }^{16}$ Zoroastrianismcc., Conversion in Mazdayasna, accessed July 07, 2010, http://www.zoroastrianism.cc/conversion_in_mazdayasna.html.
} 
as in New Zealand. It is perhaps surprising, faced by such contradictions, that they remain so positive about their future. A significant comment made by a conservative member of this group, quoting an eminent Parsi Zoroastrian scholar, Khojeste Mistree, was that it could be shown that wherever intermarriage had occurred in the past, their Zoroastrian religion had disappeared within four generations. ${ }^{17}$

In contrast to the conservative group, one of whom came from a very liberal family and two from conservative ones, all three young liberals came from liberal families (one was from a mixed marriage family whilst the parents of the other two were both Parsi), and this was reflected in their views:

"Why not accept [both intermarriage and conversion], otherwise the religion will die out?"; "I can understand why people are reluctant to do this [accept conversions]. But, if they are going to survive numerically it would be sensible to allow the children of mixed marriages to be Parsi.... I want to know why they're so picky when we're such a small community".

From this group, two felt positive about the future for Parsiism, although one expressed concerns about the limited size of the gene pool, both in New Zealand and in India, and how this might adversely affect long-term chances of survival. The other believed that their culture and religion would survive in India and world-wide but felt the lack of religious infrastructure such as a fire temple could reduce the chances of survival in New Zealand. The third was of the opinion that, unless rules are changed to allow conversion and acceptance of non-Parsis as Parsis, Parsiism will gradually die out.

On balance, the conservative group felt more positive about the future for Parsiism than did the liberal group. In a tentative way, this would seem to support Khojeste Mistree's claim, referred to above, that ethnic dilution leads ultimately to loss of ethno-religious culture. One point on which all the young were agreed was that the future survival of their religion and way of life was up to their generation.

As might be expected, the more mature interviewees divided along conservative/ liberal lines in their approach to what was needed to enhance the chances of survival.

"Parsis/Zarathushtees will survive, only if they choose to follow the religion, traditions and customs as laid down"; "there is absolutely every likelihood that the efforts of the community's faithful to keep the passion of our faith alive will

\footnotetext{
${ }^{17}$ Parsi Khabar, Diaspora: A Talk by Khojestee Mistree, accessed April 04, 2011, http://parsikhabar.net/opinion/diaspora-a-talk-by-khojeste-mistree/2158/.
} 
most certainly continue, just as it has since the loss of our original Mother-Nation some thirteen centuries ago"; "It will survive in India where the Parsi community is held in high esteem. In New Zealand [it will survive] in my generation and my daughter's, beyond that I don't know - if we can instil a sense of pride amongst the younger generation it may survive".

The emphasis here is quite clearly on looking backwards to support the only acceptable way forward. Conservatives pointed towards their historical ability to survive as a small minority group in India for the past many centuries as evidence of their ongoing ability to survive into the future, provided there is strict adherence to traditional ethnic purity rules. This need to maintain past traditions was also voiced amongst some middle of the road Parsis.

Most liberals were convinced that the future survival of Parsi identity was dependant on a more liberal approach being taken to their ethnicity rules.

"There needs to be more flexibility.... The gene pool is too small. If they allow inter-marriage then the community will survive"; "Parsiism will die out in another hundred years [but] Zoroastrianism will survive. It may be an old religion but the values are still relevant today”.

There is clearly an element of pessimism about the future for Parsiism being expressed here, as was evident in the comments from some of the younger liberals, but also a reflection of higher hopes for the future of Zoroastrianism. Another liberal interviewee, whilst believing in the survival of Parsiism, hoped that the future would bring a peaceful blending of the two extremes in mutual respect for each other, "leaving each other to do it their way".

Whilst most of the New Zealand Parsi community felt positive about the future for their community, hanging over the whole question of survival lies the ethnic purity controversy. I do not believe that the conservatives will give up their insistence on ethnic purity anytime soon. Given the ever-increasing spread of the Parsi community, including conservatives, through migration, unless there is a remarkable resurgence in birth numbers, conservatives are surely destined to continue to decline in numbers, generation on generation. The more liberal elements are likely to benefit numerically in the short term from migration and intermarriage, but their numbers will be adversely affected in 
the longer term by dilution of commitment to traditional values, generation on generation.

\section{Summary}

Over the past decade members of the Parsi community in New Zealand have become worthy and fully participating members of New Zealand society. There is every chance that in the future they will contribute culturally, socially and economically well above their numerical strength as has traditionally been their pattern of behaviour in India. But their future survival as a separate ethnicity in New Zealand is far less assured. In New Zealand, in India and globally, the pressure on maintaining purity of ethnicity is intense. The number of Parsis remaining in their Mumbai heartland has been in decline for the past fifty years and migratory groups such as the one in New Zealand remain insufficiently large to avoid dilution through intermarriage. This must inevitably threaten their long-term survival. 


\section{Part 4 Conclusions}

To understand the Parsi community in New Zealand - where they have come from, why they are here in New Zealand, their background and their chances of survival as an ethnic group - it has been necessary to look back into the past and to examine the characteristics that have given Parsis their very distinctive identity. Has their arrival in New Zealand been the result of straight chance or has there been a degree of inevitability about the migration? The results of my academic research (Parts 1 and 2), together with the oral history contained in Part 3, have collectively formed a mosaic, an overall picture of Parsiism. It is neither possible nor desirable to single out one element as being of greater significance than all the others, but overall I believe it does provide a clear image of the Parsis, first in India and then in New Zealand. From that image, I have been able to arrive at firm conclusions on my two principal hypotheses regarding the inverse correlation between individualism and community cohesion and the overall impact of migration on the longer-term chances for Parsi survival.

\section{Chapter 9 Overview}

Before discussing major issues that have led to my conclusions, and the conclusions themselves, it might be helpful to summarise briefly the main elements of my thesis:

History: Given the general paucity of knowledge about Parsis worldwide and certainly in New Zealand, it has been critical to my arguments to trace Parsi history to the emergence of Zoroastrianism as a religion of significance in Persia during the Achaemenid period. Chapter 2 includes a description of their advancement to recognition throughout India for their outstanding qualities as business people, professionals, civil servants, politicians, members of the armed forces, philanthropists and local community leaders. Their history plays a vital role in cementing in their heritage as an important part of the modern Parsi identity. Not only are they immensely proud of their heritage but they also believe it to be truly deserving of preservation. 
Insecurity and its impact: Parsis in India were foreigners in a foreign land. This created the feeling of being different and special, but it also, according to certain Parsi historians, produced a sense of impermanence and insecurity. Parsis in India were foreigners in a foreign land. After Indian independence, uncertainty about the future together with a real or perceived loss of privilege, status and prospects was to become manifest as a significant motivator for many Parsi individuals to seek fresh opportunities for themselves and their nuclear families through migration.

Religion: The distinctiveness that characterises Parsi identity is largely and fundamentally attributable to their Zoroastrian religious beliefs. The passion with which they embrace those beliefs, in particular the basic tenet of 'good thoughts, good words, good deeds', provides the foundation for their way of life, their social behaviour and their moral values. Its combination of spirituality with worldliness, permissiveness with moral rectitude has moulded the Parsi identity.

Ethnicity: Disputes over the importance or otherwise of ethnic purity have been raging with ever-increasing intensity since the beginning of the twentieth century, with no compromise or resolution in sight. It is the single most divisive question facing the entire global Parsi community.

Charity and Charitable Trusts: Charitable giving and the creation of charitable trusts is an important part of Parsi identity. These trusts have had immensely beneficial effects, in terms of providing the financial base from which to help the young and the less fortunate members of the Parsi community. There is however also a negative side to these trusts in the form of their misuse and manipulation for individual and sectorial benefit. In such a guise, they are communally divisive rather than inclusive.

Social and Economic Markers: Preeminent amongst Parsi attributes for survival and personal success is their capacity to adapt to changing circumstances and external 
conditions without sacrificing their own culture and beliefs. They are eminently comfortable within themselves and therefore integrate well with other cultures.

Education: The Parsi community provided and improved the education facilities available in Bombay long before such an emphasis was placed on education by other ethnic groups. Most remarkably of all was the equality of emphasis on education for both males and females in a country and at a time when female emancipation hardly featured. This emphasis on education provided the base from which Parsi dominance in so many areas of endeavour was able to take root and flourish.

Gender Issues: Over the last one hundred and fifty years, Parsi women have been able to benefit individually from their higher education and the ready acceptance within the Parsi community that women should have independent and meaningful careers. But such independence has another side to it. Strong-minded, well-educated women with careers and independent incomes are likely to postpone or even forego marriage and have families below sustainability levels.

Wealth Creation: Historically, wealth creation was largely in the hands of a limited number of commercial dynasties. Some of these dynasties, such as Tata and Godrej, have carried on as family dominated enterprises into the twenty-first century. The work ethic and vision of those great enterprises lives on in the individual drive and determination to be successful, so prevalent amongst Parsis in New Zealand.

Relationships: Modern New Zealand-resident Parsis are open, relaxed, fun loving, self assured and very hospitable. Whilst intensely committed to their own heritage, they integrate well with other cultures and ethnicities because they are so secure in their own selves. Within the New Zealand Parsi community, there are no signs of the insecurity, referred to above under Insecurity and its Impact, which was a feature of Parsi life in India. They combine their strong sense of family and friendship with their personal life choices by a combination of good use of modern communications and not infrequent overseas trips to attend important social functions. 
Good Thoughts, Good Words, Good Deeds: The cultural focal point for Zoroastrianism is the concept of measuring one's every act by whether or not it meets the individual's interpretation of being a good thought, a good word or a good deed. Responsibility for all decisions and standards of behaviour rests squarely on the individual.

The Sugar in the Milk: The impact of the centuries-old mythical story regarding the sugar in the milk still resonates strongly within the Parsi community here in New Zealand as elsewhere. The notion reinforces the concept of meritorious individual behaviour. It also gives impetus to the Parsi ethic of striving to add value in whatever they do.

Individualism: The need to struggle to flourish within a slightly hostile or perceived hostile environment has in turn led to a strong sense of individuality. Survival and high levels of achievement were and are very much in the hands of the individual. With this emphasis on individualism and the need to succeed, has come an element of internal communal dissent, bolstered by the traditional absence of any strong central religious or secular authority. This strong emphasis on individuality has been nurtured along the way by the community's distinctive Zoroastrian beliefs, particularly the emphasis on maintaining a direct connection between the individual and Ahura Mazda and that to be a worthy Parsi includes being successful in worldly terms. 


\section{Chapter 10 Conclusions}

In Part 1 of my thesis, I recorded the results of research into the backgrounds of the Parsi communities both in India and in New Zealand. In Part 2, I identified the specific characteristics that give Parsis their distinctive identity. Then in Part 3, I described the responses from interviewing a cross-section of the New Zealand Parsi community located in Auckland and Wellington. The principal purpose of my questions was to test my hypothesis regarding the current downward demographic spiral amongst Parsis in India and upsurge in the number of Parsis migrating to new countries such as New Zealand. Was it principally influenced by their historical and cultural inclination towards individualism at the expense of any very definitive sense of community such as has often been exhibited by other diaspora groups, notably the Chinese and the Pacific Islanders? The second principal purpose behind my questioning was to test whether or not the current migratory surge is likely to enhance the chances for long-term survival of the Parsi community in India and worldwide. My conclusions highlight the important issues that have emerged during the course of my research and provide responses to my two initial hypotheses.

In my Introduction, I listed the various reasons given by important academic commentators in support of their theories regarding the current demographic decline amongst the Parsi community in India. These included low fertility, religious exclusivity, difficulties with political realignment post-Independence, a failure to achieve religious reform and the fact of an accelerating diaspora. All these points have been shown by my interviews to be valid contributory causes, at least in the eyes of the New Zealand community. But, in my view, none of them either collectively or singly are powerful enough reasons to explain the phenomenon in full. By looking more deeply into the history of the Parsis and their distinctive identity, and taking full account of the opinions and perceptions of the New Zealand community, I am convinced that the underlying emphasis on individualism cannot be ignored.

Individualism stands out as a highly important Parsi characteristic both historically and as the principal driving force behind the current aspirations of the Parsi diaspora. It can be traced back to the origins of their religious beliefs and their 
emergence in modern times as leaders and achievers. 'Good thoughts, good words, good deeds' lies at the very heart of what makes Parsi identity so distinctive. By making the link direct between the individual and their Supreme Being, Ahura Mazda, rather than, as in most world religions, being filtered through a hierarchy and structure which maintains centralised controls and communal dominance, Zoroastrianism has laid responsibility for behaviour squarely on the individual. This emphasis on the importance of individual behaviour as part of the Parsi identity was to emerge into the limelight and shape Parsi culture, as perceived not only by themselves but by other cultures, during the nineteenth and early twentieth centuries. It carried in its wake all those attributes traditionally associated with Parsi culture: their industriousness, their adaptability, their peacefulness, their religious devotion, their self-confidence and determination to succeed, their ability to live and interact easily with other cultures. It also, however, carried the seeds for internal dissent through competitiveness, religious fervour and individual strongmindedness.

There is much in Parsi history which can be accounted for by their individualism. Their current migratory urge has not been driven by persecution or by chance but by their ongoing and individual determination to do the best they can for themselves and their families in the light of the changing socio-economic conditions that have occurred in India over the last sixty-five years. This emphasis on individualism as being central to the Parsi culture has inevitably adversely affected communal cohesion. The current diaspora whilst stemming from individually inspired driving forces must also, with time, weaken still further the communal ties and infrastructure.

The growing diaspora, combined with Parsi acculturation, presents an everincreasing risk to traditional ethnic purity. As the community becomes more thinly spread throughout different countries such as New Zealand, the opportunities to meet and interact with other communities increases at the expense of meeting and interacting with other Parsis. This can be mitigated by maintaining close relationships with family and the Parsi community in India, but for how long? As one generation succeeds the next, it is likely that those links will weaken and links within the country of adoption will strengthen. Traditional survival strategies such as strict adherence to ethnic purity are unlikely to be sustainable. Cultural boundaries will have to be redrawn, if 
Zoroastrianism and Parsi identity, in some form or other, is to endure. Barriers to any such changes include the weakness of centralised authority referred to above and the passion exhibited by conservative adherents to the traditional ethnic purity rules.

The factors listed in the Overview (Chapter 9) have not only defined Parsi identity, they have also provided a climate conducive to the current migration to countries such as New Zealand. In my Introduction, I suggested that migration might help to rejuvenate the Parsi community worldwide and lead to a renaissance of the community in India. This theory seemed to be supported by my interviews in New Zealand and the generally positive attitude towards survival taken by most interviewees regardless of their socio-religious persuasion. My interviews also seemed to support John Hinnells' contention, stated in Chapter 1, that population decline in India was being at least compensated for if not exceeded by growth in overseas communities such as New Zealand. But whatever the current statistics may be, and accurate worldwide demographic figures are non-existent, there is a much deeper concern for the future, one which gradually emerged from my interviews with New Zealand Parsis. It lies partly, but only partly, in the current bitter divide between conservative and liberal Parsis on how best to protect their ethnicity and religious beliefs in the future. More cogently it lies with the questionable survivability of such a small ethnic group which is now diluting itself by migration and thereby further reducing the internal strength and cohesiveness of its traditional community powerbase in Mumbai. As the diaspora spreads, so the risks of intermarriage and socio-religious dilution will surely increase. According to an article in Parsiana in 2006, research showed that $60 \%$ of second generation Parsis living in the United Kingdom at that time had married out of the community. ${ }^{1}$ When those who remained unmarried were taken into account, the figure rose to $69 \% .^{2}$ One need only look at the history of minorities such as the Celts and Picts in Great Britain or the indigenous populations of the Americas for precedents. John Hinnells has chosen to drop the name Parsi in favour of Zoroastrian (Chapter 1); perhaps that indeed will be the way of the future.

\footnotetext{
${ }^{1}$ Intermarriage in the UK, Parsiana, June 7, 2006, 21.

${ }^{2}$ Ibid.
} 
As has been clearly shown, Zoroastrianism is the cornerstone of Parsi identity. At the same time, Zoroastrianism, through its historical emphasis on a direct link between the individual and Ahura Mazda, has fostered self-reliance in regard to how an individual lives and behaves. This, along with the traditional absence of any strong religious or secular authority, has created a situation in which obedience to any central body is at best tenuous. The lack of any coordinated priestly jurisdiction over the laity is a significant contributory factor. With the ever-widening dispersal of the Parsi community through the diaspora, this lack of centralised authority is likely to become more pervasive with the various diaspora groups modifying their behaviour to meet local circumstances rather than conforming strictly to past practices. Such behavioural variances will be aggravated by the absence of unifying structures such as fire temples, dokhmas and permanent communal facilities, wherever Parsi communities are too small to sustain them.

With the ever-increasing global emphasis on greater equality for women, the demands of liberal Parsi women who have intermarried can only grow stronger. In a community which has a long and proud history of gender equality in terms of education and career opportunities, it is perhaps ironic that gender inequality still persists in regard to the ethnicity and religion of the children of a mixed marriage. Even amongst liberals, acceptance as being Parsi and Zoroastrian is still, in the main, dependant on the parent who has married out being the father. Furthermore, as the diaspora continues to spread and the ability to marry within the community dilutes, there will surely be increasing pressure for the non-Parsi partner to be accepted as a Zoroastrian convert, if they so wish, and even ultimately be accepted as at least an honorary member of the Parsi community. This would seem to be particularly apposite to cases where the non-Parsi mother is charged with or wishes to bring up the children in the Zoroastrian faith.

On the positive side of the inevitable loosening of the traditional ties of heritage are some of the characteristics inherent in Parsi identity, in particular their pragmatism and ability to adjust to changing circumstances. A good example of this is the practice, now wide-spread in New Zealand and in most other diaspora communities, to adopt western-style funerary rites because the use of a dokhma is just not practical. Although still not generally acceptable there, this practice is now becoming more common back in India. In a similar fashion, decisions on how best to adjust cultural practices to meet the 
changing needs of the diaspora in such matters as cultural purity may well influence the community globally, allowing Parsi identity and Zoroastrianism to survive into the future, albeit in a modified form, as they have survived in the past.

Parsis have a very strong urge to preserve their unique heritage and this will undoubtedly stand them in good stead in the future, at least for the next two or even three generations in New Zealand and other similar diaspora communities, and hopefully for longer in India itself. But there is no gainsaying that the Parsi community worldwide is under threat. Numbers in India are almost at a tipping point for long-term survival and whilst there is every chance of the diaspora communities growing demographically in the short term, the threat from dilution by dispersal and intermarriage is very real. The acrimonious debate between conservatives, who fervently believe that traditional ethnic exclusivity is the only way to survive, and liberals, who believe that some form of limited relaxation in the ethnic purity rules is imperative to achieve the same objective, is important, as it further dilutes communal cohesion and any attempts at concerted plans to enhance chances for long-term survival.

The key to survival may be the unravelling of the current intertwining of religion and ethnicity, Zoroastrianism from Parsi identity, as suggested by several amongst the more liberal-minded interviewees. This is not likely to happen amongst the conservatives, who do not acknowledge someone who is not a Parsi nor an Iranian Zoroastrian calling themselves Zoroastrians. But maybe the more liberal elements, at least in the next generation, will come to accept this. But whichever route individuals seek to embrace, the facts suggest that neither the conservative ethnic purity route nor the more liberal approach to intermarriage can realistically prevent the gradual absorption of Parsis into other cultures. Eventually the emphasis might turn towards the preservation of all that is special about Zoroastrian religion and Parsi culture rather than seeking to preserve ethnic purity as well. I believe that those who have migrated to countries such as New Zealand will inevitably become more closely tied to their adopted country and their Parsi ethnicity will become more and more diluted. Whilst currently an anathema to conservatives and many liberals alike, it is possible that, with the burgeoning acceptance of greater tolerance amongst the younger generation, those within the Parsi community who believe that the best way forward would be a separation between Parsi identity as an 
ethnicity and Zoroastrianism as a religion will gain in strength. Zoroastrianism might ultimately come to be accepted as a valuable contribution to modern living not just for Parsis but for others seeking a spiritual dimension to enhance their personal lives; one that embraces and enriches everyday lives without being encumbered by traditions of centralised authority. 


\section{Appendix A Interview Questions}

1. May I ask you about your current situation in New Zealand? Why and when did you and or your family move to New Zealand?

2. What about education, tertiary qualifications, languages and occupations?

3. Do you keep in touch with other members of the Parsi community either here in New Zealand or oversees, e.g. in India, and, if so, by what means? What about your extended family?

4. Do you ever go to India/Mumbai to visit friends and family or to renew your Parsi heritage? Would you ever consider returning to India/Mumbai permanently and if so, why?

5. Do you follow the Zoroastrian religion and, if so in what ways?

6. How does your religion relate to your identity as a Parsi now that you live in New Zealand? Does it have any relevance for how you live in New Zealand? Has it helped you to adjust to living here?

7. Would you describe yourself as a conservative Parsi, a liberal Parsi or something else?

8. Now that you are living in New Zealand, what funerary rites would you wish to follow? If you could, would you like to return to India for a traditional Zoroastrian funeral?

9. Do you think New Zealand should have its own fire temple?

10. To whom would you look for religious guidance in New Zealand?

11. What particular individual or group characteristics do you associate with the Parsi community and its unique qualities?

12. It has been said that, traditionally, Parsi women have played very important roles, both within their communities and in the family; do you agree and is it still so?

13. What about the Parsi community in New Zealand? What role should it play within the wider New Zealand community, in its connections with India and with other world-wide Parsi communities?

14. What of the future? Will the Parsi community survive here in New Zealand? In India? Worldwide? 
15. What are your views on ethnic purity within Parsi communities, intermarriage and conversion?

16. Why do you think the Parsi community in India has decreased in numbers so dramatically since Indian independence and what should be done to reverse the trend? 


\section{Bibliography}

Axelrod, Paul. "Cultural and Historical Factors in the Population Decline of the Parsis of India." Population Studies 44, no. 3 (1990): 401 - 19, accessed June 06, 2009, <http://www.jstor.org/stable/2174460. $>$.

_ _ "Myth and Identity in the Indian Zoroastrian Community." Mithraic Studies III, (1980): 150-65.

Boman-Behram, B. K. "Social Relationships between the Parsis and Othert Communitiees." In The Sugar in the Milk: The Parsis in India, edited by Nancy and Ram Singh, 52-67. Delhi, 1986.

Boyce, Mary. Zoroastrians, Their Religious Beliefs and Practices. London \& New York: Routledge and Kegan Paul, 1979.

Boyd, James W., and F. M. Kotwal. "The Indian Parsis in New Zealand." In Indians in New Zealand: Studies in a Sub Culture, edited by Kapil N. Tiwari, 163-82. Wellington: Price Milburn, 1980.

Councillor Filly K. Maravala , “Traditionals protest against disgusting Editorial of Parsiana January 2004", accessed October 2011, $<$ http://tenets.zoroastrianism.com/toParsiana33.html $>$.

Darukhanawala, H. D. M. Parsi Lustre on Indian Soil. Bombay: G. Claridge, 1939.

Dhalla, Rukshana Nanji and Homi. "The Landing of the Zoroastrians at Sanjan:

The Archaeological Evidence." In Parsis in India and the Diaspora, edited by John R. Hinnells and Alan Williams, 35-58. London and New York: Routledge, 2007.

Dhondy, Farrukh. Bombay Duck. Calcutta: Rupa, 1991.

EconomicExpert. "Matrilineality: Judaism Descent.", accessed January 29, 2011, $\leq$ http://www.economicexpert.com/a/Matrilineality.html $>$.

FEZANA. "The Zarathushti World: A Demographic Picture.” FEZANA Journal (Winter 2004).

geveN. "Zoroastrian Temple in Auckland NZ.", accessed July 14, 2010, <http://bbs.keyhole.com/ubb/ubbthreads.php?ubb=showflat\&Number=916948>. 
Gae Rustom S., "Causes and Effects of Decline in Parsi Population." In Parsi Fiction, Vol.1 edited by Navy Kapadia, Jaydipsinh Dodiya, R. K. Dhawan, 66-72, New Delhi: Prestige Books, 2001.

Godrej Group. "Products.", accessed June 08, 2011, 〈http://www.godrej.com/godrej/godrej/ourproducts.aspx?id=1\&menuid=1167〉.

_. "Profile.", accessed January 28, 2010, 〈http://new.godrej.com/godrej/Godrej/index.aspx?id=1>.

Hinnells, John R. "Changing Perceptions of Authority among Parsis in British India." In Parsis and the Diaspora, edited by John R. Hinnells and Alan Williams, 100-18. London and New York: Routledge, 2007.

—. "Parsis in India and the Diaspora in the Twentieth Century and Beyond." In Parsis in India and the Diaspora, edited by John R. Hinnells and Alan Williams, 255-76. London and New York: Routledge, 2007.

- The Zoroastrian Diaspora: Religion and Migration. Oxford: Oxford University Press, 2005.

Homji, Homi B. Minocher. $O$ Whither Parsis? Placate and Perish or Reform and Flourish? Karachi: The Mirror Press, 1998.

Javat, Teenaz. "An Interview with Dastur Khurshed of Udvada: No More an Option to Stay Quiet." FEZANA Journal (2010).

Kapadia, Novy. "The Parsis: An Introduction." In Parsi Fiction, edited by Novy Kapadia, Jaydidsinh Dodiya, R. K. Dhawan 9-17. New Delhi: Prestige Books, 2001.

Kulke, Eckehard. The Parsees in India: A Minority as Agent of Social Change. München: Weltforum Verlag, 1974.

Leckie, Jacqueline. "New Zealand." In The Encyclopedia of the Indian Diaspora, edited by Brij V. Lal, 389-95. Honolulu: University of Hawai'i Press, 2006.

Luhrmann, T. M. The Good Parsi: The Fate of a Colonial Elite in a Postcolonial Society. Cambridge, Massachusetts and London, England: Harvard University Press, 1996.

Maneck, Susan Stiles. The Death of Ahriman: Culture, Identity and Theological Change among the Parsis of India. Bombay: K.R. Cama Institute, 1997. 
McLeod, John. "Mourning, Philanthropy and M. M. Bhownaggree's Road to Parliament." In Parsis in India and the Diaspora, edited by John R. Hinnells and Alan Williams, 136-56. New York and London: Routledge, 2007.

Mehta, Nivedita. "Parsi Contribution to the Art and Cultural Life of India." In The Sugar in the Milk: The Parsis in India, edited by Nancy and Ram Singh, 25-51. Delhi: I.S.P.C.K., 1985.

Muncherji, Pesi. "The Sacred and Reverent Fire of Zarathustra." In Parsi Fiction, edited by Navy Kapadia, Jaydipsinh Dodiya and R. K. Dhawan, 39-43. New Delhi: Prestige Books, 2001.

Munshi, Sherally. "The Incredible Community." The Australian Financial Review no. Friday 14 August (2009).

Nargolwala, S. D. "Zoroastrianism and Parsis in India." In Parsi Fiction, edited by Navy Kapadia, Jaydipsinh Dodiya and R. K. Dhavan, 51-65. New Delhi: Prestige Books, 2001. NZ Herald. "Shroff and Sons Ltd: 100 Years in Hardware." NZ Herald, 13 February 1986.

Palkhivala, Nani A. "The Role of Parsis in India." In The Sugar in the Milk: The Parsis in India, edited by Nancy and Ram Singh, 125-30. Delhi: I.S.P.C.K., 1986.

Palsetia, Jesse S. The Parsis of India: Preservation of Identity in Bombay City. Reprint ed. New Delhi: Manohar, 2001.

. "Partnership in Empire: Jamsetjee Jejeebhoy and the Public Culture of Nineteenth-Century Bombay." In Parsis in India and the Diaspora, edited by John R. Hinnells and Alan Williams, 81-99. London and New York: Routledge, 2007.

Parsi Khabar. "Diaspora: A Talk by Khojestee Mistree.", accessed April 04, 2011, $<$ http://parsikhabar.net/opinion/diaspora-a-talk-by-khojeste-mistree/2158/>.

Parsiana. "A fire in North America." Parsiana no. May 21 (2009): 18.

_. "Editorial Viewpoint: Who lost?" Parsiana no. November 7 (2009): 2.

__. "Editorial Viewpoint: Publish and perish?" Parsiana no. June 21 (2009): 6.

__. "Intermarriage in the UK." Parsiana no. June 7 (2006): 21.

__. "Malaysia’s Mazdayadasnis.” Parsiana no. August 21 (2009): 38-43.

_..Pride and prejudice." Parsiana no. November 21 (2009): 19. 
Parsiana. "Priestly Progress." Parsiana no. September 7 (2009): 4.

. "Talibanization of the BPP." Parsiana no. September 7 (2009): 6.

—. "Talibanization of the BBP." Parsiana no. August 21 (2009): 76-78.

Parsiana Online, The global Zoroastrian link Medium, accessed October 19, 2011,

〈http://parsiana.com/general/aboutus.asp $>$.

"Parsiism." In Wiktionary, accessed July 26, 2011."

Sharafi, Mitra. "Judging Conversion in Zoroastrianism: Behind the Scenes of the Parsi

Panchayat Case (1908)." In Parsis in India and the Diaspora, edited by John R. Hinnells and Alan Williams, 159-80. London and New York: Routledge, 2007.

Singh, Nancy and Ram. "The Incredible Community." In The Sugar in the Milk: The

Parsis in India, edited by Nancy and Ram Singh, 1-24. Delhi: I.S.P.C.K., 1986.

Statistics New Zealand. "Births.", accessed October 20, 2010,

<http://search.stats.govt.nz/search?p=Q\&lbc=statsnz\&uid=811577908\&ts=custo

$\underline{\mathrm{m} \& \mathrm{w}=\text { births\%20per\%20million\&af=ct2:population_b>. }}$.

—_. "Census of Population and Dwellings.", accessed January 05, 2011,

<http://www.stats.govt.nz/Census/2006CensusHomePage/QuickStats/quickstatsabout-a-subject/culture-and-identity/religious-affiliation.aspx $>$.

Strausberg, Michael. "Review Articles, "Parsis of India: Two Recent Publications."

Numen 49, no. 2 (2002): 219.

Taraporevala, Sooni. Parsis: The Zoroastrians of India. Second

ed. Mumbai: Good Books, 2004.

Tata Group. "Products.", accessed June 08, 2011,

<http://www.tata.com/products/index.aspx? sectid=U2YC1EMmQuk=>.

—. "Profile.", accessed January 28, 2010 〈http://www.tata.com/>.

The Zoroastrian Association of Metropolitan Washington Jashan. "Getting to Know Parsi Zoroastrians." In Parsi Fiction, edited by Navy Kapadia, Jaydipsinh Dodiya and R. K. Dhawan, 22-35. New Delhi: Prestige Books, 2001.

Thomson, Wayne. "NZ Herald.", accessed June 16, 2010, <http://www.nzherald.co.nz/nz/news/article.cfm?c_id=1\&objectid=10432034>

Traditional Mazdayasni Zarathushtee Anjuman of New Zealand Inc. "Constitution.", accessed August 19, 2010, 〈http://www.tmzanz.org.nz/>. 
Wadia, Rusheed R. "Bombay Merchants in the eighteenth and nineteenth centuries." In Parsis in India and the Diaspora, edited by John R. Hinnells and Alan Williams, 119-35. London and New York: Routledge, 2007.

White, David L. Competition and Collaboration: Parsi Merchants and the English East India Company in 18th Century India. New Delhi: Munshiram Manoharlal Publishers Pvt Ltd, 1995.

Williams, Alan. "The structure, significance and poetic integrity of the Qesse-ye Sanjān." In Parsis and the Diaspora, edited by John R. Hinnells and Alan Williams, 15-34. London and New York: Routledge, 2007.

Zaehner, R. C. The Dawn and Twilight of Zoroastrianism. London: Weidenfeld and Nicholson, 1975.

Zarathushtrian Association of New Zealand. "Constitution.", accessed August 16, 2010, $<$ http://www.zanz.org.nz/constitution.htm>.

Zoroastrian Community Trust of New Zealand. "Trust Deed.", accessed August 17 and September 24, 2010, <http://www.zct.co.nz/deed.

Zoroastrianism.cc. "Conversion in Mazdayasna.", accessed July 07, 2010, 〈http://www.zoroastrianism.cc/conversion_in_mazdayasna.html $>$.

"Zoroastrianism and Parsiism." In Encyclopaedia Britannica: Macropaedia, 1116. Auckland: Encyclopaedia Britannica Inc., 1990. 